\title{
OXFAM
}

RESEARCH BACKGROUNDER

\section{Gender and \\ Technology}

A rights-based and intersectional analysis of key trends

Vanessa Ceia, Benji Nothwehr, and Liz Wagner 


\section{CONTENTS}

Oxfam America's Research Backgrounders 4

Author information and acknowledgements .................................................. 4

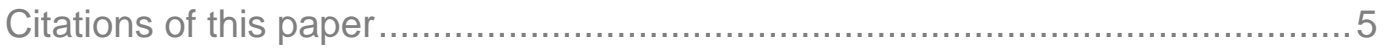

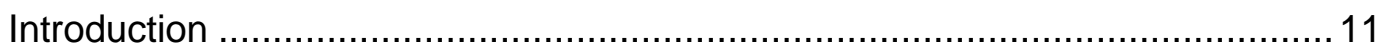

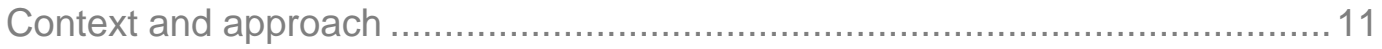

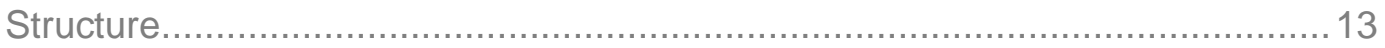

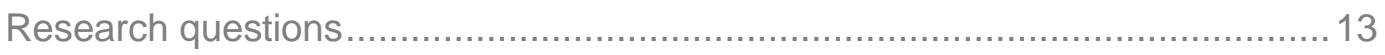

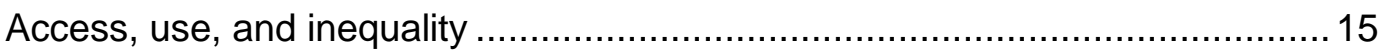

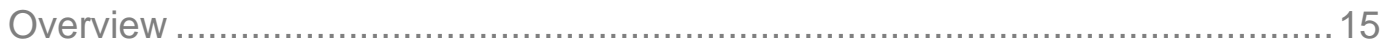

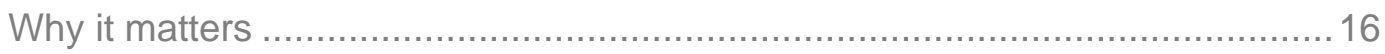

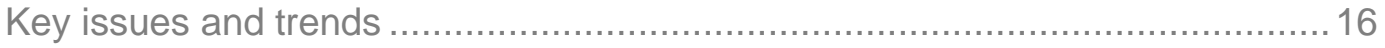

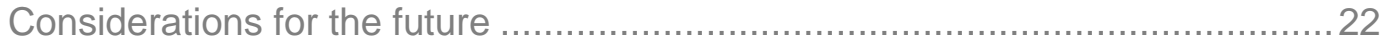

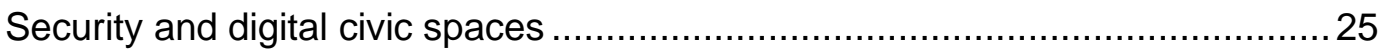

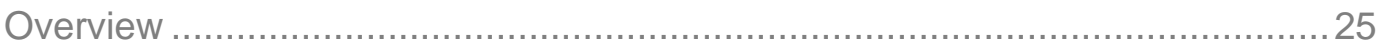

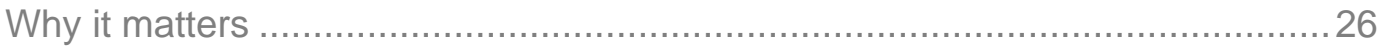

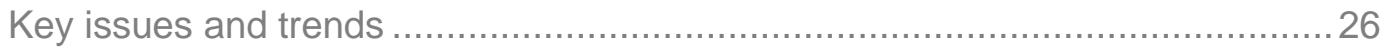

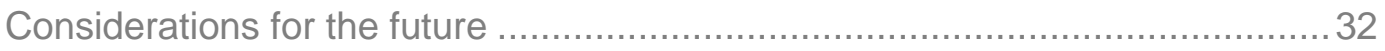

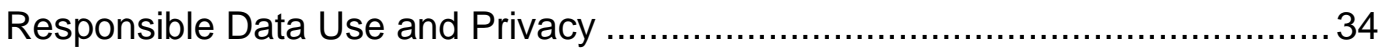

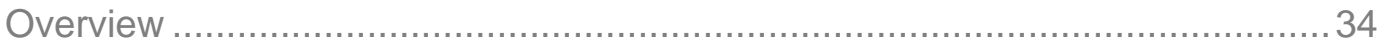

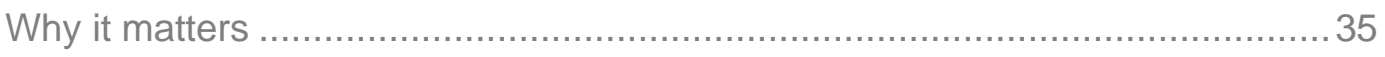

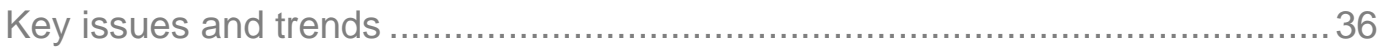

Considerations for the future ..................................................................... 42

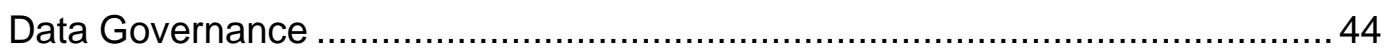

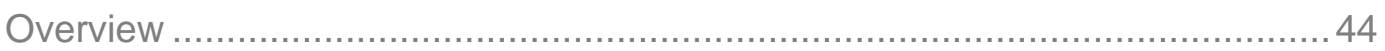

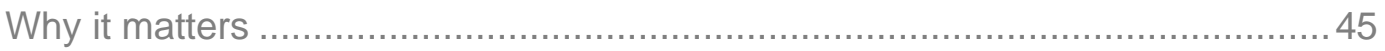

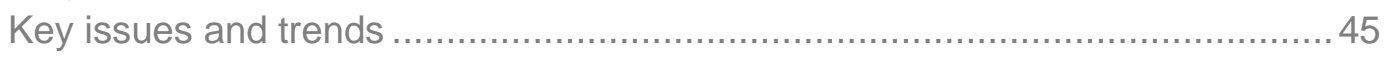

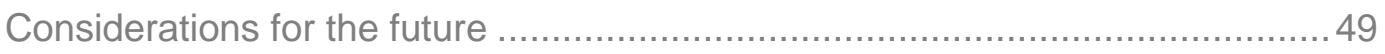

The Future of Work

Overview ……

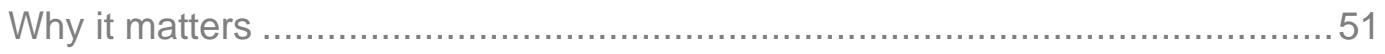

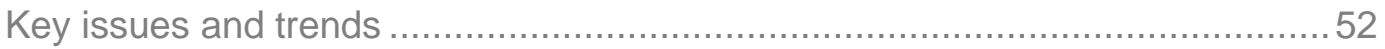

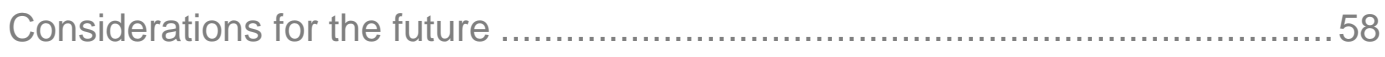

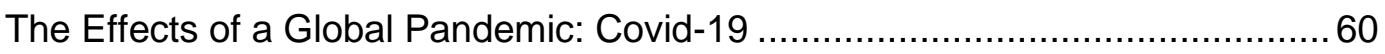

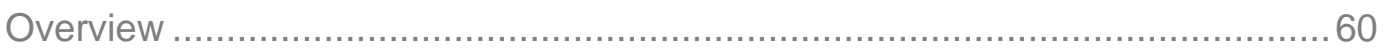

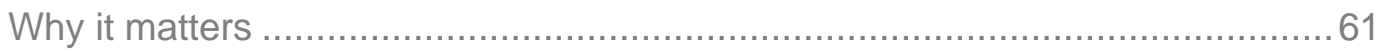




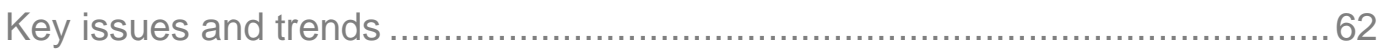

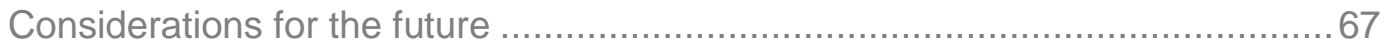

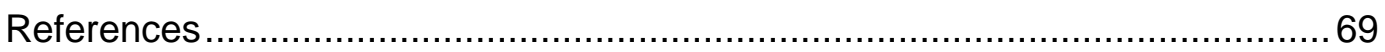

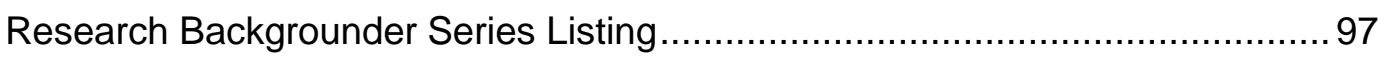




\title{
OXFAM AMERICA'S RESEARCH BACKGROUNDERS
}

\author{
Series editor: Kimberly Pfeifer
}

Oxfam America's Research Backgrounders are designed to inform and foster discussion about topics critical to poverty reduction. The series explores a range of issues on which Oxfam America works-all within the broader context of international development and humanitarian relief. The series was designed to share Oxfam America's rich research with a wide audience in hopes of fostering thoughtful debate and discussion. All Backgrounders are available as downloadable PDFs on our website, oxfamamerica.org/research, and may be distributed and cited with proper attribution (please see following page).

Topics of Oxfam America's Research Backgrounders are selected to support Oxfam's development objectives or key aspects of our policy work. Each Backgrounder represents an initial effort by Oxfam to inform the strategic development of our work, and each is either a literature synthesis or original research, conducted or commissioned by Oxfam America. All Backgrounders have undergone peer review.

Oxfam America's Research Backgrounders are not intended as advocacy or campaign tools; nor do they constitute an expression of Oxfam America policy. The views expressed are those of the authors-not necessarily those of Oxfam. Nonetheless, we believe this research constitutes a useful body of work for all readers interested in poverty reduction.

\section{Author information and acknowledgements}

Vanessa Ceia is an Assistant Professor at McGill University. Benji Nothwehr and Liz Wagner are MA candidates at McGill University. Thank you to Kimberly Pfeifer for the invitation and opportunity to work with her on Oxfam's important Gender Justice Journey Project. Thank you also to Namalie Jayasinghe, Sarah Tuckey, Diane Pueschel, Juan Orellana, and Neal McCarthy of Oxfam America for their enthusiasm and thought partnership throughout the project. And thank you to Rhian Lewis of McGill University for her invaluable input and research support. We appreciate the peer reviewers who took time to provide critical feedback on this research: Rosario Castro, Nanette Levinson, Revi Sterling, and Ronda Zelezny-Green. 


\section{Citations of this paper}

Please use the following format when citing this paper:

Ceia, Vanessa; Nothwehr, Benji; Wagner, Liz, "Gender and Technology: A Rights-based and Intersectional Analysis of Key Trends," Oxfam Research Backgrounder Series (2021): https://www.oxfamamerica.org/explore/researchpublications/gender-and-technology-a-rights-based-and-intersectional-analysisof-key-trends/ 


\section{ACRONYMS AND ABBREVIATIONS}

A4AI

APC

BOLD

DHEF

DV

FOSTA

FRVT

GBV

GDP

GDPR

GPFI

GSMA

IANA

ICT

ICT4D

NGO

OECD

$\mathrm{PHI}$

RAINN

SESTA

SDG

SGM

TeSA
Alliance for Affordable Internet

Association for Progressive Communications

Big, Open and Linked Data

Digital Health Equity Framework

domestic violence

Fight Online Sex Trafficking Act

Face Recognition Vendor Test

gender-based violence

gross domestic product

General Data Protection Regulation

Global Partnership for Financial Inclusion

Global System for Mobile Communications

Internet Assigned Numbers Authority

information and communications technology

information and communications technology for development

nongovernmental organization

Organisation for Economic Co-operation and Development

Personal Health Information

Rape, Abuse and Incest National Network

Stop Enabling Sex Traffickers Act

Sustainable Development Goal

sexual and gender minorities

Technology Skills Accelerator Project 
UNHDR United Nations Human Development Report

WED women's entrepreneurship development 


\section{EXECUTIVE SUMMARY}

Two decades into the 21st century, the pace of technological innovation has never been faster. It far outpaces the ability of the public, private, and nonprofit sectors to enact new policies, regulations, guidelines, and metrics for the ethical management of technology and its impact on society, politics, culture, the economy, and the environment. At the same time, global inequality continues to increase at alarming rates, with research showing that the digital divide between men and women is widening, particularly in developing countries. Though the full impact of technological progress on the advancement of women, girls, and other marginalized communities, such as LGBTQ communities, people of color, and disabled individuals, is currently largely uncertain and nearly impossible to measure, it is clear that advancements in digital technologies and information and communication technologies (ICTs) have great potential to improve the lives of these populations and to help reduce gender inequalities across the world.

Many initiatives aimed at empowering women through technology fail to recognize and address the intersecting and contextual factors that influence women's ability to benefit from digital technologies and ICTs. These factors include individual attributes, such as race, class, and age, and structural determinants, like geography and education. To address this gap, this report employs an intersectional feminist framework to identify and analyze key trends related to gender and technology. It aims to provide a holistic picture of how gender and technology are embedded in and influenced by a myriad of intersecting issues and challenges that complicate how ICT for development (ICT4D) initiatives concretely impact women's lives. Based on synthesized research, the report provides recommendations for relevant stakeholders on how to approach the field of international development using technology as a tool for social good in ways that benefit the most marginalized members of our global community. As such, the report falls within Oxfam's rights-based approach to development, which recognizes that access to technology is a fundamental human right.

Many of the report's key findings highlight the fact that women's lack of access to digital technologies and ICTs is a principal reason why gender inequalities persist in today's technologically driven world. Particularly in low- and middle-income countries, many women still struggle with basic access to ICTs; for instance, they may be unable to afford ICT devices, or they may face barriers to joining online networks because of a lack of digital connectivity owing to geographic, economic, social, or political factors. Women also generally possess fewer skills related to digital literacy, limiting their ability to effectively and safely use ICTs. This contributes to a gendered digital divide that impacts women's potential to use ICTs and digital technologies for social, civic, and economic purposes. Because technology is increasingly integrated into our daily lives through its ability to 
facilitate these functions, women's inability to fully access and benefit from ICTs thus compounds gender inequality offline.

That said, new opportunities for women are emerging with the rise of digital economies. These digital economies are linked to a variety of benefits, including more diverse labor markets, increased competition leading to technological innovation, and more economic partnerships across the globe. As long as women and marginalized communities are able to connect to digital networks with the use of adequate ICTs, they can join new digital workforces in online environments, driving women's economic empowerment and financial autonomy and providing them with new work experiences and digital skills. To some extent, these online economies are also able to avoid the pitfalls that prevent women from joining traditional labor forces, such as cultural norms, time limitations, and safety risks. If, however, women are unable to access ICTs and digital networks or lack the skills to navigate online work environments, they will once again be excluded from these new labor markets, with the result that digital economies have the potential to reinforce gender inequalities in certain contexts. This possibility is compounded by the general lack of social regulations and worker protections in digital economies, particularly in platform-based employment, which is especially precarious.

Largely owing to this lack of clear regulation, women face an array of concerns about safety and privacy in digital environments, which further restrict their ability to reap the benefits of ICTs and digital networks. Women may face misogynistic attacks, abuse, and violence online. Such online misogyny is primarily a product of larger offline cultures of systemic sexism combined with the unique digital affordances of online platforms, including the potential for increased anonymity and lax platform policies regarding online abuse. Furthermore, women's personal and private data are sometimes shared by others online in order to target and shame them for their gender and sexuality. However, ICTs and digital environments can also offer crucial tools for improving safety, sharing healthrelated information, advancing feminist social movements and activism, and facilitating the creation of support networks for marginalized women by enabling communication and networking beyond localities. Given that individuals and groups use ICTS in a variety of ways that can both empower and harm women, more research is needed into patterns of online violence that prevent women from using ICTs for empowerment as well as into proactive ways to address and prevent harmful behaviors.

In relation to safety issues associated with data privacy, there are also inequities at the level of digital infrastructure. Today's world is ruled by the collection and consolidation of information and digital data, which are wielded by telecommunication corporations and other entities primarily to generate profit. Frequently used to develop algorithms that guide users' activities online, the data collected often display gender or racial bias, replicating and reinforcing systems of 
oppression that structure our offline worlds within the design of ICTs. This situation has profound ramifications for marginalized populations: algorithms are involved in the vast majority of users' online activities, from applying for bank loans to conducting searches on job-listing websites. Algorithms will display different information and results for different users, with the result that access to ICTs, as well as user identity, guides key life decisions and outcomes. These disparities demand further intervention at the level of digital governance, with an emphasis on data transparency and platform policies that acknowledge and address the varied impacts of data collection on marginalized populations. Nonetheless, data can also be used for social good through techniques like crowdsourced data, data visualization, and statistical modeling. These strategies use digital data to make concrete differences in users' offline lives, revealing new modes of technological sovereignty and data agency.

Gendered disparities in the context of technological innovation and ICT development are tangible at a global scale precisely because they reflect the world we live in. Ultimately, it is important to recognize that ICTs and digital technologies are neither inherently good nor bad, but instead neutral tools that hold the potential to fundamentally challenge gender inequality in contemporary society. What matters is how individual users, online platforms, policymakers, telecommunication corporations, tech engineers, and other stakeholders use these tools. We must work together to ensure that the most marginalized members of society can access, use, and benefit from digital technologies. To this end, this report urges stakeholders to develop gender-sensitive, context-specific, evidence-based, and accountable legal frameworks and policies that promote and formalize digital rights for all. These approaches must be developed using intersectional research methodologies and rigorous data collection, center proactive strategies that prioritize those left behind or excluded by the digital revolution, and attend to diverse contexts and cultural specificities in order to ensure that digital environments are equitable, inclusive, and safe.

What is most essential, however, beyond legal frameworks, is truly listening to the needs and priorities of women and marginalized communities as they relate to digital technologies. Ultimately, fostering gender equality through ICT4D must begin with the recognition that, by virtue of a shared humanity, every woman is inherently entitled to digital rights and citizenship. Maintaining women's freedom in the digital age means that these conditions must be shaped with equal and active input from those they protect and benefit. As such, women must be centered in all ongoing and future conversations about ICTs' capacity for systemic and transformative change. 


\section{INTRODUCTION}

\section{CONTEXT AND APPROACH}

This research backgrounder uses feminist theory as a lens through which to explore major themes and social trends at the nexus of gender and technology. It draws on studies that consider how race, income, age, education, sexuality, and disability intersect with gender in the context of digital technologies and aims to identify opportunities for policy making, initiative planning, and further research in the areas of gender, equality, and technology. In focusing on the capacity of information and communications technologies (ICTs) to transform or reinforce structural power relations, this research will be relevant for nonprofit organizations and professionals; stakeholders involved in ICT for development (ICT4D) initiatives; academics; regional, national, and international policy makers; and corporations interested in a rights-based analysis of how gender and technology intersect.

As the Fourth Industrial Revolution unfolds, a growing number of scholars are identifying and critically engaging with the relationship between gender and digital technologies through feminist approaches. While some existing studies concentrate on algorithmic biases and forms of online violence (D'lgnazio and Klein 2020; Noble 2018), others assess a need for disaggregated and gendersensitive data (Gurumurthy and Chami 2017). Albeit limited in number, some are also interested in finding better and more socially and economically just alternatives to existing data policy and lawmaking practices (Janssen et al. 2020).

However, studies that consider ICTs and gender through an intersectional lens are generally lacking, leading to a crucial gap in the research and academic literature. As this report will point out, most existing studies examining markers of oppression as they relate to gender and technology tend to concentrate on just one such marker-be it gender, race, or geographic location, age, ability, or socioeconomic class. Rarely are multiple markers of marginalization addressed within the same study. This gap, coupled with the fact that the existing literature was, for the most part, either written by academics or commissioned by development agencies in the global North, impacts the data and perspectives included in this backgrounder. However, by bringing together and engaging with a wide range of single-category analyses, as well as the few intersectional studies that do exist, this backgrounder presents an explicitly intersectional and kaleidoscopic approach to gender and technology. Further, this backgrounder considers the larger social systems of marginalization which inform how which shape how the intersection of gender and technology is experienced to be embedded in larger social systems that guide how 
they are experienced by women and other marginalized individuals across different contexts.

An intersectional approach to ICTs in the context of the right to an identity-the right to exist and be treated equally and with dignity-lays the groundwork for exploring how digital technologies are or could be leveraged to help women exercise agency and challenge gender inequality. In adopting Oxfam's applied rights-based approach (Oxfam International 2019), this backgrounder follows a framework that takes into account local contexts, economy, social inclusion, and cultural rights (Offenheiser and Holcombe 2003). It is anchored in intersectional feminist theory that is attentive to how identity attributes, such as gender, race, class, sexuality, ability, and religion, should not be analyzed in isolation from one another. As such, the intersectional framework applied here provides a contextualized and grounded account of how different aspects of one's identity have distinct and varying impacts on an individual's inclusion or exclusion from development initiatives, as well as access to education, employment, and the benefits digital technologies can offer (Azevedo, Garwood, and Pretari 2019).

Systemic inequalities can be "reproduced as well as challenged in the online environment in ways that can limit the potential of ICT to be tools for women's empowerment" (Cummings and O'Neil 2015, p.1). For this reason, gender must be understood in relation to the existing political, cultural, social, and economic power relations at the center of how digital technologies and environments are developed and used. Scholars such as Safiya Umoja Noble (Algorithms of Oppression, 2018) and Catherine D'Ignazio and Lauren Klein (Data Feminism, 2020) highlight the algorithmic biases and forms of gendered violence embedded in the technologies we use. Their work reveals that inequality and power imbalances are generally ingrained in the technological landscapes and architectures we engage every day. In other words, technological structures are often in and of themselves oppressive. This study shines a light on some of these technological inequalities in order to identify ways in which digital landscapes can be made more equitable and accessible for all.

An intersectional and rights-based approach to analyzing gender and technology also enables the exploration of the many layers of the digital divide between those who have and do not have access, digital rights, education, employment, selfdetermination (Unwin 2017), as well as those with and without the ability to live a dignified life (Wells n.d.; Sen 1985). This includes having the right and ability to "do and be"-work and be healthy, for instance-including to "do and be" on the internet (Gurumurthy 2008). With this in mind, this report illuminates the potential of rights-based and intersectional approaches to gender and ICTs to aid women in their ability to access, use, and benefit from these technologies-to "do," "be," and be empowered in digital spaces. 
Moreover, the report aligns with several of the 2030 UN Sustainable Development Goals (SDGs): SDG 1 (no poverty), SDG 3 (good health and well-being), SDG 4 (quality education), SDG 5 (gender equality), SDG 6 (decent work and economic growth), SDG 10 (reduced inequalities), and SDG 12 (responsible production and consumption). Within SDG 5, the United Nations (UN) identifies ICTs as essential tools to "enhance the use of enabling technology, in particular information and communications technology, to promote the empowerment of women" ("Gender Equality and Women's Empowerment' 2020).

\section{STRUCTURE}

The trends discussed in this backgrounder are grouped into six broad categories: (1) access, use, and inequality; (2) security and digital civic spaces; (3) responsible data use and privacy; (4) governance; (5) the future of work; and (6) the effects of a global pandemic: COVID-19.

These categories are informed by Oxfam's internal policy pillars regarding digital rights-access, inequality, governance, responsible data use and privacy, security and digital civic spaces, and the future of work. They are also conceptually informed by the World Economic Forum's 2018 shared goals for the creation of a digital future that is inclusive, trustworthy and sustainable: (1) leave no person behind, (2) empower users through good digital identities, (3) make business work for people, (4) keep everyone safe and secure, (5) build new rules for a new game, and (6) break through the data barrier (World Economic Forum 2018a).

Given the spread of COVID-19, its disproportionate impact on the lives of women and marginalized communities, and the resulting increased reliance on technology to work, live, and socialize, the final section of this study considers the ongoing effects of the global pandemic on gender and technology.

\section{RESEARCH QUESTIONS}

This research backgrounder is guided by the following research questions:

- What are the major themes and social trends at the intersection of gender and ICTs?

- What are the greatest opportunities for technology to contribute to gender equality?

- What are the gendered forms of harm or risk that are implied in tech design and adoption, and how do these interfere with users' rights to life, security, and civic engagement?

- How do ICTs reflect, mitigate, or exacerbate gender disparities? 
- How has the accelerated increase in the use of ICTs in response to COVID19 impacted gender disparities?

- What recommendations does feminist research give us regarding the use of ICT as a tool for advancing gender equality?

The first trend addressed relates to access, use, and inequality. This section explores the systemic difficulties that women and marginalized populations face when trying to access and use ICTs as a means of empowerment. Here the report dives into the relationship between digital technologies and the gendered digital divide, focusing on the digital literacy skills required to effectively use and benefit from ICTs, the financial inaccessibility of ICTs, and gender disparities in ICTrelated employment, among other issues and trends. The second section, "Security and digital civic spaces," scrutinizes the emergence of online genderbased violence (GBV) and examines how digital spaces can both produce new forms of GBV for the digital world and mimic existing forms of offline GBV. The third section, "Responsible data use and privacy," evaluates various ethical concerns related to privacy and data ownership online by considering how users' personal data are monitored and collected by a variety of entities, including governments and telecommunication corporations. The section also highlights potential opportunities for data to be used as a social good through processes of data accountability and agency, as well as alternative consent models for data collection and use. Relatedly, the fourth section, "Data governance," focuses on the need for equitable and accountable data practices developed collaboratively between online platforms, telecommunication corporations, and government bodies in order to ensure the safety and privacy of all online. With disparate online safety practices in mind, the section that follows, "The future of work" addresses the effects of increasingly digitized labor for women and marginalized groups. The section examines the differential development and distribution of skill sets and highlights opportunities for women's engagement in digital economies and the development of useful skill sets for digital labor markets. As recent events have both accelerated and amplified the use of ICTs, the closing section is dedicated to COVID-19 and its effects on social and gendered disparities as they evolve in the context of the digital age.

Each of the six sections included in this research backgrounder is divided into four subsections that will help guide the reader: (1) an introductory overview of the section theme, (2) a rationale for why that particular theme matters, (3) an identification and analysis of the key trends related to the section theme, and (4) considerations for the future. 


\section{ACCESS, USE, AND INEQUALITY}

\section{OVERVIEW}

In low- and middle-income countries, women are 30 to 50 percent less likely than men to use the internet for economic and political purposes (World Wide Web Foundation 2016b; ITU 2018). Globally, women are 12 percent less likely than men to have internet access (EQUALS 2019). Four out of five women who do not have internet access live in the global South (Hilbert 2011). At the heart of these inequalities, gender converges with race, sexual orientation, age, class, geography, and ability. In fact, research reveals that social inequalities and forms of discrimination against minority and marginalized communities are maintained across digital spaces (Hilbert 2011; Ragnedda 2020). Internet users with one or more minority or marginalized identities are more likely to be limited in their ability to fully benefit from the uses of the internet than white men in the Global North (Roux and Dalvit 2014; Ragnedda 2020). It is within this context that we speak of the "digital divide" (Gunkel 2003), which reflects the digital inequalities that result from the differential opportunities available to marginalized populations when they try to access and use digital technologies (Hilbert 2011). In fact, the more that minority and marginalized identities and attributes intersect, the wider that divide is likely to be. This suggests that while the divide between white women and white men is significant, it is even wider between, for instance, Black women and white men.

Focusing on the intersection of the digital divide and gender, this first section explores the ways in which gender intersects with users' ability to access and use digital technologies and develop digital literacy, as well as how ICTs and their algorithms may widen or narrow the digital divide. Overall, we have found that socioeconomic, structural, and algorithmic obstacles not only limit the ability of women and other marginalized populations to fully benefit from the use of ICTs but also underline the persistence of digital gendered inequalities.

When considering digital inequalities, development initiatives that seek to promote digital parity now include a wider range of factors (Ragnedda 2020; UNDP 2019; Sey and Hafkin 2019; ITU 2017). In addition to one's level of access to technology, "issues of capacity and motivation to effectively and strategically use technology for its intended purpose" (Pade-Khene 2018, p.3) are now also considered factors impacting the digital divide. Additionally, ICT4D initiatives are increasingly attentive to how digital technologies can exacerbate digital inequalities (Smith and Neupane 2018) and online harm, including gender-based violence and cyberbullying, while recognizing the potential benefits and possibilities for empowerment ICTs pose for 
marginalized populations (Roux and Dalvit 2014; Mariscal et al. 2019; Kowalski, Limber, and McCord 2019).

Understanding the full picture of digital inequalities requires asking questions such as, who can access the internet? (first-level digital divide). It demands that we critically consider a user's digital literacy level and type of use (second-level digital divide) and recognize the real-life consequences of ICTs for users and communities at the local and global levels (third-level digital divide) (Deursen and Helsper 2015). Understanding the digital divide means understanding the different ways that ICTs are used, their inherent power dynamics, users' digital skills and literacy, and the implicit consequences of ICTs beyond the digital world.

\section{WHY IT MATTERS}

Understanding the digital gender divide constitutes a first step toward not only digital parity and empowerment, but also more equitable opportunities for all in an increasingly digital and digitized society. To mitigate the real-life consequences of the digital divide for marginalized populations, digital inequalities must be identified and analyzed in a way that is mindful of the different needs, contexts, and challenges of different communities. Digital inequalities become especially evident in available and digitized research on marginalized communities: while there is a growing number of studies on women's inequality online and the digital gender divide, research that considers issues of race and age in addition to gender remains almost nonexistent (Dijk 2017). In low- and middle-income countries, stigmas surrounding disability further limit the availability of reliable data on disability and digital technologies (Noble 2012). These knowledge gaps limit our understanding of the depth and range of challenges to the equitable access and use of ICTs among all women and highlight the inequalities experienced by marginalized populations, especially those whose identity intersects with that of more than one minority group.

\section{KEY ISSUES AND TRENDS}

\section{ICTs increase digital divides}

Coined in the United States in the 1990s, the expression "digital divide" (Gunkel 2003) was intended to highlight the ever-widening "gap in access to information services between those who can afford to purchase the computer hardware and software to participate in the global information network" and those who cannot (Acılar 2011). More recently, this definition has been extended to include factors such as geography, ability, gender, education, or economic development (Roux 
and Dalvit 2014; Ragnedda 2020). In developed countries, for example, Scholz, Yalcin, and Priestley (2017) remarked that disability and poverty were strongly associated, with older women reporting slightly lower rates of internet access (2017). In the context of the digital gender divide, digital inequalities relate to the potential obstacles and differential options available to marginalized populations, especially women, when attempting to access, use, and learn about digital technologies. In this sense, one's identity markers and presenting gender affect one's opportunities for educational advancement, socioeconomic empowerment, and other benefits of having equal access to digital tech, including the internet (Mariscal et al. 2019).

In one study about the digital gender divide that was conducted on CloudResearch, an all-online anonymized participant-sourcing platform, Litman et al. (2020) observed that women's hourly wages were 10.5 percent lower than men's. This finding led the researchers to conclude that offline gender norms propel women to select less remunerative opportunities than men did. As for low- and middleincome countries, women's relative progress toward online equality is slowing down despite a continuous increase in internet connectivity globally (Sey and Hafkin 2019; UNDP 2019; ITU 2017). While overall internet access rates are going up, the Organisation for Economic Co-operation and Development (OECD) observes a "worrisome" second-level digital divide increase in low- and middleincome countries (Chetty et al. 2018). With the exception of the Americas, digital technologies are widening the digital gender gap in these countries (ITU 2017; Deursen and Helsper 2015). The International Telecommunication Union lists women's lower levels of education and income as potential contributing factors (ITU 2017; Chetty et al. 2018). In line with this, Mariscal et al. (2019) found that women's internet participation had decreased by 250 million as of 2017 (ITU 2017). Despite ICT4D initiatives, such as those led by UN Women and EQUALS to promote online gender parity, "hurdles to access, affordability, lack of education as well as inherent biases and sociocultural norms curtail women and girls' ability to benefit from the opportunities offered by the digital transformation" (Chetty et al. 2018). Thus, the digital gender divide persists and does not appear to be narrowing.

\section{Different types of access}

ICT4D initiatives and reports, including the UN Human Development Report, distinguish between two levels of access: basic access and meaningful access (UNDP 2019). Whereas basic access refers to device and internet access, meaningful access refers to the uses and benefits of digital technologies, not only in terms of educational benefits but also in relation to employability. Organizations such as the OECD, the EQUALS initiative, and the US Agency for International Development (USAID) have identified tech education and a move beyond basic access as necessary steps in closing the digital gender divide (Chetty et al. 2018;

Sey and Hafkin 2019; USAID 2020). 
The question of internet access is, at the same time, deeply intertwined with digital literacy or digital skills (Sey and Hafkin 2019). A marker of marginalization such as gender, race, geographical location, or a perceptible disability might affect people's ability to obtain, maintain, and develop these skills. For instance, in Myanmar-a country located in the lobal South-only 15 percent of secondary schools are internet ready (World Wide Web Foundation 2018). This is, however, not only an issue in low- and middle-income countries: in 2017, 44 percent of Europeans lacked "even basic digital skills" (Blažič and Blažič 2020). The ITU has come up with a helpful scale to evaluate a user's digital literacy level: basic skills, intermediate skills, and advanced skills. Basic skills include being able to access the internet, retrieve information, and communicate digitally-for example, through social media. Intermediate skills include using the internet for work-related functions, digital marketing, or publishing (FutureLearn 2020). Lastly, advanced skills involve the ability to create digital technologies and tools through coding and programming, developing apps, and participating in cybersecurity (ITU 2018). While women globally have an overall basic digital literacy, fewer women than men report having advanced digital skills (UNDP 2019). The reasons for this phenomenon have not, however, been studied sufficiently to date (Sweet et al. 2020).

\section{Tech configurations exacerbate biases}

Using the internet generally means knowingly and unknowingly sharing personal data through what is often referred to as our "digital footprint," "internet footprint," "digital shadow," or "internet shadow." The websites we visit, emails we send, and the devices we use are regularly tracked by internet service providers and telecommunication companies such as AT\&T and Verizon, "free" web and social platforms like Facebook and Gmail, the government, and the corporations that own central private data centers, such as Google, Amazon, and Microsoft (Krasnov 2018). Even if internet access rates achieve gender parity, there remains a significant gender gap between those who merely engage with digital technologies and those who create digital infrastructures.

An intersectional approach to digital equality demands that we question the infrastructural systems that ground and feed the digital divide, while also being cognizant of digital power structures. Who is and is not able to access digital tools and technologies, and, more important, who owns these infrastructures? According to the OECD (2018), men are four times more likely than women to be ICT specialists. Given that the technology industry is male dominated (Baird 2018; Marco-Bujosa, Joy, and Sorrentino 2020; Chetty et al. 2018), digital technologies and data centers fail to cater to women and other marginalized groups (Amrute 2020). In fact, the digital infrastructures, data structures, and algorithms put in place by Big Tech, including America's "Big Five" (Apple, Amazon, Facebook, Microsoft, and Google) (Girard 2020), have historically exacerbated existing inequalities (Ragnedda 2020; Noble 2018; Smith and Neupane 2018). In the global 
South, Smith and Neupane $(2018$, p.12) pinpoint the absence of the infrastructural and regulatory bases needed "for an ethical and equitable application of Al Technologies" as the factors driving the digital divide. However, a similar reality can be observed in high-income countries. In the United States, for instance, Google has reinforced racial stereotypes of non-white women and girls (Noble 2018). For many years, the top Google Images search results for "Black woman," for instance, revealed images of sexualized or arrested Black women what Safiya Noble (2018) refers to as "algorithmic bias" and "algorithmic oppression."

Racial and gender bias has also been found in the implementation of facial recognition technology. A recent Face Recognition Vendor Test (FRVT) by the National Institute of Standards and Technology (NIST) found higher rates of false positives for Asian, African American, and American Indian faces than for Caucasian faces in the United States (Albiero et al. 2020; Cook et al. 2019). The FRVT and research by Cook et al. (2019) also revealed that, overall, false positives were higher for women than men. The demographic group with the highest rate of false positives was African American women (Albiero et al. 2020; Schwartz 2019). The fact that machines are primarily trained to recognize white faces (Bacchini and Lorusso 2019) reveals a persistent algorithmic bias in facial recognition technology that can generate false positives that match a suspect's face to the wrong identity. Such bias and inaccuracy can result in the wrongful accusation, arrest, and imprisonment of innocent people, especially women and people of color (Schwartz 2019). An intersectional feminist intervention in the development of these tools would involve users of diverse races, gender identities, and abilities in developing and training these systems and ensure that the data on which these biometric technologies rely are accurate.

Given the gender disparities in the creation of digital technologies (Sey and Ortoleva 2014), the technology and devices available do not always respond to women's and marginalized groups' needs (World Wide Web Foundation 2016b). While ICT4D studies are starting to disaggregate differential internet usage, the whys and hows surrounding internet use levels remain widely understudied (Sweet et al. 2020). Nevertheless, promoting female empowerment and enabling marginalized populations requires creating accessible technologies and devices. To advance digital inclusion, suggest that tech companies consider their ongoing responsibilities for technologies they previously built, and address the problems built into the interfaces of mobile devices (Wyche, Simiyu, and Othieno 2016). This work would include creating modular, user-friendly, and intuitive technology; interfaces with larger fonts for users with visual impairment; and audiovisual-based technology. Most important, reducing the digital divide must involve the active inclusion of marginalized populations in the process of tech creation and development (Noble 2018; EQUALS 2019; World Wide Web Foundation 2016b). 


\section{ICT modalities facilitate unpaid care labor}

Increasing minorities' access to digital technologies and devices leads to questions surrounding the possibilities and shortcomings of ICT modalities-whether smartphones, tablets, or home computers. Exploring smartphone ownership in low-, middle-, and high-income countries, Tsetsi and Rains (2017) conclude that smartphones are among the fastest-growing sources of Internet traffic: they are cheap, easy to carry, and multifunctional. Owning a digital device, such as a smartphone or laptop, constitutes a starting point for accessing the benefits of the internet (Bailur, Masiero, and Tacchi 2018), but this baseline metric is not enough to tackle the structural issues that underlie the digital divide. Analyzing basic internet access does not provide data on users' digital literacy. While the use of digital technology presumes basic digital literacy, it does not offer researchers insight into the degree of users' tech literacy and digital skills and whether they require accessible or assistive technology. For example, Sweet et al. (2020) found that disabled users perceived the modality of social media interfaces, such as Facebook, characterized by frequent autoplay videos and a continuous news feed, to be unaccommodating (Toyama 2011). In line with this, device ownership reveals little about how ICT enables or limits marginalized populations.

One of the few published ICT4D surveys estimated that women use digital technologies, first and foremost, to communicate with others (Kimbrough et al. 2013; Noble 2012), while men tend to use the internet to obtain information and for self-advancement (Helsper 2010). However, these findings neglect women's role in creating and maintaining social bonds, a form of unpaid care work (Berg 2019). With regard to digital technologies, Berg reveals that women's participation in social media is a form of unpaid care labor, which to date remains poorly measured and little understood (Bill and Melinda Gates Foundation 2017). Likewise, Alonso et al. discovered a proportionate relationship between internet access and unpaid digital labor, where "women in countries with higher internet access spend significantly less time on unpaid work" (Alonso et al. 2019). Given that studies tend not to quantify women's online content and unpaid digital care work in the same way as men's, there is an overall lack of data about women's online creatorship and generative technology use (Sey and Hafkin 2019; Sey and Ortoleva 2014).

Online community building is also prevalent among other marginalized populations, such as racialized or disabled users, as well as the LGBTQ community (Jackson, Bailey, and Foucault Welles 2018; Sweet et al. 2020; Gray 2018). However, only a few studies address the benefits of community building in these populations. One such study showed that improving seniors' digital literacy and ease with technology by engaging them with interactive video games led them to overcome physical barriers and social isolation (Baez et.al, 2020). Nonetheless, the issue of computer anxiety or technophobia among seniors has not been addressed sufficiently to offer viable solutions (Dijk 2006, 2017). 


\section{Not a one-size-fits-all solution}

Tsetsi and Rains, among others, report that "constant advances in Internet technology (e.g., Google fiber, gigabit Internet speeds, 5G mobile connectivity, smart watches) reinforce that how people access the Internet is still a salient issue." (2017, p.140) The access divide is particularly noticeable among people with disabilities: advances in assistive technology happen more slowly than advances in ICTs more broadly, deepening the first-level digital divide among people with disabilities (Scholz, Yalcin, and Priestley 2017). Even though recent ICT4D research has moved beyond the question of internet access to focus on the second-level digital divide, limited access continues to be one of the main issues preventing marginalized populations from benefiting from ICTs. That said, if reducing digital inequalities implies having marginalized populations, including women, move beyond basic digital skills, these populations' local contexts must be taken into account when offering solutions.

A study on women's digital participation in urban areas in 10 low- and middleincome countries found that, on average, women were 50 percent less likely to have internet access than men (World Wide Web Foundation 2016b). Lower strategic access rates preclude women from developing the digital skills needed for strategic internet use (Sey and Hafkin 2019). Working with the World Wide Web Foundation, the nonprofit Internet Society reported that only 45 percent of women in Namibia have internet access. An action plan aimed at improving Namibian women's online connectivity established a need to cut internet-related costs. Furthermore, these two groups highlighted the need to create content relevant to these women and to find ways to ensure online safety for them in accordance with women's digital rights (World Wide Web Foundation 2020) (see the section "Responsible data use and privacy" in this report).

Similarly, we must be mindful that the increasing digitization of economic processes can compromise women's control over financial resources and thus greatly affect their level of independence. The Global Partnership for Financial Inclusion (GPFI) observed that 1 billion women still lack access to formal banking services. The increasing move to online banking by financial institutions, combined with women's lack of access to digital technologies, may reduce women's financial autonomy. Nonetheless, efforts to digitize banking services have also been shown to promote women's financial autonomy. In China, for example, women's online banking activity was reported to have increased by 30 percent between 2014 and 2017. In an effort to promote financial autonomy, India's financial services have also shifted entirely to Unified Payment Interfaces, such as Google Pay. Having established a legal framework and policies that digitally document women's inclusion and access to equality, Egypt has likewise fully transitioned toward cashless payments (Better Than Cash Alliance et al. 2020). These forms of digital access have no doubt helped democratize banking for many, but they only impact 
the lives of the digitally literate owners of web-connected technologies, like smartphones, personal computers, and tablets.

\section{Affordability matters}

Access to the internet comes at a cost-in low-, middle-, and high-income countries alike. A person or a community's ability to use digital technologies strategically requires having time and public, private, personal, or nonprofit resources-financial and otherwise-to become digitally literate. At home, women's traditional role as caretakers (Ferrant, Pesando, and Nowacka 2014) may compromise their ability to access digital technologies to the same extent as men. Internet-related costs constitute a more direct affordability issue. In a study on digital gender equality in Mozambique, the World Wide Web Foundation found that $1 \mathrm{~GB}$ of data costs as much as 22 percent of a typical monthly income (World Wide Web Foundation 2016a). Unsurprisingly, Mozambique also has one of the largest digital gender gaps. Uganda has reported similar figures (World Wide Web Foundation 2016b). Since the reduction of internet costs is one of the UN's 2030 Sustainable Development Goals (SDGs), the Alliance for Affordable Internet (A4AI) has developed the "1 For 2" protocol: $1 \mathrm{~GB}$ of data for no more than 2 percent of monthly income (United Nations 2015; A4AI 2020). The A4Al also lays out a set of factors that enable internet access. While cost is a crucial factor, being able to regularly access the internet with a fast connection speed, enough data, and an appropriate device are just as important as personal finances in creating an accessible internet standard (A4AI 2020). Only in conjunction do these factors grant users functional and meaningful access to the internet.

\section{CONSIDERATIONS FOR THE FUTURE}

Entering the third decade of the $21^{\text {st }}$ century, the internet is both a reality and a necessity. Within the context of an intersectional approach, internet access and use must be made available equitably to everyone and to a degree that allows digital empowerment for all people within their specific context. Safety and education-in support of increasing women's digital literacy and use-are understood as key elements in digital empowerment for marginalized populations and as a necessary step toward gender parity online (World Wide Web Foundation 2015; Glezou 2019; Chetty et al. 2018). The World Wide Web Foundation (2015) suggests, for example, that tech literacy education should occur as early as in elementary school: not only would this increase digital literacy and use ability, but

it would further empower those populations who may be excluded from obtaining a secondary education.

In low-, middle-, and high-income countries alike, legal policies regulating the inclusion of marginalized populations have also been shown to help bridge the 
digital gender gap: in France, the Plan sectoriel mixité numérique works to raise female employment in the digital sector while implementing a legal framework aimed at promoting employment opportunities attractive to women, increasing diversity, and challenging stereotypes associated with cybersex and cyber violence (Chetty et al. 2018; see the sections "Governance" and "Security and digital civic spaces" in this report).

Moreover, the EQUALS initiative developed a 10-step plan, "10 Lessons Learnt," intended to reduce the digital gender divide by providing alternatives to the status quo. The plan addresses access, affordability, safety, and skill, among other things (EQUALS 2019), all of which the OECD has classified as factors in the digital gender divide (Chetty et al. 2018). The "lessons learnt" include reducing the costs related to ICTs and digital devices; increasing the participation of marginalized populations in science, technology, engineering, and math (STEM) fields; and creating technologies that are both relevant and enabling for women to boost their online civic engagement. Additionally, EQUALS promotes the need to consider a culture's social norms to create viable options for marginalized people. While the overall rate of marginalized populations' basic digital skills must increase, the costs associated with accessing the internet must decrease (EQUALS 2019).

The joint efforts of global ICT4D associations, such as the UN EQUALS initiative or the World Wide Web Foundation, have demonstrated that digital inequalities can be mitigated if the barriers to digital parity are recognized. In one study, for example, women who reported having overcome barriers to equality offline were also more likely to do so online. This study also observed that women with higher internet access and digital literacy rates were more likely to self-identify as activists and participate in civic engagement (World Wide Web Foundation 2015; Intel 2013; see the section "Security and digital civic spaces" in this report). The reduction of the digital divide and the concomitant increase in digital literacy and access levels can thus lead to better internet use rates, civic engagement, economic power, digital empowerment, and autonomy in marginalized populations.

Even so, there remain significant limitations when it comes to understanding the digital gender divide - both quantitatively and qualitatively (Marsan and Sey 2021). Despite development initiatives' attempts to enable and empower women, the limited data available from low- and middle-income countries make it difficult to fully grasp how access, use, digital literacy levels, and online violence affect those at the most disadvantaged end of the digital divide. Regarding those identities for whom several types of marginalization intersect, as well as for those lacking internet access, there is next to no data (Sweet et al. 2020; Chetty et al. 2018). To address these problems and fill these knowledge gaps, more research into why and how marginalized populations use digital technologies will need to be conducted. Researchers should also consider a wider range of populations that have been historically excluded or limited from digital connectivity, including 
communities from the global South and seniors (Chetty et al. 2018; Dijk 2017). By the same token, ICTs must be created with the needs of a variety of populations in mind, especially in terms of accessible and assistive technology for disabled and older users (Blažič and Blažič 2020). Ultimately, however, understanding digital inequalities and their impact on the lives of women and other marginalized groups requires us to understand digital rights as a basic human right. 


\section{SECURITY AND DIGITAL CIVIC SPACES}

\section{OVERVIEW}

Advocacy for expanded internet access must go hand in hand with attention to user data privacy as well as the risk of internet-mediated gender-based violence (GBV).

People of all genders and backgrounds are at risk for online violence; however, women and marginalized communities-particularly queer and trans communities, people of color, disabled individuals, and those who fit into more than one of these categories-are more likely to face injustice and discrimination (APC 2017; World Wide Web Foundation 2015). Four in 10 internet users report experiencing harassment online, and young women ages 18 to 24 experience disproportionate levels of severe harassment, with 26 percent reporting being stalked online and 25 percent reporting online sexual harassment (Duggan 2017). There is a broad consensus that women experience a wider variety of forms of online harassment than men and often suffer more severe consequences as a result (Lenhart et al. 2016; Lumsden and Morgan 2017; Megarry 2014; Vickery and Everbach 2018; Vitak et al. 2017). Studies also show that online violence directed toward women largely consists of attacks on their gender and sexuality (Henry and Powell 2014; Jane 2014; Nova et al. 2019; Powell, Scott, and Henry 2020).

At the same time, digital technologies are enabling new kinds of activism that rely on the communication and networking capabilities of the internet. Academics have noted that feminist movements relying on the internet's online platforms "operate at local, regional, and global levels, while activists move back and forth between online and offline political activity" (Nuñez Puente 2011, 335). Social commentators have also suggested that women's use of social media technologies for feminist activism denotes a fourth wave of the movement (Cochrane 2013; Munro 2013). However, although increasing use of social media has increased the visibility and reach of feminist issues and activism, online activism "has also facilitated increased access to movement ideas and individual women by feminist adversaries," thereby contributing to increased instances of anti-feminist harassment (Megarry 2018, 1071). The scope and range of these internetmediated interactions suggest that more research is need on what kinds of feminist discussion can thrive online and where.

This section addresses some of the key trends related to women's safety online, including the frequent nonconsensual circulation of private data, the crucial role 
and expansion of online support networks for marginalized women, the increasing precarity of women's ability to safely engage in online sex work, the urgent responsibility of law enforcement and online platforms to address and prevent online GBV, and the emergence of online feminisms, including activist strategies and challenges.

\section{WHY IT MATTERS}

GBV has been widely recognized as a human rights issue (Australian Human Rights Commission 2014; Oxfam International 2012; United Nations 2010). Increasingly common and hard to ignore, online GBV has been a problem for as long as the internet has existed and, like offline harassment, targets women "to prevent them from fully occupying public spaces" (Mantilla 2013, 569).

There is broad consensus that government legislation, telecommunication regulations, online platform policies, and activist initiatives must work together to effectively address online GBV. Addressing these issues must take into account the "context-specific and contentious nature of technological development as it is molded by the conflicting interests of an array of social forces, for example, governments, activists, and indigenous communities" (Milan and Treré 2019, 324). As such, the question of safe digital spaces is ever changing and remarkably complex-these issues must be tackled with involvement from all those affected by ICT development, which, of course, means all of us.

\section{KEY ISSUES AND TRENDS}

\section{Increased surveillance, decreased privacy}

It has been widely noted that women are especially vulnerable to forms of online violence that take advantage of unprotected data. These forms of violence manipulate and abuse the internet's function as a public commons in order to take away women's autonomy online and reduce their ability to benefit from the internet's social and economic uses. Allen (2000) identifies the key role of misogyny in perpetuating these forms of abuse, arguing that "women face special privacy problems in cyberspace because there, too, they are perceived as inferiors, ancillaries, and safe targets, and held more accountable for their private conduct" (p. 1178). Some examples of women's unprotected data being used against them include doxing, nonconsensual pornography distribution, and stalking.

In a study of online violence faced by women in South Asia, Sambasivan et al. $(2019,3)$ define doxing as "the outing of private information, such as intimate 
photos or finances, nonconsensually to the public." Doxing can carry severe consequences such as "reputation harm, emotional harm, coercive relations, and physical harm" (p. 12). They note that the sociocultural environments of India, Pakistan, and Bangladesh require context-specific ways of thinking about and approaching the interactions between law, technological platforms, and the informal support networks that their study respondents rely on.

As a specific type of doxing, nonconsensual sharing of intimate photos disproportionately targets and harms women and is twice as likely to have been perpetuated by a man (Eaton et al. 2017). Using case studies from Malawi and Uganda, Chisala-Tempelhoff and Kirya (2016) examine the impacts and incidence of "revenge porn," or the nonconsensual distribution of sexually graphic images, in East Africa. Reviewing the range of current laws and policies that apply to nonconsensual pornography, they conclude that anti-pornography or antiobscenity laws are not adequate. Instead, they suggest that nonconsensual image sharing requires "specific legislation or a nuanced interpretation of existing laws to curb [its] incidence and to ensure redress for victims" (p. 8).

That being said, activists, primarily in the global North, have developed tactics other than legislation and law enforcement to address this issue. For example, Maddocks (2018) observes how feminist activists in Australia, the United Kindgom, the United States, Latin America, and Europe have worked to rename "revenge porn" as "nonconsensual pornography," "image-based sexual abuse," and "digital rape." This change in language helps shift the blame away from the victims, making clear that the structural forces of misogyny facilitate this kind of online violence. Unlike the conclusions of Chisala-Tempelhoff and Kirya, activists interviewed by Maddocks warn against the implementation of new nonconsensual pornography laws for fear of "slipping into a 'carceral feminism' that supports the disproportionate incarceration of the most marginalized." Instead, they emphasize the fair implementation of existing laws by focusing on "training, awareness raising, and capacity building in law enforcement agencies, schools, and workplaces" (Maddocks 2018, 357).

There are also risks posed by technologies that share information about one's location or daily activities, as these can be exploited for stalking (Messing et al. 2020). Mobile apps and software are the primary means of collecting location data (Cardoso et al. 2019). For example, Girls Around Me, an app that has now been pulled from the market, used GPS technology and social media platforms to locate women within a close distance without their knowledge. Spyware installed surreptitiously on women's mobile phones or computers can track and send copies of passwords, visited websites, and emails to perpetrators. Cardoso $(2019,4)$ notes that "abusive behaviors such as monitoring someone online and tracking them via GPS do not occur in isolation," meaning that GBV often takes similar forms online and offline. As such, it is ill advised to construct a binary between "virtual" and "real" victimization since this ignores how ICTs and digital 
environments can be used to inflict harm through multiple mechanisms across digital and nondigital spaces with similar results.

\section{Finding supportive communities online}

One of the limitations of scholarship on online violence is a tendency toward singlecategory analysis (Hackworth 2018; Madden et al. 2018): studies of gender in online harassment tend to focus on gender alone, neglecting to consider how GBV intersects with other identity categories. This is especially common in large research studies focused on gendered harassment that mention race, class, or other identity markers but do not adequately examine the influence of these categories on women's multilayered experiences online. According to feminist scholar Lucy Hackworth $(2018,63)$, this oversight contributes to "simplistic and homogenous terminology, lack of intersectional analyses, and erasure or ignoring of non-gendered harassment." After all, as sociologist Katherine Cross points out, gendered harassment in isolation is possible for only a very small subsection of the population: white, middle-class, heterosexual, cisgender, able-bodied women (Cross 2015).

Though limited, there has been some attention to Black women's experiences online, partially owing to the increasing online activism carried out by women of color (see Loza 2014). For example, in dialogue with Moya Bailey's work on misogynoir (Bailey and Trudy 2018), Madden et al. (2018) offer the concept of "mediated misogynoir" to describe anti-Black misogynist online harassment that "implicates systems of power that disadvantage Black women offline as well" ( $p$. 86). Their case study of online attacks against actress Leslie Jones illustrates the underlying class dynamics at play in racist and sexist harassment online. They found that Jones's wealth and status as an actress were used rhetorically to "dismiss the pain experienced in this kind of abuse" (p. 85), regardless of the severity of attacks on Jones's identity as a Black woman.

Gray (2018) also employs an intersectional framework to explore how Black lesbian women build community, form identity, and find empowerment in online gaming platforms. Studying Xbox Live, Gray finds that specific facets of the respondents' gender expressions and sexuality change the way they negotiate their identities with other users. Some of the women Gray interviews are able to keep their lesbian identity concealed, while others are not and thus face higher risk of harassment and abuse. This discrepancy is why some of Xbox Live's features, such as private party chats, are so valuable to marginalized communities: they allow the user to "explore her identities safely with others who value each aspect" (p. 290).

A limited number of studies address the experiences of transgender individuals online. Studying online harassment specifically in the context of physical gender transition, Haimson (2016) states that transgender people online are vulnerable to 
harassment, including hate speech, physical attacks after self-disclosing online, content flagged or removed for being inappropriate, and suspended accounts in response to name changes. Haimson notes that these experiences intersect with other stigmatized identities, particularly in the case of trans women who face both transphobia and sexism.

Similarly, Powell, Scott, and Henry (2020) unsurprisingly conclude that transgender individuals experience "a greater range and greater proportion of abusive behaviours, being approximately three times as likely to be victimized compared with cisgender heterosexual participants" (p. 217). Like the attacks leveled against cisgender women, this harassment was often sexual and gender based in nature. Unfortunately, this study has significant limitations due to its small sample size and a lack of data on other aspects of participants' identity. In order to draw firm conclusions about the experiences of trans people online, more research is required, particularly analysis of qualitative data through an intersectional framework.

\section{The precarity of sexual commerce online}

Many of those excluded from mainstream capitalist economies, including women, undocumented peoples, and other marginalized individuals, rely on the informal economies of sex work for economic survival. Data show that internet-facilitated sex work is the largest sector of sex work and represents a rapidly growing market; most commercial sex is mediated through internet technologies and networks (Cunningham and Kendall 2011; Jones 2015; Sanders et al. 2017). Given the internet's ability to both enable violence and foster networks of support and solidarity, women's experiences with online sex work are mixed. However, owing to government efforts to control and reduce sexual commerce online, the safety of sex workers online is increasingly precarious.

To an extent, the internet promotes physical safety, often offers better wages, assists workers with advertising and soliciting, allows workers to screen clients before engaging with them, reduces risk of arrest and negative encounters with law enforcement, and offers new avenues for community building and sex work activism (Cunningham and Kendall 2011; Jones 2015; McLean 2013; Moorman and Harrison 2016).

However, drawing on empirical data from the Beyond the Gaze research project, a study of the working practices of online sex workers in the United Kingdom, Campbell et al. (2019) observe that sex workers commonly face online GBV. The most common type of abuse experienced was "persistent or repeated/unwanted contact or attempts to contact through email, text or social media" (p. 1545), with more female sex workers encountering these patterns of behavior than male sex workers. This behavior is partially enabled by the internet's ability to provide clients 
with a greater degree of anonymity, which may increase the sexual exploitation of sex workers (Hughes 2004).

The regulation of sex work online also has a profound impact on the safety of sex workers, in both digital and nondigital environments. Many countries have attempted to curtail sex trafficking online through the passage of legislation like the 2018 bills SESTA (Stop Enabling Sex Traffickers Act) and FOSTA (Fight Online Sex Trafficking Act) in the United States. These bills criminalize the advertisement of sexual services online with the intention of preventing sex traffickers from using online platforms to solicit sex with minors and other sex trafficking victims. Interviewing sex workers shortly after the passage of SESTA/FOSTA, Blunt and Wolf (2020) contend that these bills target sex workers who are consensually advertising their services, communicating with clients, and organizing with other sex workers, resulting in sex workers' loss of whatever supports or protections they once had. Blunt and Wolf identified financial instability, fewer safety resources, and reduced ability to organize collectively as some of the negative effects of the legislation

\section{Online violence despite offline rights}

Studies of responses to online harassment note dissatisfaction with how local authorities and online platforms handle hate speech and harassment. Suzor et al. (2019) argue that telecommunication corporations and online platforms have consistently represented themselves as "neutral intermediaries," enabling them to avoid conflicts about what is considered "free speech" versus what enacts harm against users. Systems for reporting online violence are often not well understood, are considered ineffective or overly time consuming, do not consider local contexts, resort to victim blaming, or focus on mitigating vulnerability to harassment rather than tackling harassment at the source (Blackwell et al. 2017; Kennedy et al. 2017). As such, many scholars argue that formal mechanisms for addressing online harm would benefit from changes to legislation and law enforcement that are nuanced and context driven, as well as improvements to online platform design and policies that give users more agency in reporting violence and protecting their online data.

Pointing out that solutions to address online GBV in the global South, particularly in South Asia, need to consider familial and sociocultural power relations, Sambasivan et al. (2019) find that most participants in their study "perceived lawand-order and in-app abuse reporting to be ineffective or hurtful to their reputations" (p. 12) and that what South Asian women consider harmful was not perceived as abuse by social media platform policies. Instead of reporting harassment, participants relied on informal coping mechanisms-namely family and nongovernmental organizations (NGOs)_for support following experiences of online violence. 
Similarly, following a survey of gendered online harassment in India, Pasricha (2016) notes that women were often more likely to simply block harassers or limit their online participation than report harassment. According to respondents, this was because law enforcement was not always willing or sufficiently equipped to intervene after a report was filed and because platform mechanisms for reporting and preventing online abuse were often inadequate. Pasricha argues that platforms must have staff with the linguistic competence to review and address reports of abuse, as well as procedures for handling repeated and escalating incidents. The study offers a set of potential solutions targeted at engaging local governments through better education and development of protocols for cybercrime reporting. It also suggests that tech platforms expand users' options for reporting harassment and blocking abusive users and offer more flexible and comprehensive privacy options.

In the context of the global North, Powell, Scott, and Henry (2020) likewise agree that, although legislation and law enforcement are important, there must be equal pressure on digital and social media platforms to adapt their policies, community standards, and reporting functions in order to challenge and prevent online violence. More specifically, Pater et al. (2016) recommend consistency across platforms for what constitutes harassment and the types and severity of responses that harassment warrants. They also stress the importance of platform policies that are written in plain language and that reflect community norms, suggesting that "platform operators could work with communities through participatory design or purposeful design for social norms" (p. 373). Participatory design enables all stakeholders (e.g., platform developers, employees, investors, individual users) to have a role in the design process, ideally ensuring that the platform is safe and usable for all. However, participatory design can be difficult when global platforms must adhere to local community norms of acceptable online governance and behavior. This is why a mix of approaches, such as improved platform design and policy combined with specific governmental legislation, are most likely to have a real effect on reducing online GBV.

\section{Evolving forms of feminist activism}

The social and political capabilities that digital technologies, and particularly the internet, provide have fundamentally changed the ways that feminist organizing occurs, both online and offline. The emergence of feminist blogs, apps, discussion spaces, and social media campaigns demonstrates the uses of online spaces where activism can take up, reframe, and challenge sexist discourses and behaviors online. As we have seen, however, online spaces can also be used to facilitate misogynistic attacks, something that feminist activists have addressed, for example, through vigilante tactics and hashtags.

Digital vigilantism, or digilantism, is a strategy sometimes used by feminist activists to challenge instances of sexism and misogyny online. Digilantes "respond through 
coordinated retaliation on digital media, including mobile devices and social media platforms" (Trottier 2017, 56), and, in the case of feminist digilantism, these responses focus primarily on naming and shaming approaches, such as publicly outing those who enact GBV online by establishing blogs and hashtags that widely circulate their misogynistic attacks and offensive statements (Jane 2016, 288). Jane argues that this form of activism has taken hold partially because of the lack of institutional recourse available in cases of online harassment and serves as a legitimate, although ethically questionable, strategy for addressing GBV online. Jane cautions, however, that engaging in digilantism can put activists at risk for more online attacks and could "ultimately strengthen extrajudicial cultures online" (Jane 2016, 292). Instead, Jane suggests that a hybrid approach combining individualistic and collectivist approaches to activism and mobilization is imperative to achieving the institutional reforms necessary to combat online violence.

Another form of feminist activism online that is becoming increasingly influential is the use of hashtags on social media sites. A popular example of this strategy is the \#MeToo hashtag, which gained popularity in October 2017 and showcased the sheer ubiquity of gender-based sexual violence in the workplace (Mendes, Ringrose, and Keller 2018).

A different hashtag, \#SolidaritylsForWhiteWomen, tackles the issue of race within feminist movements. Coined by Mikki Kendall, the hashtag critiques mainstream feminism's centering of white women, and their safety and comfort, at the expense of women of color (Kendall 2013). Loza (2014) writes that Twitter hashtags like this one help build a "coalitional feminism," one that recognizes difference without essentializing it and fosters unity through concrete acts of feminist activism. According to Loza, this is possible because social media enables "women of color to speak to each other across borders and boundaries" (p.1). However, conducting an analysis of tweets containing the hashtag, Holm and Castro (2018) observe that many of the most engaged tweets were authored by white women with calls to "listen and learn." These tweets recentered white women in a discussion about the silencing of women of color in feminist movements. As such, Twitter's platform, particularly its "inclusive design," can sometimes lead to "a consensus-seeking neutralization of the conflict" (Holm and Castro 2018, 331). This article reminds us that platform affordances can both "democratize" discursive space and reproduce power dynamics, a tension that shapes the political and activist potential of online platforms.

\section{CONSIDERATIONS FOR THE FUTURE}

Addressing online violence against women and marginalized communities requires "the active and careful participation of state and nonstate actors involved in Internet governance" (Suzor et al. 2019, 86). It must be acknowledged that 
"while ICTs offered new avenues to commit GBV, they also provided the platform to share information, network, and build user capacity to counter such violence" (Baker 2018, 284). Emphasis must be on proactive strategies for prevention and intervention rather than passive responses after harm has already occurred. ICTs are already used to share information, raise awareness, and network across geographic, cultural, linguistic, and other differences. These technological capabilities can be applied to counter online violence and, in fact, already are through formal and informal feminist initiatives.

There are clear gaps in the research surrounding GBV and ICTs, and this in turn affects the way that policy is written. Both government legislation and platform policies aimed at preventing digital violence need more broad-scale quantitative data, especially to understand how the risk of online violence can prevent women from taking advantage of potentially empowering uses of ICTs for fear of retribution and harassment. Another area lacking crucial research is the experiences of marginalized communities online and how these populations face unique forms of violence that may require specific solutions. Additionally, scholars and policy makers must interrogate the biases embedded in their research epistemologies and methods, particularly the tendency to "assimilate the heterogeneity of diverse contexts and to gloss over differences and cultural specificities" (Milan and Treré 2019, 324).

It is also necessary to take a careful look at where the available research and data come from. Initiatives like the UN-backed EQUALS partnership are developed in collaboration with tech companies-in this case, the GSMA — which means that figures in the industry are both defining policy and spearheading research. Such arrangements signal a possible conflict of interest; accordingly, we should be concerned about a lack of regulation of their activities and a lack of transparency about the implications of this lack of regulation for users. 


\section{RESPONSIBLE DATA USE AND PRIVACY}

\section{OVERVIEW}

As digital infrastructure enables the production and collection of more and more personal data, ethical concerns related to user privacy and the responsible use of personal data by governments, online platforms, telecommunication corporations, and other entities have become increasingly central to technological innovation and related policy-making decisions. Use of personal technological devices, such as cellphones and mobile apps, computers, and "wearables," constitute one of the main avenues through which user data are harvested (Arias et al. 2015; Binns et al. 2018; Book and Wallach 2015; Rehman et al. 2015; Seneviratne et al. 2017). As these technologies become increasingly integrated into everyday life, there is also increased risk of irresponsible use of user data, which impacts users in ways they may not be aware of. In fact, users are largely uninformed about how their data are collected and used, partly because the entities that collect it often fail to provide a clear explanation of their policies on data retention (International Data Responsibility Group 2017).

It is clear that gender plays a significant role in the design and implementation of ICTs so it should come as no surprise that forms of online surveillance are often implicitly, if not explicitly, gendered (Van der Meulen and Heynen 2016). Already vulnerable to safety threats online, women and girls face heightened risks to their data privacy that often go unrecognized. Women are generally found to be more concerned about online privacy than men but tend to possess fewer technical skills related to personal data management and have lower self-confidence about their skills (Park 2015; Rowan and Dehlinger 2014). When women do have these skills, however, they are more likely to use them to engage in privacy protective behavior (Hoy and Milne 2010). As such, the role of gender needs to be adequately examined in the privacy and data protection discourse, not just as a single category of analysis but as an analytical framework that helps illuminate how online surveillance and data collection simultaneously articulate the dynamics of race, sexuality, ability, class, health, and other gendered variables.

At the moment, there exists no consensus on approaches to data privacy and protection, as well as responsible use of personal data. Government regulations are either nonexistent, poorly implemented, or vastly different between nations, particularly in developing countries (UNCTAD 2016). Regulations that do exist are often outdated, having not kept pace with technological innovation and current data practices used by the private and public sectors (Wu 2014). This lack of oversight 
complicates efforts to develop "standardised and scalable approaches to risk management and data access" (Pawelke et al. 2017, 54). Beyond legal challenges, pressing questions of data privacy in relation to platform design and practices of data collection and use must be addressed. Thus, addressing the issue of responsible data use and privacy is a twofold task: it means not only writing comprehensive and standardized legislation around data privacy but also rethinking how data protection is built into, or excluded from, platform designs, data collection, and data analysis.

Using ethical concerns around the increased harvesting of user data as a point of departure, this section addresses some of the key issues related to data privacy from a feminist perspective, including the increasing collection of data, the imperative for users to track their own data, the dangers of data-driven algorithms, and alternative privacy and consent models for the collection and use of data. The section also discusses possible approaches to these issues through both policy and technological innovation.

\section{WHY IT MATTERS}

While earlier information systems also raised the question of responsible data use and privacy, the rise of digital media and the internet has radically changed how personal information is shared, collected, and understood, making data protection a topical and contentious issue (Nissenbaum 2011). From a human rights perspective, it is clear that users should have control over their own data and how it is used by others, even as online environments make this right difficult to define and protect. As such, it is imperative that technology and information policies take fundamental human rights and societal concerns into account, including women's rights to online safety and privacy and the question of how the costs, benefits, and risks of tech innovation get distributed.

Considering data protection through a feminist framework enables us to explore how data can operate both as a social good and as a means to consolidate power in the hands of a privileged few. Thinking intersectionally also expands the conversation to include the cultural complexity and diversity of technologies and digital practices as a factor in how individuals negotiate data privacy. Accordingly, this section adopts D'Ignazio and Klein's (2020) "data feminism" as an intersectional framework to examine the ways in which "standard practices in data science serve to reinforce ... existing inequalities," and how data science can be wielded "to challenge and change the distribution of power" in a digitally networked world (pp. 8-9). The tension between these two uses of data is what gives the question of responsible data and privacy such importance. We must critically interrogate data's shifting relationship to power in order to ensure that data are 
used as a tool to reveal and dismantle systems of oppression that harm women and marginalized communities.

\section{KEY ISSUES AND TRENDS}

\section{The "datafication" of daily life}

Technological innovation has undoubtedly increased the amount of information available about people's online behaviors, meaning that almost anything that users do with digital technologies and media can be transformed into usable information in the form of data (Van Dijck 2014). Online participatory culture, such as the growth of content creatorship and social networking sites, has facilitated efficient sharing of personal information by individuals and its subsequent collection by governments, digital platforms, and other individuals. Van Dijck (2014, p.198) writes that this culture has contributed to what many call the "datafication" of daily life, or the transformation of "social action into online quantified data." This shift has profound implications for how individuals navigate social and economic relations in digital environments, particularly the power dynamics between themselves and the larger entities collecting their data.

While there are few studies comparing the collection of men's and women's online data, we do know that the impacts of data collection vary widely based on gender. For example, data-tracking apps that collect information about a woman's reproductive history can expose users to a wide variety of risks ranging from privacy violations to public backlash. A 2016 Consumer Reports study found that serious security flaws in Glow, a menstrual-tracking app with about 4 million users, allowed fraudulent access to information, including whether a woman was pregnant or if she had had any miscarriages or abortions (Beilinson 2016). In building privacy safeguards and disclosing secondary data uses to users, app developers should consider gender disparities in the risks people face if someone accesses their private health information without their permission. The stigma surrounding many possible reproductive experiences is much greater for women than for men (Sen, Östlin, and George 2007).

Privacy concerns like these are highly relevant in the global South, especially as tech giants seek their "next billion users" and countries grapple with how to regulate the storage and reselling of user data by tech companies. A global knowledge economy has developed that relies on the economic value of personal data that have been produced and collected by digital technologies. Calling this shift "surveillance capitalism," Shoshana Zuboff $(2015,75)$ argues that this form of datafication reflects a "logic of accumulation" that uses data to predict and modify human behavior online for commercial purposes. This emphasis on the revenue associated with the control of vast amounts of data is central to an analysis of 
Uber's data practices in São Paulo (Firmino, Cardoso, and Evangelista 2019). The researchers observe that the company's reliance on surveillance through data collection compounds their drivers' precarious economic position because it enables them to be watched both by Uber and by Uber's partners and customers. This dual surveillance, combined with Brazil's poorly regulated labor market, creates a perfect storm in which labor forces can be exploited through mechanisms of extreme control. It is also worth noting that many Uber drivers in the global North are immigrants from countries in the global South, which raises concerns about how tech companies use economic disparities between countries and populations to their advantage (Rosenblat 2018).

Conversely, data can be harnessed to resist or critique the ways in which information is currently collected by governments and institutions. For instance, Ricaurte (2019) discusses the citizen-led project Femicides in Mexico, which provides detailed data on femicides, information that the Mexican government does not collect or supply for public use. These data, including details about the victim and the location of the crime, are compiled from news and media sources and then visualized on an interactive map. Ricaurte $(2019,360)$ writes that the project "provides an example of citizen resistance to the politics of governmentenforced invisibility against marginalized and vulnerable communities," drawing much-needed attention both to gender violence in Mexico and the government's unwillingness to take action. Another example includes Kimberly Seals Allers's creation of the Irth app, which combines crowdsourced data with social justice principles (D'Ignazio and Klein 2020, 46). The app functions as a public information platform and accountability tool for Black women's maternal health. Users contribute descriptions of their experiences at certain clinics or with particular doctors to allow people from marginalized gender, race, and socioeconomic backgrounds to look at the kind of maternal health care others like them experience.

Ultimately, because data are treated as a commodity, they are necessarily tied to global economic systems in which certain populations benefit at the expense of others. Some have even referred to this relationship as "data colonialism," arguing that data from the global South are being extracted by tech companies in the global North for profit, similar to colonial relationships of exploitation and control (Couldry and Mejias 2019; Milan and Treré 2019). Ricaurte (2019) also emphasizes that data collection is embraced by governments and other actors in the global South, leading to internal forms of colonization. Regardless of how the issue is framed, there must be critical attention to how these systems of surveillance and data collection operate unevenly across geographies and identities and serve to advance particular interests. 


\section{The rise of self-tracking}

As governments, telecommunication corporations, and digital platforms monitor and collect people's personal information, individuals have also begun to use the same technologies to record features of their lives for their own uses. Referred to as self-tracking, this form of data collection, commonly facilitated through mobile apps, is usually used by individuals to improve their lives in some way. Examples include mood-tracking apps, where users input information describing their emotional state and mental health, and apps that help users track their spending. In fact, sociologist Deborah Lupton (2016) estimated that in 2016 there were well over 160,000 tracking mobile apps available on the market and that health and fitness-related apps, such as those that track biometric data like calories consumed or miles run, were most popular in terms of downloads. "Wearables," or mobile sensors that can be attached or worn on the body, such as Nike's Fitbit, are also common ways of tracking physical health data.

It is important to distinguish self-tracking from other forms of biometric surveillance that produce data that cannot be controlled or accessed by the individual, such as the full body scanners frequently used at US airports (Vaughan 2015) or Bangladesh's recent decision to require biometric registration, primarily fingerprints, for all mobile phone users (Ahmed et al. 2017). These examples are often described as necessary to ensure public or national security, whereas biometric self-tracking is usually carried out for personal use.

Most responses to self-tracking technologies have been positive, with doctors praising telehealth apps for enabling them to treat patients at a distance and patients themselves appreciating greater control over their own health (Elias and Gill 2018). The impacts of these forms of self-monitoring can be seen, for example, in the growing cultural consensus in the global North and beyond that positions expectant families, and particularly women, as "health conscious subjects" (Johnson, 2014, p.330). Complicating the notion that self-tracking is voluntary, this places a social imperative on pregnant women to take on more and more of their own health-related care by tracking the minute details of their physical health during pregnancy. While these documentation processes can provide a sense of reassurance for women (Lupton and Pedersen 2016), apps that provide health information and enable users to track their pregnancies often shore up a "default heteronormativity,.. visible in the apps' technical, aesthetic, and therapeutic design" These design standards "assumes that users conform to heterosexual and gendered norms," thereby excluding LGBTQ users and their families (Ley 2017, 104).

This observation supports Lisa Nakamura (2015)'s argument that biometric surveillance serves to reinforce not only normative notions of embodiment but also hegemonic social norms. She argues that biometric forms of monitoring serve two functions: "to regulate, define, and control populations, and to create new 
gendered, racialized, abled, and disabled bodies through digital means" (p. 221). Biometric surveillance, such as facial or voice recognition, often "fails" at reading bodies that do not conform to normative standards of embodiment. For instance, trans and gender nonconforming people experience particular problems with biometric and human border security because their bodies and identities are commonly read as deceptive by machine surveillance (Beauchamp 2018). Nonnormative bodies and subjects, then, are produced as both invisible and hypervisible, thereby rendering them accessible for various forms of state and extra-state intervention.

Ultimately, self-tracking technologies are changing how individuals interpret and negotiate their experiences of health and self-identity. While these practices enable people to closely monitor their health and change their behavior for more favorable outcomes, some scholars worry that these technologies cause individuals to internalize the same reasoning that drives data harvesting onlinenamely, logics of control and quantification (Gutierrez 2016). De Souza, for instance, suggests that the practice of self-tracking produces "the ideal neoliberal citizen: the self-optimizing individual who voluntarily monitors, measures, regulates, and collects biometric data ... taking control of their own bodies on a minute and detailed level" (De Souza 2013). The individualist rhetoric of selftracking shifts the management of health away from institutions like health care systems and health-focused NGOs toward individuals themselves. Thus, as the market for health wearables expands in low- and middle-income countries and development initiatives position health-monitoring technologies as a means of improving health outcomes and health literacy among their target populations (see, for example, UNICEF's Wearables for Good program [Palmer and Gershbein 2017]), we must think critically about how these technological practices may place an undue and unsustainable burden on the individual.

\section{The unintended consequences of algorithms}

Algorithms structure human activity online-they create personalized advertisements, recommend news articles, and match individuals on dating apps, among a wide (and growing) variety of other functions. One consequence of the increased role of algorithms in contemporary life is the risk that systems of oppression that affect how we negotiate social relations offline will seep into the digital architectures of our online lives. Although algorithms are covered in the "Access, use, and inequality" section of this report, they are also tied to issues of data privacy and security. Algorithms perform calculations and provide results based on the datasets that humans supply them. This means that algorithms reflect inequities that are present in data to begin with and reinforce these biases in the results they give us.

Accordingly, Megan Garcia (2016, p. 112) defines algorithmic bias as, "When seemingly innocuous programming takes on the prejudices either of its creators or 
the data it is fed." Often, algorithmic biases result in part from unequal representation of women and minorities in the training datasets used to create artificial intelligence (Al) models. As a result, for example, women may be denied loans and credit (Vigdor 2019), their economic growth may be hampered, or speech recognition programs may misidentify words spoken by Black people at much greater rates than for white people (Koenecke et al. 2020). Sofiya Noble's concept of "algorithmic oppression" refers to this phenomenon, in which racist and sexist search results, targeted marketing, and other forms of algorithmic data exploitation are not glitches in a purportedly unbiased information system but fundamental features of the operating system of the web (Noble 2018).

Algorithmic bias is also frequently intertwined with digital platforms' commercial aims. Using beauty vlogs as a case study, Bishop (2018) explores how YouTube's algorithms create "a discriminatory hierarchy of vloggers, favouring middle class social actors who make highly gendered content aligned with advertisers' demands and needs" (p. 69). Videos made by content creators who adhere to normative performances of femininity are bumped up in search results and recommended video lists and are thus made particularly visible on the platform in an attempt to cultivate concentrated markets. More visibility, of course, translates to more viewers, which is economically beneficial for both vloggers and advertisers. In this way, an algorithm contributes to the classed and gendered stratification of certain content genres, guiding women toward "commercially recognizable feminized content" (Bishop 2018,p. 81).

Efforts to address these biases include retraining algorithms using more inclusive datasets, altering algorithmic associations to reduce gender bias, and investigating the ways that predictive algorithms trained on data from a world of racial, socioeconomic, and gendered disparities will co-create and perpetuate those same disparities (Noble 2018). These efforts must look both at the functions of the algorithm in relation to its inputs and at the meanings that the algorithm's operations have in the broader sociocultural context in which it works. However, as D'Ignazio and Klein (2020) note, trying to interrogate the biases embedded in algorithms is akin to confronting a black box: most algorithms are proprietary, and training datasets are rarely made public. Given that the use of consumers' user data in algorithmic decision making is rarely transparent, there is a need for further study of the kinds of influence that gendered internet use patterns can have on algorithmic biases, especially because algorithms use past behavior to predict, and often constrain, future behavior (D'lgnazio and Klein 2020, 55).

\section{Rethinking privacy online}

While the right to privacy and consent are inscribed within legislation, regulations about how these rights are applied in ICTs are either patchwork or not yet in place. According to a 2016 report released by the UN, countries largely fall into one of three categories: having no data protection legislation, having legislation that 
includes significant gaps and exemptions, or having legislation that allows businesses to determine the scope of data protection that they offer (UNCTAD 2016). Given the global nature of ICT networks, the UN advocates for cross-border collaboration to generate truly effective data regulations "as a way to create an environment that is more predictable for all stakeholders involved in the information economy and to build trust online" (UNCTAD 2016, xi). However, achieving such collaboration will be difficult unless all stakeholders are consulted, a virtually impossible task in light of the ubiquity and far-reaching nature of ICTs.

In the meantime, global networks of experts and organizations are collaborating to develop working suggestions for responsible data principles and standards, such as the International Data Responsibility Group. In its annual report, the group outlined three recommendations for data privacy protection moving forward: putting "privacy by design" into action; focusing on responsibility in data use; and centering transparency, trust, and user control. According to the report, in a practical sense "privacy by design" means actively addressing privacy across a project's "architectural, governance, and operational dimensions" as a structural design principle (International Data Responsibility Group 2017, 13). Beyond these design considerations, the group calls for improving data governance by, for example, establishing internal standards to do no harm and being more transparent and accountable about how and why data are collected.

Government and private sector regulation are just one way to approach data privacy, however, and feminist interventions, though few and far between, tend to argue that the basic notions of privacy and consent in a digital environment need to be further interrogated. One solution proposed by Danielle Leong (2017) is "consensual software," whereby software gives users the information they need to make informed, consensual decisions and does not assume implicit consent for any of the software's operations. Consensual software departs from current designs because it is based on the principle of opting in instead of opting out. According to Leong, this approach increases not only digital literacy but also transparency.

However, Leong's model still operates on a framework of notice-and-consent requiring that individuals be notified and give consent before their data are collected, something that other feminist scholars have challenged. Fundamental to notice-and-consent models is the idea that privacy and consent are individual rights that belong to sovereign subjects, obscuring the reality that these concepts are negotiated as functions of power relations between groups of people. Instead, Nissenbaum (2011) points out that notice-and-consent models operate on the assumption that individuals are able to freely choose what they do or do not want to do online. In reality, there is no opting out in a networked society-doing so may result in individuals losing services and resources integral to, for example, finding work or connecting with friends. Critiquing notions of digital environments as entirely separate from our material lives, Nissenbaum (2011) suggests that privacy 
protocols online should largely follow the social norms of discretion that structure our offline lives in order to "[partition] information along contextual contours rather than along lines of corporate ownership" (p. 44). So if a digital platform refers to itself as a book retailer, for instance, then that platform would be expected to follow the same privacy norms as a brick-and-mortar bookseller.

In a similar vein, Weinberg (2017) also critiques the idea of privacy founded on individualism because, as she remarks, "concerns over individual privacy rights tend to obfuscate how information technologies produce profit ... through the aggregate of anonymized data from all users" (p. 16). Although individuals can use privacy rights discourse to access legal recourse, Weinberg argues that approaches to data protection must consider privacy as a collective, social condition in order to fully address how data collection largely functions onlinethat is, through the mass collection of relatively anonymous data which is ideally suited for "the masking of inequality ... and for the multiplication of profit-making tools and techniques, which can escape audit, regulation, and social control" (Appadurai 2015, 102). As such, feminist perspectives on data protection shake up many of the underlying assumptions built into existing legislation; urge us to think about how data collection impacts users collectively, although not always equally; and offer new routes for implementing regulatory measures in ways that support digital equity initiatives.

\section{CONSIDERATIONS FOR THE FUTURE}

Despite the increasing attention to and urgency of protecting online data, how this could be "appropriately, enforceably, and effectively achieved in the borderless virtual world of the internet with the shifting landscape is a big challenge" (Wu 2014, 150). Many of the issues surrounding data privacy boil down to the fact that data are political. Digital technologies are connected with a political economy of data exploitation, and there are numerous institutional and ideological forces shaping the production and use of data. However, as Hesmondhalgh (2010) has stressed, we cannot erase the cultural complexity of digital and online practices by understanding data simply as a commodity. Data can be used for social good, as with the Irth app discussed earlier, and be harnessed for resistance and activist purposes, exemplified through the Femicides in Mexico project. Data techniques like statistical modeling, crowdsourcing, and data visualization are powerful tools for fighting inequality, encouraging civic engagement online and offline, and building progressive movements. As such, these uses open up new possibilities for technological sovereignty and data agency.

Moving forward, it may be useful to shift our thinking from responsible data use to accountable data use. The notion of accountability implies a more active, concrete engagement with the ramifications of data collection and use and demands 
structural changes to data governance. D'Ignazio and Klein (2020) model this paradigm in their book Data Feminism by including a section titled "Our Values and Our Metrics for Holding Ourselves Accountable." This collaborative document describes the shared feminist values that shape their project and outlines how the authors developed a set of metrics for effectively measuring the extent to which those values were represented in their published book. For example, D'Ignazio and Klein wished to center the experiences of people of color and set an aspirational metric: 75 percent of the feminist data projects they discussed would be led by people of color. The authors created the metric before the research and writing process, consulted it after finishing the first draft of the book, and consulted it again after completing the final draft. In the end, they found that only 42 percent of the projects they considered were led by people of color. This metric served as a tool to keep the authors accountable to their feminist values through the project, and including it in the book provides a transparent account of the project's successes and failures. In the end, D'Ignazio and Klein remark, "Values are not enough. We have to put those values into action and hold ourselves accountable time and time again," which is a reminder that all digital stakeholders and users could benefit from (p. 221). 


\section{DATA GOVERNANCE}

\section{OVERVIEW}

As Al technology, Big Data, algorithms, and policy and lawmaking practices undergo continual development, the way our data are collected, managed, and governed foreground existing power relations (UNDP 2019; EQUALS 2019). In the context of data governance, a complex network of policy regulations, laws, stakeholders, and institutional and corporate actors negotiate about power structures, control over data, and uses of data (UNDP 2019; Janssen et al. 2020; NetMundial Initiative 2014). Data governance and its concomitant power hierarchies, as well as a lack of responsible data collection, affect marginalized populations disproportionately (Gurumurthy and Chami 2017; Janssen et al. 2020). For example, a study on Singapore and female leadership in tech found that women's tech leadership was overall viewed negatively (Dutta 2018). Similarly, out of 32 OECD countries, only 4 view the advancement of e-inclusion as one of the 15 most pressing objectives. Overall, this objective is ranked second to last in the priority pool and projected to still come in only 13th in 2022 (OECD 2017). Similarly, the UN's SDG report indicates that only 10 of the " 54 indicators for gender equality are rated as 'reliably monitored' at the global level" (Rose Taylor 2020, 9; UN Women 2020b).

The digital inclusion of populations marginalized by factors such as age, ability, sexual orientation, gender identity, or race is currently generally not understood as an essential objective within policy making and data governance (Clarke 2020; Stone and Calderon 2019). In line with this, Rose Taylor notes that existing policies are not conceived with marginalized populations and equitable opportunities in mind. Instead, they are established to maintain and contain power for those who already have it. This situation reflects a lack of data visibility or women and minorities at the level of policy making (Rose Taylor 2020).

Janssen et al. (2020) define data governance as the ways in which organizations and their personnel define, apply, and monitor "the patterns of rules and authorities for directing proper functioning of, and ensuring the accountability for, the entire life-cycle of data and algorithms within and across organizations." Thus data governance is "about allocating authority and control over data" (Janssen et al. $2020, X X)$. It "defines decisions on the roles of managing, policies and procedures that control data assets" (Busobozi and Kalema 2017, 5; Holmes 2016).

An intersectional approach to rights-based data governance must consider not only the data itself, but also how data are collected, managed, and ultimately used (Janssen et al. 2020). Inclusive data governance should follow the FAIR principles, 
meaning that data should be "findable, accessible, interoperable, and reusable" (Stone and Calderon 2019).

To fully understand how gender and data governance interact, we must consider how the data we share are used, who benefits from the current distribution of power over ICTs and the different uses of ICTs, and what role civic engagement plays in these processes (Bouzguenda, Alalouch, and Fava 2019). It is also essential to investigate how the Fourth Industrial Revolution can harm some communities more than others, as well as what factors impact the drafting of public and private ICT policies and legal frameworks.

\section{WHY IT MATTERS}

While responsible and gender-sensitive data collection is central to responsible data governance, current digital policies and legal frameworks rarely create safe, enabling, and empowering environments for marginalized populations. A UNESCO survey on the digital inclusion of low-skilled populations in low- and middle-income countries found that low levels of digital literacy in conjunction with complex user interfaces can prevent users from participating in the benefits of ICTs, particularly those technologies that were created to promote inclusion and digital participation (UNESCO 2018). Issues with existing data governance and the large number of flawed regulatory proposals highlight the difficulty of establishing viable and equitable data governance solutions (Bouzguenda, Alalouch, and Fava 2019). A rights-based approach to gender in the context of data governance and policy making allows for the development of trustworthy, fair, and accountable data practices that are in accordance with context-specific needs (Stone and Calderon 2019). Gurumurthy and Chami (2017) call for the inclusion of more intersectionality in rights-based research as a way to mitigate online gender disparities and establish data privacy and safety laws that will protect the most marginalized populations and their data rights.

\section{KEY ISSUES AND TRENDS}

\section{Producing smart citizens}

"Smart cities" are the fusion of technology and the urban landscape (Yigitcanlar et al. 2019), with urban spaces being "hubs of technological innovation as opposed to cities of sustainable development" (Bouzguenda, Alalouch, and Fava 2019, 47). While the smart city was initially conceptualized in relation to the environmental challenges of urban life, it is now primarily understood in the context of ICTs. Lips (2020) notes that the social well-being of those living in smart cities rests on 
information systems being "distributed, transparent, trustworthy and usercontrolled" (p. ). It is therefore critical that governments act on the principles of responsible data and policy transparency, while ensuring each citizen's right to personal data privacy, ownership, and autonomy. That said, the World Economic Forum (2017) has observed an increase in countries' efforts to create shared smart city policies, regulations, and systems, particularly in Estonia, India, Singapore, and the United Arab Emirates.

Singapore's GovTech initiative showcases the potential of smart cities to improve society. Participatory and user based, GovTech incorporates artificial intelligence, robotics, and blockchain to identify the "most beneficial products and services for citizens" (World Economic Forum 2017). The Singaporean government has also created the Technology Skills Accelerator Project (TeSA), a tripartite initiative aimed at developing ICT professionals' digital skills. The Rwandan government is part of a public-private partnership that has reduced the cost and timeline associated with the delivery of government services while increasing the services' transparency and efficiency (World Economic Forum 2017).

A study of female leadership in STEM fields in Singapore found that traditional Confucian cultural values, which identify men as household providers, result in men's being disproportionately represented in STEM careers. Accordingly, women working in STEM fields reported that female leadership was "not appreciated." The study notes that, of the 52 female participants, only 4 held at least a low- to midlevel leadership role (Dutta 2018). In failing to recognize these realities, Singapore's smart city and society model neglects the normative and educational challenges that women face when trying to obtain ICT employment, capabilities, and leadership positions.

\section{The effects of Al on talent recruitment}

Issues surrounding data governance include algorithmic biases in Al-based talent recruitment programs, where Al video programs, such as WePow, HireVue, and SparkHire, analyze candidates' emotions, eye movements, voice cadence, and age and then suggest the most suitable candidates for the position to be filled. Aside from consent and data privacy issues, such Al-based programs are racially biased and often misinterpret and miscode candidates' expressions, such as voice, inflection, and accents (Fernández and Fernández 2019). Further, there is evidence that the racially biased processing of biometric data collection can prevent racialized groups from accessing the same employment opportunities as non-marginalized and non-minority candidates (Cook et al. 2019; see the sections "Access, use and, inequality" and "Effects of a global pandemic: COVID-19" in this report). 


\section{From identity to digital identities}

A growing number of countries rely on ICTs and Al to provide government services to citizens (World Economic Forum 2017). When governed responsibly and consensually, Al can bear significant societal benefits, especially in terms of mitigating inequalities in health, education, and governance (UNDP 2019). In Japan, for example, the standardization of bilateral and trilateral collaborations between and across actors has led to an increase in cybersecurity and intelligence sharing. Similarly, Germany instigated a legal framework in 2015 aimed at tackling cyberterrorism through advanced ICTs (World Economic Forum 2017).

While Big, Open, and Linked Data (BOLD) can lead governments to analyze the behavior of individuals, increase control, and reduce privacy BOLD can also help governments foster relationships with their citizens, other governments, ICT4D agencies, and corporate stakeholders that are based on the principles of fairness and transparency (Janssen et al. 2020).

Aadhaar, one of the largest biometric-based digital identity systems in the world, has attributed more than 1.15 billion unique identities to Indian citizens since 2009 and provided them with digital access to government services. Given that marginalized populations in India often lack personal identification and as a result are excluded from accessing health services, education, and government benefits, Aadhaar's service has been especially beneficial to those who were previously unable to access many government services (World Economic Forum 2017).

Nevertheless, Gurumurthy and Chami (2017) observe that practice diverges from theory. The researchers note that, in Gujarat, women were denied access to maternity entitlements because "their biometric authentication failed due to errors in linking their personal information with their unique ID" (Ibid.). Owing to a system error and the absence of data policy frameworks, these women were left without the support to which they were legally entitled.

Similarly, China collaborated with Sesame Credit to develop a national "social credit system, which ranks the level of trustworthiness of every citizen" (Gurmurthy and Chami 2017). As part of China's plan to create a fully digital government, China's credit system aims to contain all government and citizen information, including minor traffic violations, which it then uses to determine credit limits for loan applicants. Unsurprisingly, this approach has proven to be highly controversial. Not only does such a system infringe on citizens' privacy rights, it can also result in increased policing as well as social and economic exclusion for some citizens. Furthermore, Gurumurthy and Chami estimate that, in the absence of data protection laws, increased national surveillance can and will lead to an increase in the policing of women's bodies. This is especially true in the global South, where cultural norms often outweigh data protection laws (Gurumurthy and Chami 2017). 


\section{The politicization of women's bodies}

The large-scale collection of personal and health data can impose significant and potentially negative consequences, especially for women and other minority groups (Corple and Linabary 2020; Gurumurthy and Chami 2017). Online Big Data tends to be perceived as "disembodied and place-less," which reduces people's data privacy concerns in online environments (Corple and Linabary 2020). However, within digital environments, the body persists and becomes a "body-asinformation." The "datafication of the body" occurs regardless of whether digital users opt in or out of having their data collected. Especially problematic, the researchers note, is the misuse of data by menstruation-tracking apps and similar health apps that make users' data available to third-party entities (Gurumurthy and Chami 2017; Mitchell and Thurtle 2013).

Similarly, Levoplant, a contraceptive microchip endorsed by Bill and Melinda Gates, was found to have a negative impact on women's lives (Gurumurthy and Chami 2017). Designed for women in the global South, Levoplant is a slow-release hormonal microchip that can be activated and deactivated remotely (Homewood 2016). While Levoplant claims to give women control over their bodies, how it is controlled remotely and what personal information is being stored and used by the microchip manufacturers (Shanghai Dahua Pharmaceutical n.d.) have not been fully disclosed to users (Homewood 2016).

\section{Patient information remains unregulated online}

According to Busobozi and Kalema's (2017) research on the quality of patient data in South African health organizations, health-related data governance is challenged by poor data management practices, a lack of data standardization, and the collection of low-quality data. This issue is not limited to the global South.

Examining the data governance challenges related to the retrieval of personal health information (PHI) in the United Kingdom, Winter and Davidson (2019) observed recent nonconsensual data transmissions of patients' PHI. In the case of the Royal Free London NHS Foundation Trust, the researchers discovered that $\mathrm{PHI}$ data were migrated to a subsidiary of Alphabet without patients' consent, in violation of the contextual integrity of the data. Winter and Davidson further imply that because patients were not given the choice of opting out from this data transfer, patients were precluded from engaging in an informed discussion about the use of their data." Given the lack of data use regulations and cybersecurity, the researchers suggest that data governance needs to be used in a way that is "consistent with patient consent" while offering an "ethical oversight of $\mathrm{PHI}$ data" (Winter and Davidson, 20,49). 


\section{CONSIDERATIONS FOR THE FUTURE}

Overall, there is a need for transparent, standardized, gender-sensitive, and userbased data governance. To understand inclusivity and privacy laws, more applied research should be conducted on the challenges and opportunities of Big and Open Data for governments and citizens (Bouzguenda, Alalouch, and Fava 2019). One example of a successful data protection and privacy framework is the European Union's General Data Protection Regulation (GDPR), initiated in 2018, which regulates data sharing (European Parliament and Council of the European Union 2016). Similarly, the World Economic Forum foundation proposes several participatory and inclusive policies to mitigate the issues surrounding data governance. These include promoting inclusive policies at the government level, developing new approaches to policy making through crowdsourcing, and generally increasing trust in governments through rule making processes that are more participatory and inclusive (World Economic Forum 2018b).

Even though quantifiable data can render visible the challenge that marginalized populations face (Janssen et al. 2020), existing studies on policy analysis generally lack intersectional considerations. As Levac and Denis (2019) note, "data disaggregation by gender is often omitted from published research results, particularly its intersection with such other variables as age, Indigeneity, (dis)ability and racialization" (p.14). To address this issue, future research should be attentive to intersecting identities and consider an increasingly rights-based approach to data collection (Janssen et al. 2020).

There is also a need for increased data transparency, with rules that make it clear who has access to what data. Furthermore, rules regulating and defining data ownership must be carefully scrutinized and continuously reevaluated in order to adapt to ever-changing technologies and forms of data collection. Finally, intersectional policy recommendations that respond to a more diverse set of needs can help to ensure that data are ethically, transparently, and justly governed (Gurumurthy and Chami 2017). 


\section{THE FUTURE OF WORK}

\section{OVERVIEW}

Rapid technological innovation, globalization, demographic shifts, and geopolitical developments are posing unprecedented challenges to local, regional, and global economies and the workers embedded within them (World Economic Forum 2018b). The transition to economies that rely on digital environments, labor markets, and skills has transformed economic geographies, enabling those from across the globe to connect with one another in ways that reflect the capabilities and exclusions of digital technologies. In 2017 the majority of the world's population became connected to the internet, making connectivity a standard rather than an exception (Roser, Ritchie, and Ortiz-Ospina 2015). Still, this means that half of the world lacks access, so it is crucial to understand what the increasing digitization of the economy means for those at the geographic, social, and economic margins of society.

There are clear economic benefits to having businesses and individuals connected through global networks of ICTs. Digital connectivity results in greater access to economic markets across the world, more efficient delivery of goods and services, heightened labor productivity, increased economic competition and technological innovation, and more global trade partnerships, among other benefits (World Economic Forum 2016). It is argued that connectivity and the emergence of digital economies is instrumental to women's economic empowerment, making it easier for women to earn an income even if they are excluded from traditional labor markets. According to the World Bank, this is particularly relevant for women living in developing countries, "where cultural bias, mobility restrictions, security, and time limitations often prevent women from taking their rightful place in the workforce" (World Bank 2015). As such, ICTs have the potential to change the composition of the global economy and labor market, improving the economic position of women and marginalized populations.

At the same time, these widely noted advantages must be weighed against issues of access to and control of ICTs, a topic discussed in the "Access and inequality" section of this report. Because women have, on average, less access to digital technologies and fewer digital skills, the rise of digital economies may serve to further enforce gender inequality. This possibility reflects the different forms of structural power associated with and designed into ICTs. As academic Mark Graham $(2019,7)$ notes, "Because people have very different types of control over the modes and methods of connectivity, ICT does not necessarily shrink distance or bring a digitally shared space into being." In other words, even if someone does have access to the internet and digital technologies, that person may not be able 
to use that access to improve their economic standing in the same ways that someone of a different social position and geographic location might. As such, it is important to develop a contextual, grounded, and intersectional analysis of digital economies that considers both the advantages and disadvantages of digitally mediated work and identifies who gets to benefit from these developments and in what ways.

With this approach in mind, this section will discuss several questions: How does digitization impact employment rates and the types of jobs available? Which skill sets are needed to perform these jobs? Does the distribution of these skill sets reflect social inequalities, and how can these structural biases be addressed? How do platform and gig economies impact workers and their lives? And how should social regulations and worker protections in digitized work environments be enforced? These issues and trends will be considered through a feminist lens, using examples and case studies that center gender in order to reveal how digital technologies are impacting women's abilities to navigate the future of work.

\section{WHY IT MATTERS}

A greater focus on the experiences of women and marginalized communities in digital economies is sorely needed to effectively regulate these new economic domains in ways that ensure that everyone can engage equitably in digital economies. There are a growing number of signs that gender is an especially crucial and complex variable in online economies. According to researchers Abigail Hunt and Emma Samman (2019), these signs include the growth of digital economies in areas of gendered labor where women are disproportionately concentrated, such as service and domestic work; the continued presence of gendered digital divides, which affect women's ability to capitalize on digital economies; and indications of gender inequalities in online work that present in new digitally facilitated ways. Furthermore, most of the information and data regarding digital economies comes from the global North and high-income economies, with the result that we know relatively little about the impacts of digitization on lower-income economies (Graham 2019). These huge gaps in research affect how regulatory legislation and policy are written (and not written), which must be interrogated with the knowledge that "digital information, services, and goods are always embedded in, and part of, broader sociotechnical systems" (Graham 2019, 2). 


\section{KEY ISSUES AND TRENDS}

\section{Expanding network connectivity}

As the speed of technological innovation has increased, many scholars, policymakers, and industry pundits have identified a Fourth Industrial Revolution that "will fundamentally alter the way we live, work and relate to one another" (Schwab 2016, 1). According to World Economic Forum founder Klaus Schwab, who coined the expression, a key feature of the Fourth Industrial Revolution is a fusion of digital, physical, and biological technologies that makes it difficult to fully separate digital environments from physical ones. Schwab $(2016,12)$ remarks that this shift "creates a world in which virtual and physical systems of manufacturing globally cooperate with each other in a flexible way." Examples include the adoption of virtual assistants that rely on artificial intelligence, like Apple's Siri, and the widespread reliance on the video conferencing software Zoom for virtual education in the wake of the COVID-19 pandemic. These examples rely on basic access to global communication networks, such as the internet and other ICTssomething that is not yet guaranteed for all.

This gap has been recognized by government institutions, NGOs, and corporations that have established initiatives to connect the world's poor and those living in rural and remote areas to global networks (Friederici, Ojanperä, and Graham 2017; Galperin and Viecens 2017). These include Alphabet's Loon, a project that uses high-altitude balloons to create aerial wireless networks in rural areas, and Internet.org, a partnership between Facebook and six network services firms, that employs a combination of free apps and unmanned aircraft to deliver internet access to remote areas. Based on the logic that increased connectivity spurs economic growth and inclusive development, both plans make Africa a priority region (Graham 2019). Though this reasoning is true to some extent, Friederici, Ojanperä, and Graham (2017) point out that evidence of the impacts of the internet and other ICTs on economic development and inequality is inconclusive. In fact, they state, "There is even indication that connectivity can exacerbate, rather than limit, existing inequalities" (Friederici, Ojanperä, and Graham 2017, 15), citing studies finding that the effects of ICTs are interdependent with skill levels, usage patterns, initial class disadvantages, and other factors. This claim is echoed in Humer's (2011) study on ICT use and gender inequality in sub-Saharan Africa, which argues that ICTs may help women become financially independent but will not change the sociocultural environment that restricts women's ability to capitalize on digital technology.

Other studies show more positive outcomes stemming from increased connectivity, particularly when examining how ICTs have helped women economically in absolute terms, irrespective of whether or not men benefited more. For example, when a locality in South Africa received network coverage, the employment rate increased by 15 percent, mostly owing to the greater employment 
of women (Klonner and Nolen 2010). Relatedly, in Kenya, Suri and Jack (2016) found that access to mobile money services helped 196,000 households, mostly headed by women, out of poverty, largely because the services enabled 184,000 women to switch from agricultural jobs to higher-skilled and higher-paying jobs. Overall, investing in expanding connectivity may be a quick and relatively costeffective way of expanding economic opportunities for women (Auriol and Gonzalez Fanfalone 2014), even if this approach does not address the structural factors in the way of women's advancement.

Nevertheless, it is important to think critically about the fact that these initiatives are not solely purposed to connect individuals in ways that expand their freedoms and enable them to achieve their capabilities (Sen 2001). They also facilitate the growth of new markets sparked by increased digital access. Particularly because many of these projects are led by private corporations that are interested in profiting from emerging markets, we must ask, who stands to benefit most from this expanded connectivity? Quoting the Feminist Principles of the Internet (available at https://feministinternet.org/en/principles), Jac sm Kee urges us to "'[interrogate] the capitalist logic that drives technology towards further privatization, profit and corporate control,' to understand ... emerging forms of circulation of capital that may act to exacerbate or narrow inequalities" (Kee 2017, 85). The Fourth Industrial Revolution has encouraged connectivity to be understood as a universal good that benefits women's economic empowerment. However, the impacts of expanded ICT access are much more complex than many realize because they intersect with a myriad of structural factors that affect who benefits from the Fourth Industrial Revolution and why. Ultimately, more rigorous research is needed to truly assess the varied impacts of this trend across different populations.

\section{Displaced jobs and unequal opportunity}

Another key characteristic of the Fourth Industrial Revolution is the increased role of technology and automation in job tasks and work environments. Debates surrounding technology-facilitated work and automation via machines are often polarizing. Many point to the beneficial role of technological innovation in the labor industries, including a decrease in jobs consisting of repetitive and menial tasks, the creation of higher-skilled jobs, access to more economic opportunities, and financial empowerment and independence (Sinha 2018). While some embrace these new opportunities, others fear that the speed with which technological innovation is occurring means that more and more jobs are becoming automated, leading to job loss (World Economic Forum 2016). As such, there is the possibility that digital economies, at least in the short term, will destroy more jobs than they create (Degryse 2016).

However, the World Economic Forum $(2016, v)$ notes that this possibility is "highly specific to the industry, region and occupation in question as well as the ability of 
various stakeholders to manage change." Certain fields, such as service jobs and those requiring fewer technical skills, are more susceptible to machine automation (Florito, Aneja, and Beneke de Sanfeliu 2018). Because these fields are typically highly gendered, automation has differential effects on men and women, leading women to face higher risk of unemployment (Florito, Aneja, and Beneke de Sanfeliu 2018). Geographic location also plays a role-easily automated jobs are frequently outsourced from the global North to the global South, rendering the labor markets of low- and middle-income countries increasingly precarious. The World Bank has estimated that the share of jobs at risk of automation is strikingly higher in the global South: 85 percent of all jobs in Ethiopia are at risk, compared with an average of 57 percent of jobs in the OECD (Frey and Rahbari 2016).

Of course, these figures are even grimmer when gendered skill gaps are taken into account. Because of education gaps, domestic responsibilities, and sociocultural norms, women are frequently relegated to lower-skilled jobs that are more easily automated (Florito, Aneja, and Beneke de Sanfeliu 2018). For example, Sharmistha Sinha's (2018) study of the gendered digital divide in India reveals that women must be not only literate but also must possess "critical and analytical skills to make sense of the vast amount of information available, make informed choices, and safeguard one's security and privacy" (p. 302). Beyond lack of education and digital literacy skills, women also face social barriers in gaining decent employment, such as lack of family support, social stigma, and safety issues. For these reasons, women in India are typically confined to a limited number of job sectors, primarily in manufacturing and services, where "even if there is access to digital technology, there is very little scope to leverage it for economic purpose" (Sinha 2018, 303).

In response, women's entrepreneurship development (WED) programs aim to address both education and skill gaps and give support and resources to women navigating restrictive sociocultural norms (ILO 2008; UNCTAD 2014). UNCTAD (2014) situates women's entrepreneurship as a key means of increasing gender equality through the creation of employment opportunities that generate economic growth and reduce poverty levels. Once again, however, the beneficial impacts of these programs are not yet fully clear. Guihuan (2005) identifies a number of benefits linked to businesses run and owned by women, including increased likelihood of repayment on microloans, alternative management styles, and increased self-confidence. However, a recent study questions the neoliberal discourses women must subject themselves to in order to benefit from these programs (McCarrick and Kleine 2019). McCarrick and Kleine (2019) observe that WED reinforces ideas about the ideal entrepreneurial woman, one who is flexible, self-reliant, and motivated, and "moves explanations for inequality away from structural factors and places it on the shoulders of the individual" (p. 111). In turn, the logic underlying these programs neglects the systemic changes necessary to create long-term change. 
This critique of the neoliberal framing of WED programs is echoed by Tim Unwin (2017), who argues that the primary purpose of expanded ICT access and use is economic development and the growth of labor markets, rather than reducing inequality. This is due both to the economic interests underlying the development of ICT and the conflation of economic growth and development (Graham 2019; Unwin 2017). For example, gross domestic product (GDP), a measure of economic growth, is often used as a proxy for understanding states of development but does not give any concrete information about a country's social welfare (Graham 2019). Instead, ICTs could be used to offer new pathways to digital self-determination, which may or may not include economic empowerment, for those whose autonomy is threatened by existing inequalities. Reframing WED programs in this way would encourage women to explore and discuss deeper social issues related to technology and gender in ways that might illuminate possibilities for greater empowerment, economic and otherwise.

\section{Increasingly precarious employment}

The emergence of platform economies is related to the Fourth Industrial Revolution's fusion of daily life and work with digital technologies and virtual environments. These new forms of digitally mediated labor enable individuals to exchange resources, goods, skills, services, and time with each other over the internet and other digital communication networks. Most of these "gigs" require access to a smartphone and various platform apps, as well as a credit card and, in some cases, a verified social media identity (Kim 2019). Common examples of platform economies include the use of Uber as an on-demand lift service and Airbnb as a digital marketplace to advertise temporary accommodations. These new economic models are often promoted as increasing worker flexibility and autonomy, allowing workers to boost their total income with part-time work in the platform economy, providing an easy-to-enter job market, and providing convenience and lower costs to consumers (Zwick and Spicer 2019). Much of the language and rhetoric surrounding platform economies represents them as "anticommercial, community-minded, equitable, and sustainable" (Kerzhner 2019, 429).

However, as scholars have been quick to point out, these forms of labor are linked both to growing inequality for workers and to capital accumulation for corporations (Scholz 2017; Zwick 2018), which "mediate, aggregate, regulate and incentivize sharing," taking advantage of these economic models for profit (Kee 2017, 85). Though it is true that platform economies offer some benefits to workers, these benefits are easily exploited by corporations. For instance, the increased flexibility that accompanies gig-based work allows individuals to schedule their work around other responsibilities, such as childcare and formal work. But, as Kerzhner observes, this flexibility can also backfire, as in the case of Airbnb hosts who must skip work shifts to accommodate unpredictable guests $(2019,430)$. The tipping practices of DoorDash and Instacart have also been under scrutiny recently 
because, although these companies allow workers to make extra cash, they do not allow workers to keep tips. Instead, these companies pool their workers' tips and redistribute them as wages for other workers, making hourly wages for workers highly variable (Green 2019).

The emergence of platform economies has particular impacts on women and marginalized populations. Particularly in low- and middle-income countries, many women cannot access these forms of work both because of women's disproportionately lower access to and use of mobile technology and ICTs (Rowntree 2018) and because of gender norms that restrict the use of digital technologies to male family members and limit women's movement and activities outside the home (Hunt, Samman, and Mansour-Ille 2017). Women who enter the gig economy often suffer from a gender earnings gap, sometimes earning as little as two-thirds of men's average hourly rate (Barzilay and Ben-David 2017). Additionally, many tasks related to gig work involve emotional and social labor, forms of feminized care work that often fall to women. Airbnb hosting is one such example, obliging women to adopt a "labour-intensive housekeeper role" in order to find success on the platform (Kerzhner 2019, 430). Often undercompensated and unrecognized, the responsibilities of an Airbnb host-advertising, booking, cleaning, etc.-require women to balance their formal work and career aspirations with their roles as hosts, which carries implications for long-term employment and social mobility (Kerzhner 2019).

Beyond gender, platform economies also have implications for racial and classbased oppression. Companies reliant on gig hires frequently contribute to processes of gentrification in urban centers. The most obvious example is Airbnb, which makes the majority of its money by transforming entire homes and apartments into informal hotels serving tourists (Picascia, Romano, and Teobaldi 2017). This practice contributes to rising rents and home prices, driving out longterm renters and businesses (Kerzhner 2019). It has also been recently shown that the pricing algorithms of Uber and Lyft, two ride-sharing services, vary based on whether the pickup point or destination is in a neighborhood with more ethnic minority and Black residents (Pandey and Caliskan 2020). Cost per mile is higher in areas with fewer white residents, lower average house prices, or lower average educational attainment, thus compounding preexisting inequities.

On an individual level, however, the affordances of platform economies can be used strategically in ways that offset the tolls of working such jobs. For example, Zwick and Spicer $(2019,425)$ find that the flexibility of Uber allows people to "fill income gaps, or to find new leads during bouts of precariousness in their careers" and note that some driver-partners with primary careers use Uber to network and gain new clients. Similarly, Berg (2016) reveals that pornographic actors and actresses, who are largely hired on short-term contracts, often use porn's satellite industries (e.g., strip clubs, escort services, Twitter branding) to harness alternative income sources, allowing them to "maximize earning potential, resist 
burnout, and otherwise exert control over their work life" (p. 161). Though it may be true that companies like Uber and Airbnb, as well as porn's associated industries, are "just as much a tool for workers to survive bouts of precariousness," the corporations embedded in platform economies profit off this economic precarity, benefiting from the same structures of inequality that allow them to thrive in today's world (Zwick and Spicer 2019, 425). Because these same structures will continue to shape digital economies into the future, it is imperative that policymakers and companies critically assess how these platforms rely on and perpetuate inequality while also holding potential for benefiting one's individual economic status.

\section{Changing labor relations}

Underlying the precarity of platform work is the absence of worker protections in digital economies. Because workers, consumers, and companies are often spatially separated in online economies, it is more difficult to enforce the social regulations common to most formal employment relationships (Graham, Hjorth, and Lehdonvirta 2019). The most urgent issues related to labor relations in digital platform economies include unfair pay, dangerous working conditions, a lack of benefits, and an absence of union representation. These problems stem from the fact that individuals are rarely considered employees by platform companies and are instead classified as independent contractors or "partners" (Aloisi 2019; Findlay and Seah 2020; Green 2019; Hunt and Machingura 2016). This, along with the fact that national labor laws rarely apply to digital workers, allows companies to avoid the responsibilities of traditional employer-employee relations, including providing sick leave and health care, guaranteed minimum wage, or overtime pay (Aloisi 2019).

It is crucial to study how gender and other identity categories influence the impacts of these changing labor relations, particularly given the increasing presence of marginalized women from developing countries in digital economies (Hunt and Machingura 2016). In the context of South African platform economies, housekeepers and maids often make less than the minimum wage set for domestic workers and almost never make a living wage (Hunt et al. 2019). This is compounded by some platforms' reliance on worker bids rather than standardized pricing, often resulting in a race to the bottom, in which workers underbid in order to secure work owing to fierce competition among gig workers (Graham, Hjorth, and Lehdonvirta 2019, 275). According to Hunt et al.'s (2019) interviews with female domestic workers, clients sometimes underestimate the time it takes to complete cleaning tasks, meaning that workers must take on extra hours, which are not agreed to at the outset and are often unpaid. Safety is an additional concern, peculiarly because workers often must sacrifice their safety to travel to faraway work sites at unpredictable hours for clients that they do not know or feel comfortable with (Hunt and Machingura 2016). Some workers complained to their platforms about the actions of clients, but it was unclear whether the platforms had 
taken any responding action (Hunt et al. 2019). Despite these conditions, it is important to keep local labor contexts in mind; opportunities provided by the gig economy may actually be incrementally better than these workers' previous employment (Hunt and Samman 2019).

Digital workers have so far been largely unable to build any large-scale digital labor movements in response to these conditions (Graham, Hjorth, and Lehdonvirta 2019). One practical reason is that workers spread across the globe likely have conflicting agendas, needs, and preferences, complicating the formation of alliances. It is possible, however, for workers to use ICTs to facilitate information exchange, to circulate petitions, to share bad experiences and best practices, and even to organize digital strikes whereby workers log out of platforms en masse (Aloisi 2019). Though Hunt et al. (2019) find few signs of worker activism owing to fear of retaliation from platforms, such as deactivation of their accounts and the subsequent loss of crucial survival funds, they note that workers use social media to have private conversations about working conditions.

According to Doorn (2018), the structure of gig-based work, particularly the fact that individuals often work through multiple platforms simultaneously, highlights the necessity of actions and solutions at the industry level. Although typical labor regulations are based on nondigital forms of work, progress has been made on this front. Some trade unions have begun to represent and advocate for platform workers (Aloisi 2019); in California a 2019 labor law requires platform companies to treat their workers as full employees (Conger and Scheiber 2019). More radical approaches have been proposed as well, such as the establishment of platform cooperatives (Aloisi 2019; moulden 2019). Owned and operated by the gig workers themselves, cooperatives "combine platform technology with sustainable working conditions and the nonprofit business model of a cooperative" (Aloisi 2019, 2324). According to community organizer dominic t. moulden, small-scale, shared economies like these give more control to workers and consumers to build a "strong, local, and democratic economy rooted in racial and gender equity" (moulden 2019, 444). At the present moment, it is likely that a combination of approaches, legislative and regulatory, grassroots and community-driven, must be used to truly ensure a safe and equitable digital economy for all.

\section{CONSIDERATIONS FOR THE FUTURE}

The conditions of precarity that characterize digital economies stem, at least partially, from the combined pressures of mass unemployment, fiscal austerity, the rollback of welfare programs, and the revoking of workplace protections (Doorn 2017). It is easy to assume that expanded access to digital economies will provide a quick fix for these conditions, and to some extent they do provide ways for individuals to navigate uncertain economies. However, it is equally true that we 
must "move away from over privileging technology and connectivity as primary agents of change" and instead focus on how we-individual workers, companies, and policy makers-can use ICTs and other technological tools as mediums to enact systemic change (Graham 2019, 14). Such a shift involves taking an honest look at how these tools are currently leveraged for economic gain and how they have the potential to be used for much more: the kinds of digital self-determination and freedoms that inspire equitable economic fulfillment. 


\section{THE EFFECTS OF A GLOBAL PANDEMIC: COVID-19}

\section{OVERVIEW}

The COVID-19 pandemic has sparked a global increase in internet use, with more people engaging with digital technologies than ever before (ITU 2020). It has also exacerbated systemic inequities that limit the livelihoods of women and other marginalized populations (Bowleg 2020). With constantly evolving regulations put in place to reduce the spread of COVID-19, we must consider how the pandemic, and public and private responses to it, are informing women's and minority populations' access to digital technologies, financial autonomy, health, education, and digital safety and rights.

Persistent gender inequities have made women and minority groups more vulnerable to the effects of COVID-19. For instance, "women are disproportionately represented in industries that are expected to decline the most in 2020 due to COVID-19," such as retail, food service, arts, and education (Madgavkar et al. 2020). Since the initial outbreak and subsequent lockdowns across the globe, there has been a significant increase in GBV (UN Women 2020b; Chuka 2020; Ruiz-Pérez and Pastor-Moreno 2020). At the same time, COVID-19 mortality rates for Black populations have been found to be higher than for white populations (Kopel et al. 2020; Phillips et al. 2020).

What sets COVID-19 apart from previous major communicable health crises is that-for the first time-digital technologies significantly affect exposure rates and health risks (Robinson et al. 2020). Since the start of the pandemic, lockdown and social distancing measures have generated an increase of 50 to 70 percent in internet use (ITU 2020). Nevertheless, many women lack digital access and the means for reliable identification, which can compromise their access to health and government services, especially in low- and middle-income countries, where 45 percent of women lack national identification (Madgavkar et al. 2020). In light of the "digital pandemic," it is crucial to assess how digital technologies, ICT4D initiatives, and policies have adapted to new gendered needs that have emerged as a result of the pandemic. This entails examining who has access to digital technologies and ICTs and ability to use them, as well as how the pandemic disrupts women's participation in a digitally networked world. Looking at gender and technology in the midst of a global crisis gives contextualized insight into how digital technologies impact gender disparities both positively and negatively when access to them is particularly consequential. 
Research on past epidemics and health crises highlights a need to improve "the effectiveness of health interventions and [to] promote gender and health equity goals" (Wenham, Smith, and Morgan 2020, 395). To date, "gender analysis has been conspicuously absent from policy debates, documents, and processes" (Smith 2019, 356). Rather than addressing the structural issues underlying gender inequities, emergency responses and policies tend to focus on biomedical needs. For instance, the WHO's Ebola Response Roadmap dedicated only one sentence to women (Smith 2019; Harman 2016), and, in its report The Economic Impact of the 2014 Ebola Epidemic, the World Bank neglected to mention women altogether (Smith 2019; World Bank 2014). Recent intersectional studies on previous viral outbreaks observe that women had poorer health outcomes and fewer economic opportunities than men. Poverty rates and food insecurity worsened for women (UN Women 2020b; Wenham, Smith, and Morgan 2020; Smith 2019), and women faced greater challenges than men in financing follow-up care in the most-affected regions (Wenham, Smith, and Morgan 2020). Additionally, research reveals that women increasingly lack power over their reproductive and sexual health during periods of outbreak (Enguita-Fernàndez et al. 2020).

As COVID-19 persists, it becomes increasingly crucial to understand how pandemics may exacerbate or mitigate gender disparities and impede or facilitate marginalized populations' access to the very digital resources that have become essential to living and working safely during a dangerous viral outbreak. Taking an intersectional approach, this closing section considers the persistence of gender norms, differential access to health care, and gender-based violence to understand the gendered consequences of the digital pandemic for women and minority groups.

\section{WHY IT MATTERS}

Research on previous viral outbreaks has established that marginalized populations are the likeliest to be negatively impacted by health crises (Wenham, Smith, and Morgan 2020; Smith 2019; RCCE 2020). As women and marginalized populations are disproportionately restricted from accessing and using online services, these populations are equally restricted from accessing digital health care services, like telemedicine and health-related notices, guidelines, and other critical information (RCCE 2020). Moreover, there is a correlation between the emergence of the pandemic and increases in both online and offline gender-based violence (ITU 2020; Chuka 2020). Studying the ramifications of COVID-19 for women and marginalized groups helps us to understand the structural barriers that prevent digital inclusiveness, ultimately enabling us to design better and more inclusive solutions, structures, and programs for vulnerable populations. 


\section{KEY ISSUES AND TRENDS}

\section{Persistent gender norms put women at higher risk}

COVID-19 is both illuminating and widening the gender gap: since the outbreak of the pandemic, women have, for instance, decreased their work hours but taken on more housework and childcare, thus reinforcing normative gender patterns and patterns of unpaid care work (Oreffice and Quintana-Domeque 2020). Globally, more than 75 percent of women do unpaid care work, which equates to 9 percent of global GDP (King 2020; see the sections in this report on unpaid care work in "Access, use, and inequality" and "The future of work"). In the context of COVID19 , an increase in women's unpaid care work has been exacerbated by two factors: first, women are more likely to care for the elderly and the sick, which increases their risk of infection, and second, the pandemic has led to an inequitable division of domestic tasks, with tasks related to schooling and housework being "disproportionately borne by women" (King 2020, 80).

Likewise, women are disproportionately overrepresented in the health care workforce, including as doctors, nurses, and retirement home caregivers (Wenham, Smith, and Morgan 2020; USAID 2020; RCCE 2020; EnguitaFernàndez et al. 2020). As such, more women than men find themselves on the front lines of the pandemic. In fact, studies show that, while women have less decision-making power about how the outbreak is managed (UNFPA 2020), they constitute up to 70 percent of the frontline health care workers globally (Better Than Cash Alliance et al. 2020; UNFPA 2020). In Hubei, China, this figure climbs to 90 percent (Wenham, Smith, and Morgan 2020). As a result, female health care workers, and women overall, run a higher risk of not only contracting the virus, but also experiencing the socioeconomic and psychological consequences of their profession. These consequences include working longer hours, living apart from their families for extended periods, and being exposed to highly stressful environments.

\section{Women experience a decrease in financial opportunities}

Correlated with an increase in female unpaid care work, COVID-19 has caused a spike in unemployment rates for women (OECD 2020; Gezici and Ozay 2020). In OECD countries, women were more likely to be unemployed than men in April 2020, with rates increased by 3.3 percent for women and 2.6 percent for men compared to pre-pandemic (OECD 2020). In the UK, women's unemployment is estimated to be 15 percentage points higher than men's. Furthermore, half as many men (4.4 percent) as women (8.6 percent) reported having lost their jobs because of the pandemic. Similarly, while women did 45 percent more housework than men before the pandemic, they now do 48 percent more housework than men (Oreffice and Quintana-Domeque 2020). Similar asymmetric observations have 
been made in the United States, with racialized women being the highest population to be unemployed as a result of the pandemic (Gezici and Ozay 2020).

In light of such unemployment rates, some communities and companies are considering how women can take control over their finances and become a part of local economies (USAID 2020). For example, Digital Skills is a First Nation-led digital literacy program in Long Lake 58, Ontario, Canada, that provides Indigenous women with the necessary digital skills to increase their employment opportunities. Because it equips local women with the ability to work remotely, the program has become vitally important to the community during the pandemic (Hawkins 2020). Likewise, West African countries have seen an increase in online banking since lowering service fees to facilitate access for women specifically (World Wide Web Foundation 2020). To support initiatives like this, the UN has implemented a new policy to promote a shift toward online banking to increase women's financial autonomy. Under this policy, the UN will, for instance, advise governments on the most effective ways to put cash in women's hands, including through cash transfer programs and mobile banking "to ensure women can both access and control the use of funds" (UN Women 2020b, 9).

Concrete cases, studies, and recommendations of how digital tools could aid women and minority groups in attaining financial autonomy remain overall scarce. However, the recency of the pandemic may be why these issues have yet to be formally examined. While unemployment rates are disproportionately affecting women during COVID-19, existing research on the effects of the pandemic for women and other marginalized populations tends to stop at identifying a gender employment gap (OECD 2020). Although studies rightly point to a growing increase in the unpaid care work gap (Collins et al. 2020), currently available research does not, at present, consider factors beyond one's gender in relation to one's access to employment; we found just one study that considers race in addition to gender (Gezici and Ozay 2020). Furthermore, most of the studies center on the United States, so there is a need for research that considers other, and multiple, intersectional factors, such as race, ability, age, class, and geography. Gezici and Ozay point to this reality when stating that more intersectional research on the pandemic is needed given "the magnitude of unemployment probability associated with holding multiple identities" (p. 16).

\section{COVID-19 compromises access to health care}

While it is believed that COVID-19 can infect anybody, certain socioeconomic and cultural factors may increase the likelihood of one's access to or denial of digital health services and consequently one's health outcomes (RCCE 2020; Kopel et al. 2020). Women and marginalized groups are found to be especially affected by lower access to health care and health-related services (RCCE 2020; UNFPA 2020; UN Women 2020b; Phillips et al. 2020; Pendo 2020; Sweet et al. 2020). For example, the pandemic has been found to contribute to increases in maternal and 
newborn mortality, unmet needs for contraception, unsafe abortions, and sexually transmitted infections (UNFPA 2020). Compounding this issue, in Sri Lanka, women are expected to increase their productive work to meet the higher demands resulting from the pandemic. They are equally expected to maintain their reproductive work-bearing and rearing children (McLaren et al. 2020). Further, in a recent policy brief, UN Women estimated that an additional 18 million women will be precluded from accessing contraceptives in Latin America and the Caribbean as a direct result of the pandemic (UN Women 2020b).

Digital technologies have proven to be an important asset to improving health services and health care access. In the face of the pandemic, numerous healthrelated apps, websites, and online services have been put in place to support women remotely (Crawford and Serhal 2020). These digital services range from health-centered apps to telehealth services to helplines. In some areas, chat bots have been introduced to help determine users' COVID-19 symptoms in order to lower the workload of health care workers. In the United States, the Center for Democracy and Technology outlined policy and legal adjustments that would be needed to support continued telehealth services. Aside from increasing funding for telehealth services, the United States is developing cybersecure and encrypted platforms to safeguard patients' privacy on telehealth platforms (Barnard 2020).

Benefiting from such technologies and policy adjustments requires that the populations most at risk have access to telehealth services, but this is frequently not the case, especially for people with disabilities, racialized populations, and gender and sexual minorities (UNFPA 2020; Lam et al. 2020; Phillips et al. 2020). In the United States and Latin America, ICT access is lower among immigrant populations. Phillips et al. (2020) found that, in the United States, "Black and Hispanic/Latinx populations bear a greater burden of the pandemic than White populations" (p. 279). Supporting this finding, Kopel et al. (2020) found that, although Black people account for only 13 percent of the population, they make up 33 percent of hospitalized patients; in comparison, whites made up 45 percent of the patients despite representing 76 percent of the nation.

In the context of delivering care through telemedicine, the increased use of digital technologies can be a challenge for the elderly, as well as for disabled people and populations that have difficulty operating digital technologies independently (Lam et al. 2020; Pendo 2020; Khilnani, Schulz, and Robinson 2020). The increase in digital and remote health care delivery services may thus preclude these populations from receiving in-person and regular care. Furthermore, Lam et al. (2020) indicate that lower rates of access to telemedical services among older populations correlate with higher poverty rates: those who reported a feeling of general "unreadiness" in terms of using digital technologies were more likely to be lower income. This could lead to a widening of the digital divide. To help bridge the digital divide in the United Kingdom, initiatives such as FutureDotNow or 
DevicesDotNow provide vulnerable populations with free devices and the training they need to operate them (Robinson et al. 2020).

Recent research on the consequences of COVID-19 for sexual and gender minorities drew similar conclusions: not only are sexual and gender minorities more likely to require health care, they are also less likely to get care as health care systems are ill equipped to provide these patients with the gender-sensitive attention they need (Phillips et al. 2020; National LGBT Health Education Center 2016). A "lack of cultural responsiveness among health care professionals" (p.280) was observed as one of the primary reasons for such differential access to health care services. In the case of transgender people, for instance, COVID-19 has made it more difficult to access hormone care and gender-affirming surgeries. As a result, transgender people are at a higher risk of suicide (Ramo 2020) and of developing mental health issues (Wang et al. 2020; Phillips et al. 2020). A recent study conducted in Beijing supports this hypothesis: reduced access to hormone therapy - and thus an implicit prolongation of gender dysphoria-was found to be directly related to "high levels of anxiety and depression" (Wang et al. 2020, 565). To adequately support these populations, an intersectional approach would include continuous and extensive training of the health care staff to directly improve these populations' health care access (Phillips et al. 2020). By the same token, future research and data collection must be disaggregated by markers of marginalization, including gender, race, and ability (UN Women 2020b).

\section{COVID-19 increases gender-based violence}

Since the onset of the pandemic, there has been a substantial increase in domestic violence (UN Women 2020b; Madgavkar et al. 2020; ITU 2020; Chuka 2020). Though previous health crises resulted in an influx of survivors of domestic abuse into shelters, US domestic violence shelters are exceeding capacity for the first time in history. This may be the direct result of confinement measures that force perpetrators and victims to spend more time together, creating more opportunities for acts of violence to take place (Chuka 2020). Furthermore, confinement measures may limit victims' ability to seek out spaces that will provide them with needed care and assistance. Another result of increased confinement measures is that fewer cases of domestic violence are being reported (Enguita-Fernández et al. 2020). In an effort to address domestic violence during COVID-19, intervention apps such as I-DECIDE, iSafe, and myPlan have become indispensable digital tools supporting victims of domestic violence. MyPlan, for example, provides users with a safety plan that can be tailored to a victim's specific needs and help that person make informed decisions about their safety, local options, and well-being (Chuka 2020).

Beyond apps, 24/7 hotlines and 24/7 digital responses have been put in place to meet the increased demand for support in the United States (Chuka 2020). For instance, RAINN (Rape, Abuse and Incest National Network) released an app 
service in August 2020 to support survivors of sexual assault "anytime, anywhere" (RAINN 2020). Services such as telecounseling and telepsychiatry are also increasingly supporting survivors of domestic abuse. These services offer increased privacy, 24/7 availability, and greater modularity so that they can be tailored to a user's specific needs. Such digital support services have become essential for victims of GBV who, owing to social isolation and confinement, lack a local and accessible support system (Chuka 2020).

While a growing number of digital platforms are being developed to counter the increase in domestic and gender-based violence, COVID-19 has also exacerbated gender-based violence in online spaces (Chair 2020). The recent spike in domestic violence, particularly against women and children, correlates with an increase in online GBV (Chuka 2020; UNFPA 2020). Online GBV, harassment, and nonconsensual or unregulated data retrieval and dissemination can greatly compromise women's ability to seek out and attain digital, social, and economic empowerment (see the section "Security and digital civic spaces" in this report). While women and girls are more likely than men to use the internet, they are also more likely to be victims of online violence (ITU 2020).

Since the start of the pandemic, traffic to helplines, harm reduction websites, and domestic violence centers and calls to crisis hotlines have also gone up (Chair 2020; Chuka 2020). The UK Revenge Porn Helpline, a government-funded platform that supports victims of intimate image abuse, or the nonconsensual spreading of intimate images, saw a 50 percent increase in website traffic in March 2020 (Price 2020). Calls to Spain's crisis hotlines also increased by more than 10 percent in March 2020. Notably, demand for their online consulting services in Spain increased by 182 percent between March 2019 and March 2020 (Ruiz-Pérez and Pastor-Moreno 2020).

Guyana has taken a different stance on how to mitigate GBV directed at women and minority groups by addressing some of the underlying structural issues. The Guayanese government has created intervention programs to detect and challenge "violent masculinities" (Khanlou and Ssawe 2020, 26). During COVID19, these services moved online (UN Women 2020b; Khanlou and Ssawe. 2020). Likewise, South Africa and some Caribbean island nations, such as Antigua and Barbuda, have cooperated with telecom mobile companies to deliver safety messages and texts offering digital intervention services directly to citizens' phones (UN Women 2020b Khanlou and Ssawe ,2020).

Lastly, during COVID-19, hashtags are rendering domestic violence visible and creating digital support networks for survivors, including \#YouAreNotAlone and \#AntiDomesticViolenceDuringEpidemic (Chuka 2020). In China the hashtag \#AntiDomesticViolenceDuringEpidemic connects users with online resources and raises awareness about the signs and risks of gender-based violence (UN Women 2020b). Likewise, women with internet access can use social media as a means 
of vocalizing their concerns and information about the pandemic. One US study that examined COVID-19 posts on social media noted that, overall, young racialized women, and especially Black and Hispanic women, published more online posts related to COVID-19 than white women or men in general. The online presence of racialized women-among the most at risk of being affected by the pandemic -indicates that young women of color use social media platforms not only to educate others and create online support networks, but also to point to the structural issues that hinder them economically and health-wise (Campos-Castillo and Laestadius 2020).

\section{CONSIDERATIONS FOR THE FUTURE}

Despite many efforts aimed at reducing gender disparities and promoting equitable access to digital technologies, COVID-19 is widening the digital divide overall (Sadeque 2020; RCCE 2020; Campos-Castillo and Laestadius 2020). In its brief on online GBV, the ITU $(2020,6)$ advocates an intersectional and evidence-based approach that highlights the "multiple forms of oppression and harassment online, as part of the continuum of violence" faced by women and sexual and gender minorities. Further, it recommends that protocols, codes and laws be revised and adjusted to address the increase in online violence directed at women and girls. As digital devices and technologies evolve, and new policies and regulatory mechanisms are needed to improve ICTs related to. related to domestic violence (Chuka 2020, n.d.). Anongoing collaboration between various stakeholdersresearchers, ICT4D initiatives, and survivors-is paramount for the creation of these improved ICTs .

Furthermore, there is an imperative to address structural issues and offer contextualized solutions that are mindful of the particular realities, needs, and modes of empowerment of various populations and marginalized groups (UN Women 2020b). For instance, to facilitate the elderly's access to ICTs, initiatives must be tailored to the specific capabilities and needs of this population, including translating information into local languages and dialects (RCCE 2020, 4). Creating context-specific solutions will involve disaggregating all data collected by sex, age, disability, ethnicity, and geographic location in order to understand the specific needs of specific groups.

An example of an intersectional health research project is the Digital Health Equity Framework (DHEF), which takes social inequities and power imbalances into account when assessing individuals' access to health care (Crawford and Serhal 2020). The first of its kind, the DHEF considers an individual's social positioning, age, race, income, gender, lifestyle, and rurality. Crawford and Serhal (2020) find that individuals' social location is directly correlated with their health outcome: the better their social location, the better their access to digital health services, the 
better the quality of health care they receive overall, and the higher their chances of experiencing positive health outcomes. The DHEF identifies structural inequities that underlie health care access based on the premise that individuals' social location and the extent of their economic and systemic power determine their health outcomes.

Additionally, because people with disabilities have been disproportionately affected by the pandemic in terms of job insecurity, Pendo (2020) proposes an increase in flexible and remote employment options. The RCCE also suggests that documents and texts should be communicated in "clear and simple language" and that formats should be adapted to accommodate those who read braille or require larger fonts (RCCE 2020, 3).

Alongside the development of intersectional research models, there is a structural need for "cultural responsiveness trainings" for health care employees to provide vulnerable populations, such as sexual and gender minorities, with "competent, respectful, and welcoming care" (Phillips et al. 2020). Phillips et al. underline that future health equity research must focus on intersecting identities as they relate not only to the pandemic, but also to specific social, psychological, physiological, and financial impacts directly resulting from the pandemic. A growing number of digital programs and services aimed at supporting and empowering women and minority groups disproportionately affected by COVID-19. While not without limitations, implementing needs-specific ICTs can help to remove barriers which prevent these populations obtaining care and benefits. 


\section{REFERENCES}

A4Al (Alliance for Affordable Internet). 2020. "Meaningful Connectivity Unlocking the Full Power of Internet Access." https://a4ai.org/meaningfulconnectivity/.

Acılar, Ali. 2011. "Exploring the Aspects of Digital Divide in a Developing Country." Issues in Informing Science and Information Technology 8: 231-244. https://papers.ssrn.com/abstract=1850742.

Ahmed, Syed Ishtiaque, Md. Romael Haque, Shion Guha, Md. Rashidujjaman Rifat, and Nicola Dell. 2017. "Privacy, Security, and Surveillance in the Global South: A Study of Biometric Mobile SIM Registration in Bangladesh." In Proceedings of the $2017 \mathrm{CHI}$ Conference on Human Factors in Computing Systems, 906-18. New York: Association for Computing Machinery. https://doi.org/10.1145/3025453.3025961.

Albiero, Vitor, K. S. Krishnapriya, Kushal Vangara, Kai Zhang, Michael C. King, and Kevin W. Bowyer. 2020. "Analysis of Gender Inequality in Face Recognition Accuracy." In 2020 IEEE Winter Applications of Computer Vision Workshops (WACVW), 81-89. New York: IEEE. https://doi.org/10.1109/WACVW50321.2020.9096947.

Allen, Anita L. 2000. "Gender and Privacy in Cyberspace." Stanford Law Review 52 (5): 1175. https://doi.org/10.2307/1229512.

Aloisi, Antonio. 2019. "Negotiating the Digital Transformation of Work: NonStandard Workers' Voice, Collective Rights and Mobilisation Practices in the Platform Economy." EUI Working Paper. Fiesole, Italy: European University Institute. https://doi.org/10.2139/ssrn.3404990.

Alonso, Cristian, Mariya Brussevich, Era Dabla-Norris, Yuko Kinoshita, and Kalpana Kochhar. 2019. Reducing and Redistributing Unpaid Work: Stronger Policies to Support Gender Equality. Washington, DC: International Monetary Fund.

Amrute, Sareeta. 2020. "Bored Techies Being Casually Racist: Race as Algorithm." Science, Technology, \& Human Values 45 (5): 903-33. https://doi.org/10.1177/0162243920912824.

APC (Association for Progressive Communications). 2017. Online Gender-Based Violence: A Submission from the Association for Progressive Communications to the United Nations Special Rapporteur on Violence against Women, Its Causes and Consequences. Johannesburg, South 
Africa.

https://www.genderit.org/sites/default/files/apcsubmission_unsr_vaw_gbv. pdf.

Appadurai, A. 2015. Banking on Words: The Failure of Language in the Age of Derivative Finance. Chicago: University of Chicago Press.

Arias, Orlando, Jacob Wurm, Khoa Hoang, and Yier Jin. 2015. "Privacy and Security in Internet of Things and Wearable Devices." IEEE Transactions on Multi-Scale Computing Systems 1 (2): 99-109.

https://doi.org/10.1109/TMSCS.2015.2498605.

Auriol, E, and A. L. Gonzalez Fanfalone. 2014. Benefits and Costs of the Infrastructure Targets for the Post-2015 Development Agenda.

Copenhagen: Copenhagen Consensus Center. http://www.copenhagenconsensus.com/sites/default/files/infrastructure__assessment_-_auriol_fanfalone.pdf.

Australian Human Rights Commission. 2014. "Violence against Women." Australian Human Rights Commission (blog), November 25. https://humanrights.gov.au/our-work/sex-discrimination/projects/violenceagainst-women.

Bacchini, Fabio, and Ludovica Lorusso. 2019. "Race, Again: How Face Recognition Technology Reinforces Racial Discrimination." Journal of Information, Communication and Ethics in Society 17 (3): 321-35. https://doi.org/10.1108/JICES-05-2018-0050.

Bailey, Moya, and Trudy. 2018. "On Misogynoir: Citation, Erasure, and Plagiarism." Feminist Media Studies 18 (4): 762-68. https://doi.org/10.1080/14680777.2018.1447395.

Bailur, Savita, Silvia Masiero, and Jo Tacchi. 2018. "Gender, Mobile, and Development: The Theory and Practice of Empowerment: Introduction." Information Technologies \& International Development 14: 96-104.

Baird, Chardie L. 2018. "Male-Dominated Stem Disciplines: How Do We Make Them More Attractive to Women?" IEEE Instrumentation and Measurement Magazine 21 (3): 4-14. https://doi.org/10.1109/MIM.2018.8360911.

Baker, Sara. 2018. "We Want That for Ourselves': How Girls and Young Women Are Using ICTs to Counter Violence and Demand Their Rights." Gender \& Development 26 (2): 283-97.

https://doi.org/10.1080/13552074.2018.1473229. 
Barnard, Mason. 2020. "Telehealth Policy and COVID-19: Expanding Access without Compromising Privacy." Center for Democracy and Technology (blog), August 6. https://cdt.org/insights/telehealth-policy-and-covid-19expanding-access-without-compromising-privacy/.

Barzilay, Arianne Renan, and Anat Ben-David. 2017. "Platform Inequality: Gender in the Gig Economy." Seton Hall Law Review 47: 393-432.

Beauchamp, Toby. 2018. Going Stealth: Transgender Politics and U.S. Surveillance Practices. Durham, NC: Duke University Press.

Beilinson, Jerry. 2016. "Glow Pregnancy App Exposed Women to Privacy Threats, Consumer Reports Finds." Consumer Reports, July 28. https://www.consumerreports.org/mobile-security-software/glowpregnancy-app-exposed-women-to-privacy-threats/.

Berg, Heather. 2016. "'A Scene Is Just a Marketing Tool': Alternative Income Streams in Porn's Gig Economy." Porn Studies 3 (2): 160-74. https://doi.org/10.1080/23268743.2016.1184478.

Berg, Janine. 2019. "Protecting Workers in the Digital Age: Technology, Outsourcing and the Growing Precariousness of Work." SSRN Scholarly Paper ID 3413740. https://doi.org/10.2139/ssrn.3413740.

Better Than Cash Alliance, Women's World Banking, and the World Bank Group. 2020. Advancing Women's Digital Financial Inclusion. Global Partnership for Financial Inclusion. https://www.gpfi.org/sites/gpfi/files/sites/default/files/saudig20_women.pdf

Bill and Melinda Gates Foundation. 2017. "Unpaid Care Work." https://www.gatesfoundation.org/equal-isgreater/static/Unpaid\%20care\%20work575fb6baaebbe7a4ded72efee07e2b2c.pdf.

Binns, Reuben, Ulrik Lyngs, Max Van Kleek, Jun Zhao, Timothy Libert, and Nigel Shadbolt. 2018. "Third Party Tracking in the Mobile Ecosystem." Proceedings of the 10th ACM Conference on Web Science. New York: Association for Computing Machinery. https://doi.org/10.1145/3201064.3201089.

Bishop, Sophie. 2018. "Anxiety, Panic and Self-Optimization: Inequalities and the YouTube Algorithm." Convergence 24 (1): 69-84. https://doi.org/10.1177/1354856517736978. 
Blackwell, Lindsay, Jill Dimond, Sarita Schoenebeck, and Cliff Lampe. 2017. "Classification and Its Consequences for Online Harassment: Design Insights from HeartMob." Proceedings of the ACM on Human-Computer Interaction 1 (CSCW): 1-19. https://doi.org/10.1145/3134659.

Blažič, Borka Jerman, and Andrej Jerman Blažič. 2020. "Overcoming the Digital Divide with a Modern Approach to Learning Digital Skills for the Elderly Adults." Education and Information Technologies 25 (1): 259-79. https://doi.org/10.1007/s10639-019-09961-9.

Blunt, Danielle, and Ariel Wolf. 2020. "Erased: The Impact of FOSTA-SESTA and the Removal of Backpage on Sex Workers." Anti-Trafficking Review, no. 14 (April): 117-21. https://doi.org/10.14197/atr.201220148.

Book, Theodore, and Dan S. Wallach. 2015. "An Empirical Study of Mobile Ad Targeting." ArXiv:1502.06577 [Cs]. http://arxiv.org/abs/1502.06577.

Bouzguenda, Islam, Chaham Alalouch, and Nadia Fava. 2019. "Towards Smart Sustainable Cities: A Review of the Role Digital Citizen Participation Could Play in Advancing Social Sustainability." Sustainable Cities and Society 50 (October): 101627. https://doi.org/10.1016/j.scs.2019.101627.

Bowleg, Lisa. 2020. "We're Not All in This Together: On COVID-19, Intersectionality, and Structural Inequality." American Journal of Public Health 110 (7): 917. https://doi.org/10.2105/AJPH.2020.305766.

Busobozi, Viola Vivian, and Billy M. Kalema. 2017. "Leveraging Data Governance to Improve Data Quality in Health Organizations." International Journal of Multi-Disciplinary Research, 23. http://www.multiresearch.net/cms/publications/CFP4382017.pdf.

Campbell, Rosie, Teela Sanders, Jane Scoular, Jane Pitcher, and Stewart Cunningham. 2019. "Risking Safety and Rights: Online Sex Work, Crimes and 'Blended Safety Repertoires." British Journal of Sociology 70 (4): 1539-60. https://doi.org/10.1111/1468-4446.12493.

Campos-Castillo, Celeste, and Linnea I. Laestadius. 2020. "Racial and Ethnic Digital Divides in Posting COVID-19 Content on Social Media among US Adults: Secondary Survey Analysis." Journal of Medical Internet Research 22 (7): e20472. https://doi.org/10.2196/20472.

Cardoso, Lauren F., Susan B. Sorenson, Olivia Webb, and Sara Landers. 2019. "Recent and Emerging Technologies: Implications for Women's Safety." Technology in Society 58 (August): 101108. https://doi.org/10.1016/j.techsoc.2019.01.001. 
Chair, Chenai. 2020. "There's a Pandemic of Online Violence against Women and Girls." World Wide Web Foundation, July 14.

https://webfoundation.org/2020/07/theres-a-pandemic-of-online-violenceagainst-women-and-girls/.

Chetty, Krish, Liu Qigui, Nozibele Gcora, Jaya Josie, Li Wenwei, and Chen Fang. 2018. "Bridging the Digital Divide: Measuring Digital Literacy." Economics: The Open-Access, Open-Assessment E-Journal 12 (2018-3): 1-20. https://doi.org/10.5018/economics-ejournal.ja.2018-23.

Chisala-Tempelhoff, Sarai, and Monica Twesiime Kirya. 2016. "Gender, Law and Revenge Porn in Sub-Saharan Africa: A Review of Malawi and Uganda." Palgrave Communications 2 (1): 1-9. https://doi.org/10.1057/palcomms.2016.69.

Chuka, Emezue. 2020. "Digital or Digitally Delivered Responses to Domestic and Intimate Partner Violence During COVID-19." JMIR Public Health and Surveillance 6 (3): 319831. https://publichealth.jmir.org/2020/3/e19831/.

Clarke, Amanda. 2020. "Data Governance: The Next Frontier of Digital Government Research and Practice." In E. Dubois and F. Martin-Bariteau (eds.), Citizenship in a Connected Canada: A Research and Policy Agenda. Ottawa: University of Ottawa Press. https://papers.ssrn.com/abstract=3620525.

Cochrane, Kira. 2013. All the Rebel Women: The Rise of the Fourth Wave of Feminism. London: Guardian Shorts.

Collins, Caitlyn, Liana Christin Landivar, Leah Ruppanner, and William J. Scarborough. 2020. "COVID-19 and the Gender Gap in Work Hours." Gender, Work \& Organization 28 (S1): 101-112. https://doi.org/10.1111/gwao.12506.

Conger, Kate, and Noam Scheiber. 2019. "California Bill Makes App-Based Companies Treat Workers as Employees." New York Times, September 11. https://www.nytimes.com/2019/09/11/technology/california-gigeconomy-bill.html.

Cook, Cynthia M., John J. Howard, Yevgeniy B. Sirotin, Jerry L. Tipton, and Arun R. Vemury. 2019. "Demographic Effects in Facial Recognition and Their Dependence on Image Acquisition: An Evaluation of Eleven Commercial Systems." IEEE Transactions on Biometrics, Behavior, and Identity Science 1 (1): 32-41. https://ieeexplore.ieee.org/abstract/document/8636231. 
Corple, Danielle J., and Jasmine R. Linabary. 2020. "From Data Points to People: Feminist Situated Ethics in Online Big Data Research." International Journal of Social Research Methodology 23 (2): 155-68. https://doi.org/10.1080/13645579.2019.1649832.

Couldry, Nick, and Ulises A. Mejias. 2019. "Data Colonialism: Rethinking Big Data's Relation to the Contemporary Subject." Television \& New Media 20 (4): 336-49. https://doi.org/10.1177/1527476418796632.

Crawford, Allison, and Eva Serhal. 2020. "Digital Health Equity and COVID-19: The Innovation Curve Cannot Reinforce the Social Gradient of Health." Journal of Medical Internet Research 22 (6). https://doi.org/10.2196/19361.

Cross, Katherine. 2015. "Online Harassment Isn't Only about Misogyny, Regardless of What 'Gendertrolling' Implies." Rewire News Group, November 27. https://rewire.news/article/2015/11/27/online-harassmentisnt-misogyny-regardless-gendertrolling-implies/.

Cummings, Clare, and Tam O'Neil. 2015. Do Digital Information and Communications Technologies Increase the Voice and Influence of Women and Girls? London: Overseas Development Institute. https://www.odi.org/sites/odi.org.uk/files/odi-assets/publications-opinionfiles/9622.pdf

Cunningham, Anthony, and Todd Kendall. 2011. "Prostitution 2.0: The Changing Face of Sex Work." Journal of Urban Economics 69 (May): 273-87. https://doi.org/10.1016/j.jue.2010.12.001.

Degryse, Christophe. 2016. "Digitalisation of the Economy and Its Impact on Labour Markets." Working Paper 2016-02. Brussels: European Trade Union Institute. http://www.ssrn.com/abstract=2730550.

De Souza, Poppy. 2013. "Self-Tracking and Body Hacking: The Biopolitics of the Quantified Self in the Age of Neoliberalism." The Transfigure Project (blog). June 11. https://bodycartography.wordpress.com/2013/06/11/selftracking-and-body-hacking-the-biopolitics-of-the-quantified-self-in-theage-of-neoliberalism/.

Deursen, Alexander J. A. M. van, and Ellen J. Helsper. 2015. "The Third-Level Digital Divide: Who Benefits Most from Being Online?" Communication and Information Technologies Annual 10: 29-52. https://doi.org/10.1108/S2050-206020150000010002.

D'Ignazio, Catherine, and Lauren F. Klein. 2020. Data Feminism. Cambridge, MA: MIT Press. https://mitpress.mit.edu/books/data-feminism. 
Dijk, Jan A. G. M. van. 2006. "Digital Divide Research, Achievements and Shortcomings." Poetics 34: 211-35.

https://www.researchgate.net/publication/241880596_Digital_Divide_Res earch_Achievements_and_Shortcomings.

. 2017. "Digital Divide: Impact of Access." In P. Rössler, C. A. Hoffner, and L. Zoonen (eds.), The International Encyclopedia of Media Effects, 1-11. Hoboken, NJ: John Wiley \& Sons. https://doi.org/10.1002/9781118783764.wbieme0043.

Doorn, Niels van. 2017. "Platform Labor: On the Gendered and Racialized Exploitation of Low-Income Service Work in the 'on-Demand' Economy." Information, Communication \& Society 20 (6): 898-914. https://doi.org/10.1080/1369118X.2017.1294194.

2018. "On the Conditions of Possibility for Worker Organizing in PlatformBased Gig Economies." Notes from Below, June 8. https://notesfrombelow.org/article/conditions-possibility-workerorganizing-platform.

Dragiewicz, Molly, Jean Burgess, Ariadna Matamoros-Fernández, Michael Salter, Nicolas P. Suzor, Delanie Woodlock, and Bridget Harris. 2018. "Technology Facilitated Coercive Control: Domestic Violence and the Competing Roles of Digital Media Platforms." Feminist Media Studies 18 (4): 609-25. https://doi.org/10.1080/14680777.2018.1447341.

Duggan, Maeve. 2017. “Online Harassment 2017.” Pew Research Center: Internet, Science \& Tech (blog), July 11. https://www.pewresearch.org/internet/2017/07/11/online-harassment$2017 /$.

Dutta, Debalina. 2018. “Women's Discourses of Leadership in STEM Organizations in Singapore: Negotiating Sociocultural and Organizational Norms." Management Communication Quarterly 32 (2): 233-49. https://doi.org/10.1177/0893318917731537.

Eaton, Asia A., Holly Jacobs, and Yanet Ruvalcaba. 2017. 2017 Nationwide Online Study of Nonconsensual Porn Victimization and Perpetration: A Summary Report. Miami: Cyber Civil Rights Initiative, Florida International University. https://www.cybercivilrights.org/wpcontent/uploads/2017/06/CCRI-2017-Research-Report.pdf.

Elias, Ana Sofia, and Rosalind Gill. 2018. "Beauty Surveillance: The Digital SelfMonitoring Cultures of Neoliberalism." European Journal of Cultural Studies 21 (1): 59-77. https://doi.org/10.1177/1367549417705604. 
Enguita-Fernàndez, Cristina, Elena Marbán-Castro, Olivia Manders, Lauren Maxwell, and Gustavo Correa Matta. 2020. "The COVID-19 Epidemic through a Gender Lens: What If a Gender Approach Had Been Applied to Inform Public Health Measures to Fight the COVID-19 Pandemic?" Social Anthropology 28 (2): 263-64.

https://onlinelibrary.wiley.com/doi/full/10.1111/1469-8676.12803.

EQUALS. 2019. 10 Lessons Learnt: Closing the Gender Gap in Internet Access and Use: Insights from the EQUALS Access Coalition. EQUALS Global Partnership and GSMA.

https://www.gsma.com/mobilefordevelopment/wpcontent/uploads/2019/09/EQUALS-Access-Coalition-10-LessonsLearnt.pdf.

European Parliament and Council of the European Union. 2016. "Regulation (EU) 2016/ 679 of the European Parliament and of the Council on the Protection of Natural Persons with Regard to the Processing of Personal Data and on the Free Movement of Such Data, and Repealing Directive 95/ 46/ EC (General Data Protection Regulation)." Official Journal of the European Union, 88.

Fernández, Carmen, and Alberto Fernández. 2019. "Ethical and Legal Implications of AI Recruiting Software." ERCIM News 116 (special theme: Transparency in Algorithmic Decision Making): 22-23.

Ferrant, Gaëlle, Luca Maria Pesando, and Keiko Nowacka. 2014. Unpaid Care Work: The Missing Link in the Analysis of Gender Gaps in Labour Outcomes. Paris: OECD Development Centre.

Findlay, Mark James, and Josephine Seah. 2020. "Data Imperialism: Disrupting Secondary Data in Platform Economies Through Participatory Regulation." SMU Centre for Al \& Data Governance Research Paper No. 2020/06. Singapore: Singapore Management University. https://doi.org/10.2139/ssrn.3613562.

Firmino, Rodrigo José, Bruno de Vasconcelos Cardoso, and Rafael Evangelista. 2019. "Hyperconnectivity and (Im)Mobility: Uber and Surveillance Capitalism by the Global South." Surveillance \& Society 17 (1/2): 205-12. https://doi.org/10.24908/ss.v17i1/2.12915.

Florito, Jose, Urvashi Aneja, and Margarita Beneke de Sanfeliu. 2018. A Future of Work That Works for Women. T20 Argentina. https://t20argentina.org/publicacion/gender-economic-equity-and-thefuture-of-work-a-future-of-work-that-works-for-women/. 
Frey, Carl Benedikt, and Ebrahim Rahbari. 2016. "Do Labor-Saving Technologies Spell the Death of Jobs in the Developing World?" Washington, DC:

Brookings Institute. https://www.brookings.edu/wpcontent/uploads/2016/07/Global_20160720_Blum_FreyRahbari.pdf.

Friederici, Nicolas, Sanna Ojanperä, and Mark Graham. 2017. "The Impact of Connectivity in Africa: Grand Visions and the Mirage of Inclusive Digital Development." Electronic Journal of Information Systems in Developing Countries 79 (1): 1-20. https://doi.org/10.1002/j.16814835.2017.tb00578.x.

FutureLearn. 2020. "The Complete Guide to Digital Skills." FutureLearn (blog). April 30. https://www.futurelearn.com/info/blog/the-complete-guide-todigital-skills.

Galperin, Hernan, and M. Fernanda Viecens. 2017. "Connected for Development? Theory and Evidence about the Impact of Internet Technologies on Poverty Alleviation." Development Policy Review 35 (3): 315-36. https://doi.org/10.1111/dpr.12210.

Garcia, Megan. 2016. "Racist in the Machine: The Disturbing Implications of Algorithmic Bias." World Policy Journal 33 (4): 111-17. https://doi.org/10.1215/07402775-3813015.

Gezici, Armagan, and Ozge Ozay. 2020. "How Race and Gender Shape COVID19 Unemployment Probability." Available at SSRN. https://papers.ssrn.com/abstract=3675022.

Girard, Michel. 2020. "We Need Standards for Digital Cooperation to Occur." IEEE Technology and Society Magazine 39 (2): 68-74. https://doi.org/10.1109/MTS.2020.2991501.

Glezou, Nefeli. 2019. "Feminist Standpoint Epistemology in Education." Science for the People, 642.

Graham, Mark, ed. 2019. "Changing Connectivity and Digital Economies at Global Margins." In Mark Graham (ed.), Digital Economies at Global Margins, 1-18. Cambridge, MA: The MIT Press.

Graham, Mark, Isis Hjorth, and Vili Lehdonvirta. 2019. "Digital Labor and Development: Impacts of Global Digital Labor Platforms and the Gig Economy on Worker Livelihoods." In Mark Graham (ed.), Digital Economies at Global Margins, 269-94. Cambridge, MA: The MIT Press. 
Gray, Kishonna L. 2018. "Gaming Out Online: Black Lesbian Identity Development and Community Building in Xbox Live." Journal of Lesbian Studies 22 (3): 282-96. https://doi.org/10.1080/10894160.2018.1384293.

Green, Jamaal W. 2019. "Where Is Economic Development in the Platform City?" Planning Theory and Practice 20 (3): 439-42.

Guihuan, Li. 2005. "The Effect of ICT on Women's Enterprise Creation: A Practical Example from China." In Gender and ICTs for Development: A Global Sourcebook, 25-32. Oxford, UK: Oxfam GB.

Gunkel, David J. 2003. "Second Thoughts: Toward a Critique of the Digital Divide." New Media \& Society 5 (4): 499-522. https://doi.org/10.1177/146144480354003.

Gurumurthy, Anita. 2008. Gender Equality through ICT Access and Appropriation: Taking a Rights-Based Approach. Bangalore: National Printing Press.

Gurumurthy, Anita, and Nandini Chami. 2017. A Feminist Action Framework on Development and Digital Technologies. Johannesburg, South Africa: Association for Progressive Communications. https://digital.fundacionceibal.edu.uy/jspui/handle/123456789/256.

Gutierrez, Christopher. 2016. "The Other Self in Free Fall: Anxiety and Automated Tracking Applications." CM: Communication and Media 11 (38): 111-34. https://doi.org/10.5937/comman12-11285.

Hackworth, L. 2018. "Limitations of 'Just Gender': The Need for an Intersectional Reframing of Online Harassment Discourse and Research." In Jacqueline Ryan Vickery and Tracy Everbach (eds.), Mediating Misogyny, 51-70. Cham, Switzerland: Palgrave Macmillan.

Haimson, Oliver L. 2016. "Harassment, Threats, and Trolling Online, Transgender Experiences with Online Harassment." Presented at the Social Computing Symposium 2016. https://www.microsoft.com/enus/research/video/social-computing-symposium-2016-harassmentthreats-and-trolling-online-transgender-experiences-with-onlineharassment/.

Harman, Sophie. 2016. "Ebola, Gender and Conspicuously Invisible Women in Global Health Governance." Third World Quarterly 37 (3): 524-41. https://doi.org/10.1080/01436597.2015.1108827. 
Helsper, Ellen Johanna. 2010. "Gendered Internet Use across Generations and Life Stages." Communication Research 37 (3): 352-74. https://doi.org/10.1177/0093650209356439.

Henry, Nicola, and Anastasia Powell. 2014. "Beyond the 'Sext': TechnologyFacilitated Sexual Violence and Harassment against Adult Women." Australian \& New Zealand Journal of Criminology 48 (1): 104-18. https://doi.org/10.1177/0004865814524218.

Hesmondhalgh, David. 2010. "User-Generated Content, Free Labour and the Cultural Industries." Ephemera: Theory and Politics in Organizations 10 (3/4): 267-84.

Hilbert, Martin. 2011. "Digital Gender Divide or Technologically Empowered Women in Developing Countries? A Typical Case of Lies, Damned Lies, and Statistics." Women's Studies International Forum 34 (6): 479-89. https://doi.org/10.1016/j.wsif.2011.07.001.

Holm, Malin, and Jorge Humberto Ojeda Castro. 2018.

"\#solidarityisforwhitewomen: Exploring the Opportunities for Mobilizing Digital Counter Claims." PS: Political Science \& Politics 51 (02): 331-34. https://doi.org/10.1017/S1049096517002463.

Holmes, John H. 2016. "Privacy, Security, and Patient Engagement: The Changing Health Data Governance Landscape." EGEMS (Washington, DC) 4 (2): 1261. https://doi.org/10.13063/2327-9214.1261.

Homewood, Sarah. 2016. "Turned On/Turned Off: Investigating the Interaction Design Implications of the Contraceptive Microchip." Thesis, Malmö University, Malmö, Sweden.

https://muep.mau.se/bitstream/handle/2043/21265/Sarah\%20Homewood \%20TP2\%20MUEP.compressed. pdf? sequence=2\&isAllowed=y.

Hoy, Mariea Grubbs, and George Milne. 2010. "Gender Differences in PrivacyRelated Measures for Young Adult Facebook Users." Journal of Interactive Advertising 10 (2): 28-45. https://doi.org/10.1080/15252019.2010.10722168.

Hughes, Donna M. 2004. "Prostitution Online." Journal of Trauma Practice 2 (34): 115-31. https://doi.org/10.1300/J189v02n03_06.

Humer, Petra. 2011. "Information and Communication Technologies as Instruments for Women's Empowerment." Österreichische Zeitschrift für Soziologie 36 (3): 49-58. https://doi.org/10.1007/s11614-011-0050-y. 
Hunt, Abigail, and Fortunate Machingura. 2016. A Good Gig? The Rise of OnDemand Domestic Work. London: Overseas Development Institute. https://www.odi.org/sites/odi.org.uk/files/resource-documents/11155.pdf.

Hunt, Abigail, and Emma Samman. 2019. Gender and the Gig Economy: Critical Steps for Evidence-Based Policy. London: Overseas Development Institute. https://www.odi.org/sites/odi.org.uk/files/resourcedocuments/12586. pdf.

Hunt, Abigail, Emma Samman, and Dina Mansour-Ille. 2017. Syrian Women Refugees in Jordan: Opportunity in the Gig Economy? London: Overseas Development Institute. https://www.odi.org/sites/odi.org.uk/files/resourcedocuments/11742.pdf.

Hunt, Abigail, Emma Samman, Sherry Tapfuma, Grace Mwaura, and Rhoda Omenya. 2019. Women in the Gig Economy: Paid Work, Care and Flexibility in Kenya and South Africa. London: Overseas Development Institute. https://www.odi.org/sites/odi.org.uk/files/resourcedocuments/women_in_the_gig_economy_final_digital.pdf.

Ibarra, Francisco, et al. 2020. "A Systematic Review on Technology-supported Interventions to Improve Old-age Social Wellbeing: Loneliness, Social Isolation, and Connectedness." Journal of Healthcare Engineering.

ILO (International Labour Office). 2008. "ILO Strategy on Promoting Women's Entrepreneurship Development." Geneva: ILO. https://www.ilo.org/wcmsp5/groups/public/---ed_norm/--relconf/documents/meetingdocument/wcms_090565.pdf.

Intel. 2013. Women and the Web. Santa Clara, CA: Intel. https://www.intel.com/content/dam/www/public/us/en/documents/pdf/wom en-and-the-web.pdf.

International Data Responsibility Group. 2017. International Data Responsibility Group Annual Report 2017: People First in a Digital Age. The Hague, Netherlands: International Data Responsibility Group. https://www.scribd.com/document/349742071/idrg-report-201729052017?secret_password=ZRGhKhSZaz3GMfzWcjvR\#download\&from embed.

ITU (International Telecommunication Union). 2016. Measuring the Information Society Report. Geneva: ITU.

2017. Measuring the Information Society Report. Geneva: ITU.

2018. Digital Skills Toolkit. Geneva: ITU. 
- 2020. Measuring the Information Society Report. Geneva: ITU.

Jackson, Sarah J., Moya Bailey, and Brooke Foucault Welles. 2018.

"\#GirlsLikeUs: Trans Advocacy and Community Building Online." New Media \& Society 20 (5): 1868-88.

https://doi.org/10.1177/1461444817709276.

Jane, Emma A. 2014. "'Your a Ugly, Whorish, Slut." Feminist Media Studies 14 (4): 531-46.

_. 2016. "Online Misogyny and Feminist Digilantism." Continuum 30 (3): 284-97. https://doi.org/10.1080/10304312.2016.1166560.

Janssen, Marijn, Paul Brous, Elsa Estevez, Luis S. Barbosa, and Tomasz Janowski. 2020. "Data Governance: Organizing Data for Trustworthy Artificial Intelligence." Government Information Quarterly 37 (3): 101493. https://doi.org/10.1016/j.giq.2020.101493.

Johnson, Sophia Alice. 2014. "Maternal Devices,' Social Media and the SelfManagement of Pregnancy, Mothering and Child Health." Societies 4 (2): 330-50. https://doi.org/10.3390/soc4020330.

Jones, Angela. 2015. "Sex Work in a Digital Era." Sociology Compass 9 (7): 55870. https://doi.org/10.1111/soc4.12282.

Kee, Jac sm. 2017. "Imagine a Feminist Internet." Development 60 (1-2): 83-89. https://doi.org/10.1057/s41301-017-0137-2.

Kendall, Mikki. 2013. "\#SolidaritylsForWhiteWomen: Women of Color's Issue with Digital Feminism." Guardian, August 14.

https://www.theguardian.com/commentisfree/2013/aug/14/solidarityisforw hitewomen-hashtag-feminism.

Kennedy, George, Andrew McCollough, Edward Dixon, Alexei Bastidas, John Ryan, Chris Loo, and Saurav Sahay. 2017. "Technology Solutions to Combat Online Harassment." In Proceedings of the First Workshop on Abusive Language Online, 73-77. Vancouver, BC, Canada: Association for Computational Linguistics. https://doi.org/10.18653/v1/W17-3011.

Kerzhner, Tamara. 2019. "Labour, Gender and Making Rent with Airbnb." Planning Theory and Practice 20 (3): 428-31.

Khanlou, K., and A. Ssawe. 2020. "COVID-19 Pandemic Guidelines for Mental Health Support of Racialized Women at Risk of Gender-based Violence." Knowledge Synthesis Report, July (2020). 
Khanlou, Nazilla, and Andrew Ssawe. 2020. COVID-19 Pandemic Guidelines for Mental Health Support of Racialized Women at Risk of Gender-Based Violence: Initial Knowledge Synthesis Report. Ottawa: Canadian Institutes of Health Research. https://www.srchc.ca/wpcontent/uploads/2020/11/COVID19-Guidelines-for-mental-health-supportof-racialized-women-at-risk-of-Gender-Based-Violence-SynthesisReport.pdf.

Khilnani, Aneka, Jeremy Schulz, and Laura Robinson. 2020. "The COVID-19 Pandemic: New Concerns and Connections between EHealth and Digital Inequalities." Journal of Information, Communication and Ethics in Society 18 (3): 393-403. https://doi.org/10.1108/JICES-04-2020-0052.

Kim, Anna Joo. 2019. "The Gentrification of 'Sharing': From Bandit Cab to Ride Share Tech." Planning Theory and Practice 20 (3): 431-35.

Kimbrough, Amanda M., Rosanna E. Guadagno, Nicole L. Muscanell, and Janeann Dill. 2013. "Gender Differences in Mediated Communication: Women Connect More Than Do Men." Computers in Human Behavior 29 (3): 896-900. https://doi.org/10.1016/j.chb.2012.12.005.

King, Tania. 2020. "Reordering Gender Systems: Can COVID-19 Lead to Improved Gender Equality and Health?," Lancet 396 (10244): 80-81.

Klonner, Stefan, and Patrick Nolen. 2010. "Cell Phones and Rural Labor Markets: Evidence from South Africa." In Proceedings of the German Development Economics Conference, 1-36. Hannover. https://www.econstor.eu/bitstream/10419/39968/1/354_klonner.pdf.

Koenecke, Allison, Andrew Nam, Emily Lake, Joe Nudell, Minnie Quartey, Zion Mengesha, Connor Toups, John R. Rickford, Dan Jurafsky, and Sharad Goel. 2020. "Racial Disparities in Automated Speech Recognition." Proceedings of the National Academy of Sciences 117 (14): 7684-89. https://doi.org/10.1073/pnas.1915768117.

Kopel, Jonathan, Abhilash Perisetti, Ali Roghani, Muhammad Aziz, Mahesh Gajendran, and Hemant Goyal. 2020. "Racial and Gender-Based Differences in COVID-19." Frontiers in Public Health 8. https://doi.org/10.3389/fpubh.2020.00418.

Kowalski, Robert M., Susan P. Limber, and Anne McCord. 2019. "A Developmental Approach to Cyberbullying: Prevalence and Protective Factors." Aggression and Violent Behavior 45 (March-April): 20-32. https://doi.org/10.1016/j.avb.2018.02.009. 
Krasnov, Aleks Sergeevich. 2018. "Digital Shadow and Digital Portrait of Online Customers in Social Networks." In Margarethe Ueberwimmer, Robert Fuereder, Martina Gaisch, and Yasel Costa (eds.), Proceedings: CrossCultural Business Conference 2018. Aachen, Germany: Shaker Verlag. 2018.https://www.researchgate.net/profile/Martina_Gaisch/publication/32 5619557_Proceedings_Cross-

Cultural_Business_Conference_2018/links/5b190a9da6fdcca67b63453e/ Proceedings-Cross-Cultural-Business-Conference-2018. pdf\#page $=100$.

Lam, Kenneth, Amy D. Lu, Ying Shi, and Kenneth E. Covinsky. 2020. “Assessing Telemedicine Unreadiness among Older Adults in the United States during the COVID-19 Pandemic." JAMA Internal Medicine 180 (10): 1389-91. https://doi.org/10.1001/jamainternmed.2020.2671.

Lenhart, Amanda, Michele Ybarra, Kathryn Zickuhr, and Myeshia Price-Feeney. 2016. Online Harassment, Digital Abuse, and Cyberstalking in America. New York: Data \& Society Research Institute. https://www.datasociety.net/pubs/oh/Online_Harassment_2016.pdf.

Leong, Danielle. 2017. "Consensual Software: How to Prioritize User Safety." InfoQ, May 18. https://www.infoq.com/articles/consensual-software/.

Levac, Leah, and Ann B. Denis. 2019. "Combining Feminist Intersectional and Community-Engaged Research Commitments: Adaptations for Scoping Reviews and Secondary Analyses of National Data Sets." Gateways: International Journal of Community Research and Engagement 12 (1): ID 6193-ID 6193. https://doi.org/10.5130/ijcre.v12i1.6193.

Ley, Barbara L. 2017. "Mothers, Fathers, and the Pregnancy App Experience: Designing with Expectant Users in Mind." In Elana Levine (ed.), Cupcakes, Pinterest, and Ladyporn: Feminized Popular Culture in the Early Twenty-first Century. Urbana: University of Illinois Press. http://illinois.universitypressscholarship.com/view/10.5406/illinois/978025 2039577.001.0001/upso-9780252039577-chapter-006.

Lips, Miriam. 2020. Digital Government: Managing Public Sector Reform in the Digital Era. New York: Routledge and CRC Press. https://www.routledge.com/Digital-Government-Managing-Public-SectorReform-in-the-Digital-Era/Lips/p/book/9781138655652.

Litman, Leib, Jonathan Robinson, Zohn Rosen, Cheskie Rosenzweig, Joshua Waxman, and Lisa M. Bates. 2020. "The Persistence of Pay Inequality: The Gender Pay Gap in an Anonymous Online Labor Market." PLOS One 15 (2): e0229383. https://doi.org/10.1371/journal.pone.0229383. 
Loza, Susana. 2014. "Hashtag Feminism, \#SolidaritylsForWhiteWomen, and the Other \#FemFuture." Ada: A Journal of Gender, New Media, and Technology, no. 5. https://adanewmedia.org/2014/07/issue5-loza/.

Lumsden, Karen, and Heather Morgan. 2017. "Media Framing of Trolling and Online Abuse: Silencing Strategies, Symbolic Violence, and Victim Blaming." Feminist Media Studies 17 (6): 926-40. https://doi.org/10.1080/14680777.2017.1316755.

Lupton, Deborah. 2016. "The Diverse Domains of Quantified Selves: SelfTracking Modes and Dataveillance." Economy and Society 45 (1): 10122. https://doi.org/10.1080/03085147.2016.1143726.

Lupton, Deborah, and Sarah Pedersen. 2016. "An Australian Survey of Women's Use of Pregnancy and Parenting Apps." Women and Birth 29 (4): 368-75. https://doi.org/10.1016/j.wombi.2016.01.008.

Madden, Stephanie, Melissa Janoske, Rowena Briones Winkler, and Amanda Nell Edgar. 2018. "Mediated Misogynoir: Intersecting Race and Gender in Online Harassment." In Jacqueline Ryan Vickery and Tracy Everbach (eds.), Mediating Misogyny, 71-90. Cham, Switzerland: Springer. https://doi.org/10.1007/978-3-319-72917-6_4.

Maddocks, Sophie. 2018. "From Non-Consensual Pornography to Image-Based Sexual Abuse: Charting the Course of a Problem with Many Names." Australian Feminist Studies 33 (97): 345-61. https://doi.org/10.1080/08164649.2018.1542592.

Madgavkar, Anu, Olivia White, Mekala Krishnan, Deepa Mahajan, and Xavier Azcue. 2020. "COVID-19 and Gender Equality: Countering the Regressive Effects." McKinsey, July 15. https://www.mckinsey.com/featured-insights/future-of-work/covid-19-andgender-equality-countering-the-regressive-effects\#.

Mantilla, Karla. 2013. "Gendertrolling: Misogyny Adapts to New Media." Feminist Studies 39 (2): 563-70.

Marco-Bujosa, Lisa M., Lois Joy, and Rachel Sorrentino. 2020. "Nevertheless, She Persisted: A Comparison of Male and Female Experiences in Community College STEM Programs." Community College Journal of Research and Practice (February): 1-19. https://doi.org/10.1080/10668926.2020.1727382.

Mariscal, Judith, Gloria Mayne, Urvashi Aneja, and Alina Sorgner. 2019. "Bridging the Gender Digital Gap." Economics: The Open-Access, Open- 
Assessment E-Journal 13 (2019-9): 1-12.

https://doi.org/10.5018/economics-ejournal.ja.2019-9.

Marsan, Giulia Ajmone, and Araba Sey. 2021. "Women's Participation in the Digital Economy: Improving Access to Skills, Entrepreneurship, and Leadership Across ASEAN."

McCarrick, Hannah, and Dorothea Kleine. 2019. "Digital Inclusion, Female Entrepreneurship, and the Production of Neoliberal Subjects: Views from Chile and Tanzania." In Digital Economies at Global Margins, 103-28. Cambridge, MA: The MIT Press.

McLaren, Helen Jaqueline, et al. 2020. "Covid-19 and women's triple burden: Vignettes from Sri Lanka, Malaysia, Vietnam and Australia." Social Sciences 9.5 (2020): 87.

McLean, Andrew. 2013. "'You Can Do It from Your Sofa': The Increasing Popularity of the Internet as a Working Site among Male Sex Workers in Melbourne:" Journal of Sociology 51 (4): 887-902. https://doi.org/10.1177/1440783313480416.

Megarry, Jessica. 2014. "Online Incivility or Sexual Harassment? Conceptualising Women's Experiences in the Digital Age." Women's Studies International Forum 47 (November): 46-55. https://doi.org/10.1016/j.wsif.2014.07.012.

— 2018. "Under the Watchful Eyes of Men: Theorising the Implications of Male Surveillance Practices for Feminist Activism on Social Media." Feminist Media Studies 18 (6): 1070-85. https://doi.org/10.1080/14680777.2017.1387584.

Mendes, Kaitlynn, Jessica Ringrose, and Jessalynn Keller. 2018. "\#MeToo and the Promise and Pitfalls of Challenging Rape Culture through Digital Feminist Activism." European Journal of Women's Studies 25 (2): 23646. https://doi.org/10.1177/1350506818765318.

Messing, Jill, Meredith Bagwell-Gray, Megan Lindsay Brown, Andrea Kappas, and Alesha Durfee. 2020. "Intersections of Stalking and TechnologyBased Abuse: Emerging Definitions, Conceptualization, and Measurement." Journal of Family Violence 35: 693-704. https://doi.org/10.1007/s10896-019-00114-7.

Milan, Stefania, and Emiliano Treré. 2019. "Big Data from the South(s): Beyond Data Universalism." Television \& New Media 20 (4): 319-35. https://doi.org/10.1177/1527476419837739. 
Mitchell, Robert, and Phillip Thurtle. 2013. Data Made Flesh : Embodying Information. New York: Routledge.

https://doi.org/10.4324/9780203873274.

Moorman, Jessica D., and Kristen Harrison. 2016. "Gender, Race, and Risk: Intersectional Risk Management in the Sale of Sex Online." Journal of Sex Research 53 (7): 816-24.

https://doi.org/10.1080/00224499.2015.1065950.

moulden, dominic t. 2019. "Shared Economy: WeWork or We Work Together." Planning Theory and Practice 20 (3): 443-46.

Munro, Ealasaid. 2013. "Feminism: A Fourth Wave?” Political Insight 4 (2): $22-$ 25. https://doi.org/10.1111/2041-9066.12021.

Nakamura, Lisa. 2015. "Afterword: Blaming, Shaming and the Feminization of Social Media." In Rachel E. Dubrofsky and Shoshana Amielle Magnet (eds.), Feminist Surveillance Studies, 221-28. Durham, NC: Duke University Press.

National LGBT Health Education Center. 2016. Providing Inclusive Services and Care for LGBT People. Boston: National LGBT Health Education Center. https://www.Igbtqiahealtheducation.org/wp-content/uploads/ProvidingInclusive-Services-and-Care-for-LGBT-People.pdf.

NetMundial Initiative. 2014. "NETmundial Multistakeholder Statement," April 24. http://netmundial.br/netmundial-multistakeholder-statement/.

Nissenbaum, Helen. 2011. "A Contextual Approach to Privacy Online." Daedalus 140 (4): 32-48. https://doi.org/10.1162/DAED_a_00113.

Noble, Cecilia Dionco. 2012. "Cyberspace as Equalizer: Opening Up Lifeworlds and Empowering Persons with Disabilities in the Philippines." Thesis, University of Hawaii at Manoa, Honolulu, HI, USA. http://scholarspace.manoa.hawaii.edu/handle/10125/101417.

Noble, Safiya. 2018. Algorithms of Oppression: How Search Engines Reinforce Racism. New York: New York University Press.

Nova, Fayika Farhat, MD. Rashidujjaman Rifat, Pratyasha Saha, Syed Ishtiaque Ahmed, and Shion Guha. 2019. "Online Sexual Harassment over Anonymous Social Media in Bangladesh." In Proceedings of the Tenth International Conference on Information and Communication Technologies and Development - ICTDX '19, 1-12. Ahmedabad, India: ACM Press. https://doi.org/10.1145/3287098.3287107. 
Nuñez Puente, Sonia. 2011. "Feminist Cyberactivism: Violence against Women, Internet Politics, and Spanish Feminist Praxis Online." Continuum 25 (3): 333-46. https://doi.org/10.1080/10304312.2011.562964.

OECD (Organisation for Economic Co-operation and Development). 2017. OECD Digital Economy Outlook 2017. Paris: OECD. https://doi.org/10.1787/9789264276284-en.

- 2020. "Record Rise in OECD Unemployment Rate in April 2020." Updated June 2020. News release, June 9. http://www.oecd.org/newsroom/unemployment-rates-oecd-update-june2020.htm.

Oreffice, Sonia, and Climent Quintana-Domeque. 2020. "Gender Inequality in Covid-19 Times: Evidence from UK Prolific Participants." IZA Discussion Paper no. 13463. Bonn: IZA (Institute of Labor Economics). https://papers.ssrn.com/abstract=3648803.

Oxfam International. 2012. Ending Violence against Women: An Oxfam Guide. Oxford, UK: Oxfam International. https://www-cdn.oxfam.org/s3fspublic/file attachments/ending-violence-against-women-oxfam-guidenov2012 2.pdf.

— 2019. "What We Believe." https://www.oxfam.org/en/what-wedo/about/what-we-believe.

Pade-Khene, Caroline. 2018. "Embedding Knowledge Transfer in Digital Citizen Engagement in South Africa: Developing Digital Literacy." Reading \& Writing 9 (1): 1-9. https://doi.org/10.4102/rw.v9i1.193.

Palmer, Blair, and Denise Gershbein. 2017. Wearables for Good: Use Case Handbook. New York: UNICEF. https://www.unicef.org/innovation/reports/wearables-good-challenge-usecase-handbook.

Pandey, Akshat, and Aylin Caliskan. 2020. "Iterative Effect-Size Bias in Ridehailing: Measuring Social Bias in Dynamic Pricing of 100 Million Rides." http://arxiv.org/abs/2006.04599.

Park, Yong Jin. 2015. "Do Men and Women Differ in Privacy? Gendered Privacy and (in)Equality in the Internet." Computers in Human Behavior 50 (September): 252-58. https://doi.org/10.1016/j.chb.2015.04.011.

Pasricha, Japleen. 2016. 'Violence' Online In India: Cybercrimes against Women and Minorities on Social Media. Feminism in India. 
https://feminisminindia.com/wp-

content/uploads/2016/05/FII_cyberbullying_report_website.pdf.

Pater, Jessica A., Moon K. Kim, Elizabeth D. Mynatt, and Casey Fiesler. 2016. "Characterizations of Online Harassment: Comparing Policies across Social Media Platforms." In Proceedings of the 19th International Conference on Supporting Group Work, 369-74. New York: Association for Computing Machinery. https://doi.org/10.1145/2957276.2957297.

Pawelke, Andreas, Michael Cañares, Kevin Hernandez, and Pedro Prieto Martin. 2017. Data for Development: What's Next? Bonn: Deutsche Gesellschaft für Internationale Zusammenarbeit. http://webfoundation.org/docs/2018/01/Final_Data-fordevelopment_Whats-next_Studie_EN.pdf.

Pendo, Elizabeth. 2020. "Protecting the Rights of People with Disabilities." In S. Burris, S. de Guia, L. Gable, D. E. Levin, W. E. Parmet, and N. P. Terry (eds.), Assessing Legal Responses to COVID-19. Boston: Public Health Law Watch. https://ssrn.com/abstract=3675789.

Phillips, Gregory, Dylan Felt, Megan M. Ruprecht, Xinzi Wang, Jiayi Xu, Esrea Pérez-Bill, Rocco M. Bagnarol, Jason Roth, Caleb W. Curry, and Lauren B. Beach. 2020. "Addressing the Disproportionate Impacts of the COVID19 Pandemic on Sexual and Gender Minority Populations in the United States: Actions Toward Equity." LGBT Health 7 (6): 279-282. https://doi.org/10.1089/lgbt.2020.0187.

Picascia, Stefano, Antonello Romano, and Michela Teobaldi. 2017. "The Airification of Cities: Making Sense of the Impact of Peer to Peer Short Term Letting on Urban Functions and Economy." In Proceedings of the Annual Congress of the Association of European Schools of Planning. SocArXiv, November 25.https://doi.org/10.31235/osf.io/vs8w3.

Powell, Anastasia, Adrian J Scott, and Nicola Henry. 2020. "Digital Harassment and Abuse: Experiences of Sexuality and Gender Minority Adults."

European Journal of Criminology 17 (2): 199-223. https://doi.org/10.1177/1477370818788006.

Price, Hannah. 2020. "'Revenge Porn' Lockdown Surge Hits Helpline." BBC News, April 25. https://www.bbc.com/news/stories-52413994.

Ragnedda, Massimo. 2020. "Theorizing Inequalities." In Massimo Ragnedda (ed.), Enhancing Digital Equity: Connecting the Digital Underclass, 11-37. Cham, Switzerland: Springer. https://doi.org/10.1007/978-3-030-490799_2. 
RAINN (Rape, Abuse, and Incest National Network). 2020. "RAINN's New App Offers Support Anytime, Anywhere." August 7.

https://www.rainn.org/news/rainns-new-app-offers-support-anytimeanywhere\#.

Ramo, Danielle. 2020. "The Double-Edged Sword of Technology for LGBTQ+ Teens." Scientific American (blog), June 23.

https://blogs.scientificamerican.com/voices/the-double-edged-sword-oftechnology-for-lgbtq-teens/.

RCCE (Regional Risk Communication and Community Engagement). 2020. COVID-19: How to Include Marginalized and Vulnerable People in Risk Communication and Community Engagement. https://reliefweb.int/sites/reliefweb.int/files/resources/COVID19_CommunityEngagement_130320.pdf.

Rehman, Muhammad, Chee Liew, Teh Wah, Junaid Shuja, and Babak Daghighi. 2015. "Mining Personal Data Using Smartphones and Wearable Devices: A Survey." Sensors 15 (2): 4430-69. https://doi.org/10.3390/s150204430.

Ricaurte, Paola. 2019. "Data Epistemologies, the Coloniality of Power, and Resistance." Television \& New Media 20 (4): 350-65. https://doi.org/10.1177/1527476419831640.

Robinson, Laura, et al. 2020. "Digital inequalities in time of pandemic: COVID-19 exposure risk profiles and new forms of vulnerability." First Monday.

Rose Taylor, Sara. 2020. "UN Women's Feminist Engagement with Governance by Indicators in the Millennium and Sustainable Development Goals." Global Social Policy 20 (3): 352-66. https://doi.org/10.1177/1468018120931696.

Rosenblat, Alex. 2018. Uberland: How Algorithms Are Rewriting the Rules of Work. Oakland, CA: University of California Press.

Roser, Max, Hannah Ritchie, and Esteban Ortiz-Ospina. 2015. "Internet." Our World in Data. https://ourworldindata.org/internet.

Roux, Kayla, and Lorenzo Dalvit. 2014. "Mobile Women: Investigating the Digital Gender Divide in Cellphone Use in a South African Rural Area." Proceedings of the e-Skills for Knowledge Production and Innovation Conference 2014, Cape Town, South Africa, 401-16. http://proceedings.e-skillsconference.org/2014/e-Skills401416Roux833.pdf. 
Rowan, Mark, and Josh Dehlinger. 2014. "Observed Gender Differences in Privacy Concerns and Behaviors of Mobile Device End Users." Procedia Computer Science 37 (2014): 340-47. https://doi.org/10.1016/j.procs.2014.08.050.

Rowntree, Oliver. 2018. Connected Women: The Mobile Gender Gap Report 2018. London: GSMA. https://www.gsma.com/mobilefordevelopment/wpcontent/uploads/2018/04/GSMA_The_Mobile_Gender_Gap_Report_2018 _32pp_WEBv7.pdf.

Ruiz-Pérez, Isabel, and Guadalupe Pastor-Moreno. 2020. "Medidas de contención de la violencia de género durante la pandemia de COVID-19." Gaceta Sanitaria (April 24). https://doi.org/10.1016/j.gaceta.2020.04.005.

Sadeque, Samira. 2020. "How the COVID-19 Pandemic Is Affecting Women's Sexual and Reproductive Health." Inter Press Service, April 7. https://tinyurl.com/jdzs8x2w.

Sambasivan, Nithya, Sunny Consolvo, Amna Batool, Nova Ahmed, Tara Matthews, Kurt Thomas, Laura Sanely Gaytán-Lugo, David Nemer, Elie Bursztein, and Elizabeth Churchill. 2019. “They Don't Leave Us Alone Anywhere We Go': Gender and Digital Abuse in South Asia." In Proceedings of the 2019 CHI Conference on Human Factors in Computing Systems - CHI '19, 1-14. New York: Association for Computing Machinery. https://doi.org/10.1145/3290605.3300232.

Sanders, Teela, Jane Scoular, Rosie Campbell, Jane Pitcher, and Stewart Cunningham. 2017. Internet Sex Work: Beyond the Gaze. Cham, Switzerland: Springer.

Scholz, Frederike, Betul Yalcin, and Mark Priestley. 2017. "Internet Access for Disabled People: Understanding Socio-Relational Factors in Europe." Cyberpsychology: Journal of Psychosocial Research on Cyberspace 11 (1). https://doi.org/10.5817/CP2017-1-4.

Scholz, Trebor. 2017. Uberworked and Underpaid: How Workers Are Disrupting the Digital Economy. Cambridge, UK: Polity Press.

Schwab, K. 2016. The Fourth Industrial Revolution. Geneva: World Economic Forum.

Schwartz, Matthew. 2019. Master's thesis, Georgetown University, Washington, DC.

Sen, Amartya. 1985. Commodities and Capabilities. Amsterdam: North-Holland. 
ـ 2001. Development As Freedom. Oxford, UK: Oxford University Press.

Sen, G., P. Östlin, and A. George. 2007. "Gender Inequity in Health: Why It Exists and How We Can Change It." Global Public Health 3 (S1): 1-12. http://www.tandfonline.com/doi/abs/10.1080/17441690801900795.

Seneviratne, Suranga, Yining Hu, Tham Nguyen, Guohao Lan, Sara Khalifa, Kanchana Thilakarathna, Mahbub Hassan, and Aruna Seneviratne. 2017. "A Survey of Wearable Devices and Challenges." IEEE Communications Surveys and Tutorials 19 (4): 2573-2620.

https://doi.org/10.1109/COMST.2017.2731979.

Sey, Araba, and Nancy Hafkin. 2019. Taking Stock: Data and Evidence on Gender Equality in Digital Access, Skills, and Leadership. Macau: United Nations University Institute on Computing and Society.

Sey, Araba, and Peppino Ortoleva. 2014. "All Work and No Play? Judging the Uses of Mobile Phones in Developing Countries." Information Technologies \& International Development 10 (3): 1-17.

Shanghai Dahua Pharmaceutical. n.d. Accessed September 16, 2020. http://www.dahua-sh.com/.

Sinha, Sharmistha. 2018. "Gender Digital Divide in India: Impacting Women's Participation in the Labour Market." In National Institute of Labour Economics Research and Development (ed.), Reflecting on India's Development: Employment, Skill and Health, 293-310. Singapore: Springer. https://doi.org/10.1007/978-981-13-1414-8_14.

Smith, Julia. 2019. "Overcoming the 'Tyranny of the Urgent': Integrating Gender into Disease Outbreak Preparedness and Response." Gender \& Development 27 (2): 355-69. https://doi.org/10.1080/13552074.2019.1615288.

Smith, Matthew, and Sujaya Neupane. 2018. Artificial Intelligence and Human Development: Toward a Research Agenda. Ottawa: International Development Research Centre. https://idl-bncidrc.dspacedirect.org/handle/10625/56949.

Stone, Paul, and Ania Calderon. 2019. "CARE Principles: Unpacking Indigenous Data Governance." Open Data Charter, November 4. https://medium.com/@opendatacharter/spotlight-care-principlesf475ec2bf6ec. 
Suri, T., and W. Jack. 2016. "The Long-Run Poverty and Gender Impacts of Mobile Money.” Science 354 (6317): 1288-92.

https://doi.org/10.1126/science.aah5309.

Suzor, Nicolas, Molly Dragiewicz, Bridget Harris, Rosalie Gillett, Jean Burgess, and Tess Van Geelen. 2019. "Human Rights by Design: The Responsibilities of Social Media Platforms to Address Gender-Based Violence Online." Policy \& Internet 11 (1): 84-103. https://doi.org/10.1002/poi3.185.

Sweet, Kayla S., Jennifer K. LeBlanc, Laura M. Stough, and Noelle W. Sweany. 2020. "Community Building and Knowledge Sharing by Individuals with Disabilities Using Social Media." Journal of Computer Assisted Learning 36 (1): 1-11. https://doi.org/10.1111/jcal.12377.

Toyama, Kentaro. 2011. "Technology as Amplifier in International Development." In Proceedings of the 2011 IConference, 75-82. New York: Association for Computing Machinery. https://doi.org/10.1145/1940761.1940772.

Trottier, Daniel. 2017. "Digital Vigilantism as Weaponisation of Visibility." Philosophy \& Technology 30 (1): 55-72. https://doi.org/10.1007/s13347016-0216-4.

Tsetsi, Eric, and Stephen A. Rains. 2017. "Smartphone Internet Access and Use: Extending the Digital Divide and Usage Gap." Mobile Media \& Communication 5 (3): 239-55. https://doi.org/10.1177/2050157917708329.

UNCTAD (United Nations Conference on Trade and Development). 2014. Empowering Women Entrepreneurs through Information and Communications Technologies. Geneva: UNCTAD. https://unctad.org/en/PublicationsLibrary/dtlstict2013d2_en.pdf.

- 2016. Data Protection Regulations and International Data Flows: Implications for Trade and Development. Geneva: UNCTAD. https://unctad.org/en/PublicationsLibrary/dtlstict2016d1_en.pdf.

UNDP (United Nations Development Programme). 2019. Human Development Report 2019: Beyond Income, beyond Averages, beyond Today: Inequalities in Human Development in the 21st Century. New York: UNDP.

UNESCO (United Nations Educational, Scientific, and Cultural Organization). 2018. Digital Inclusion for Low-Skilled and Low-Literate People: A Landscape Review. Paris: UNESCO. https://tinyurl.com/5b4v2fzk. 
UNFPA (United Nations Population Fund). 2020. COVID-19: A Gender Lens. New York: UNFPA. https://www.unfpa.org/sites/default/files/resourcepdf/COVID-19_A_Gender_Lens_Guidance_Note.pdf.

United Nations. 2010. Handbook for Legislation on Violence against Women. New York: United Nations.

— 2015. "Transforming Our World: The 2030 Agenda for Sustainable Development." https://sdgs.un.org/2030agenda.Unwin, Tim. 2017. Reclaiming Information and Communication Technologies for Development. Oxford, UK: Oxford University Press.

UN Women. 2020a. Online and ICT Facilitated Violence against Women and Girls during COVID-19. New York: UN Women. https://www.itu.int/net4/wsis/forum/2020/Files/talkx/Session13/briefonline-and-ict-facilitated-violence-against-women-and-girls-during-covid19-en.pdf.

- 2020b. "Policy Brief: The Impact of COVID-19 on Women." New York: UN Women. https://www.unwomen.org//media/headquarters/attachments/sections/library/publications/2020/polic $y$-brief-the-impact-of-covid-19-on-women-en.pdf?la=en\&vs=1406.

USAID (United States Agency for International Development). 2020. "Women's Economic Empowerment." https://www.usaid.gov/what-we-do/genderequality-and-womens-empowerment/womens-economic-empowerment.

Van der Meulen, Emily, and Robert Heynen, eds. 2016. Expanding the Gaze: Gender and the Politics of Surveillance. Toronto, ON: University of Toronto Press.

Van Dijck, Jose. 2014. "Datafication, Dataism and Dataveillance: Big Data between Scientific Paradigm and Ideology." Surveillance \& Society 12 (2): 197-208. https://doi.org/10.24908/ss.v12i2.4776.

Vaughan, Jill. 2015. "Privacy Impact Assessment Update for TSA Advanced Imaging Technology." Washington, DC: US Department of Homeland Security. https://www.dhs.gov/sites/default/files/publications/privacy-tsapia-32-d-ait.pdf.

Vickery, Jacqueline Ryan, and Tracy Everbach. 2018. Mediating Misogyny: Gender, Technology and Harassment. Cham, Switzerland: Palgrave Macmillan. https://doi.org/10.1007/978-3-319-72917-6.

Vigdor, Neil. 2019. "Apple Card Investigated after Gender Discrimination Complaints." New York Times, November 10. 
https://www.nytimes.com/2019/11/10/business/Apple-credit-cardinvestigation.html.

Vitak, Jessica, Kalyani Chadha, Linda Steiner, and Zahra Ashktorab. 2017. "Identifying Women's Experiences with and Strategies for Mitigating Negative Effects of Online Harassment." In Proceedings of the 2017 ACM Conference on Computer Supported Cooperative Work and Social Computing, 1231-45. New York: Association for Computing Machinery. https://doi.org/10.1145/2998181.2998337.

Wang, Yuanyuan, Bailin Pan, Ye Liu, Amanda Wilson, Jianjun Ou, and Runsen Chen. 2020. "Health Care and Mental Health Challenges for Transgender Individuals during the COVID-19 Pandemic." Lancet Diabetes \& Endocrinology 8 (7): 564-65. https://doi.org/10.1016/S22138587(20)30182-0.

Web Foundation. 2018. The Case \#ForTheWeb. Washington DC: Web Foundation

Weinberg, Lindsay. 2017. "Rethinking Privacy: A Feminist Approach to Privacy Rights after Snowden." Westminster Papers in Communication and Culture 12 (3): 5-20. https://doi.org/10.16997/wpcc.258.

Wells, Thomas. n.d. "Sen's Capability Approach." Internet Encyclopedia of Philosophy. Accessed September 11, 2020. https://iep.utm.edu/sen-cap/.

Wenham, Clare, Julia Smith, and Rosemary Morgan. 2020. "COVID-19: The Gendered Impacts of the Outbreak." Lancet 395 (10227): 846-48. https://www.thelancet.com/journals/lancet/article/PIIS01406736(20)30526-2/fulltext?te=1\&nl=inher\%20words\&emc=edit_gn_20200317.

Winter, Jenifer Sunrise, and Elizabeth Davidson. 2019. "Big Data Governance of Personal Health Information and Challenges to Contextual Integrity." Information Society 35 (1): 36-51. https://doi.org/10.1080/01972243.2018.1542648.

World Bank. 2014. The Economic Impact of the 2014 Ebola Epidemic: Short and Medium Term Estimates for West Africa. Washington, DC: World Bank. https://www.worldbank.org/en/region/afr/publication/the-economic-impactof-the-2014-ebola-epidemic-short-and-medium-term-estimates-for-westafrica.

2015. "Empowering Women through Jobs in the Digital Economy." World Bank, October 20. 
https://www.worldbank.org/en/news/feature/2015/10/20/empoweringwomen-through-jobs-in-the-digital-economy.

World Economic Forum. 2016. The Future of Jobs: Employment, Skills and Workforce Strategy for the Fourth Industrial Revolution. Geneva: World Economic Forum.

http://www3.weforum.org/docs/WEF_Future_of_Jobs.pdf.

_ 2017. Digital Policy Playbook: Approaches National Digital Governance. White Paper 310817. Geneva: World Economic Forum. http://www3.weforum.org/docs/White_Paper_Digital_Policy_Playbook_Ap proaches_National_Digital_Governance_report_2017.pdf.

_ 2018a. "Preparing for the Future of Work." Geneva: World Economic Forum.

http://www3.weforum.org/docs/WEF_System_Initiative_Future_Education _Gender_Work_Preparing_Future_Work_2-P....pdf.

- 2018b. Our Shared Digital Future: Building an Inclusive, Trustworthy, and Sustainable Digital Society. Geneva: World Economic Forum. http://www3.weforum.org/docs/WEF_Our_Shared_Digital_Future_Report _2018.pdf.

World Wide Web Foundation. 2015. Women's Rights Online: Translating Access into Empowerment. Geneva: World Wide Web Foundation. http://webfoundation.org/docs/2015/10/womens-rightsonline21102015.pdf.

World Wide Web Foundation. 2016a. "Women's Rights Online: Report Card: Mozambique." http://webfoundation.org/docs/2016/09/WF_GR_Mozambique.pdf.

_. 2016b. "Women's Rights Online: Report Cards." http://webfoundation.org/docs/2016/09/WRO-Gender-ReportCard_Overview.pdf.

—. 2020. "Women's Rights Online: Report Card: Namibia." http://webfoundation.org/docs/2020/08/GenderReport-Namibia.pdf.

Wu, Yuehua. 2014. "Protecting Personal Data in E-Government: A CrossCountry Study." Government Information Quarterly 31 (1): 150-59. https://doi.org/10.1016/j.giq.2013.07.003.

Wyche, Susan, Nightingale Simiyu, and Martha E. Othieno. 2016. "Mobile Phones as Amplifiers of Social Inequality among Rural Kenyan Women." 
ACM Transactions on Computer-Human Interaction 23 (3): article 14. https://dl.acm.org/doi/10.1145/2911982.

Yigitcanlar, Tan, Md. Kamruzzaman, Marcus Foth, Jamile Sabatini-Marques, Eduardo da Costa, and Giuseppe loppolo. 2019. "Can Cities Become Smart without Being Sustainable? A Systematic Review of the Literature." Sustainable Cities and Society 45 (February): 348-65. https://doi.org/10.1016/j.scs.2018.11.033.

Zuboff, Shoshana. 2015. "Big Other: Surveillance Capitalism and the Prospects of an Information Civilization." Journal of Information Technology 30 (1): 75-89. https://doi.org/10.1057/jit.2015.5.

Zwick, Austin. 2018. "Welcome to the Gig Economy: Neoliberal Industrial Relations and the Case of Uber." GeoJournal 83: 679-669.

Zwick, Austin, and Zachary Spicer. 2019. "Blight or Remedy: Understanding Ridehailing's Role in the Precarious 'Gig Economy." Planning Theory and Practice 20 (3): 424-28. Bouzguenda, Islam, Chaham Alalouch, and Nadia Fava. "Towards smart sustainable cities: A review of the role digital citizen participation could play in advancing social sustainability." Sustainable Cities and Society 50 (2019): 101627. 


\section{RESEARCH BACKGROUNDER SERIES LISTING}

"Making Investments in Poor Farmers Pay: A Review of Evidence and Sample of Options for Marginal Areas," by Melinda Smale and Emily Alpert (2009).

"Turning the Tables: Global Trends in Public Agricultural Investments," by Melinda Smale, Kelly Hauser, and Nienke Beintema, with Emily Alpert (2009).

"Risk and Risk Transfer in Agriculture: Facilitating Food Security and Poor Farmer Participation," by Leander Schneider (2010).

"From the Ground Up: Strategies for Global Community-based Disaster Risk Reduction," by Kelly Hauser (2010).

"Impact of Climate Change on Response Providers and Socially Vulnerable Communities in the US," by John Cooper and Jasmine Waddell (2010).

"Climate Change and Violent Conflict: A Critical Literature Review," by Ellen Messer (2010).

“Under Pressure: Reducing Disaster Risk and Enhancing US Emergency Response Capacity in an Era of Climate Change," by Marc Cohen, Kelly Hauser, Ellen Messer, and M. Cristina Tirado (2011).

"Impact of Garment and Textile Trade Preferences on Livelihoods in Cambodia," by Sophal Chan and Sothea Oum (2011).

"In Need of a Better WASH: Water, Sanitation, and Hygiene Policy Issues in Post-earthquake Haiti," by Figaro Joseph (2011).

"Local Capacity in Humanitarian Response: Vision or Mirage?," by Michael Delaney and Jacobo Ocharan (2012).
"Systems, Power and Agency in Marketbased Approaches to Poverty," by Chris Jochnick (2012).

"Measuring Economic Progress and WellBeing: How to move beyond GDP?," by Heloisa Marone (2012).

"Land Rights, Land Tenure, and Urban Recovery: Rebuilding Post-Earthquake Portau-Prince and Léogâne," by Harley F. Etienne (2012).

"Haiti Rice Value Chain Assessment: Rapid Diagnosis and Implications for Program Design," by David C. Wilcock and Franco Jean-Pierre (2012).

"From Controversy to Consensus: Lessons Learned from Government and Company Consultations with Indigenous Organizations in Peru and Bolivia," edited by Emily Greenspan (2012).

"Community Consent Index: Oil, Gas, and Mining Company Public Positions on Free. Prior, and Informed Consent (FPIC)," by Marianne Voss and Emily Greenspan (2012).

"Harvesting Data: What Can 10 Years of Official Development Assistance Data Tell Us About US International Agricultural Development?," by Kelly Hauser (2012).

"Summary of reports on mining and development in the province of Espinar, Peru," by Gerardo Castillo Guzmán (2013).

"US Investment in Large-scale Land Acquisitions in Low- and Middle-Income Countries," by Joshua Humphreys, Ann Solomon, and Emmanuel Tumusiime (2013).

“Local Institutions, External Interventions, and Adaptations to Climate Variability: The 
case of the Borana pastoralists in southern Ethiopia," by Dejene Negassa Debsu (2013).

“Local Institutions, External Interventions, and Adaptations to Climate Variability: The case of southern Mali," by Rebecca Joy Howard (2013).

"The Power of Oil Palm: Land grabbing and impacts associated with the expansion of oil palm crops in Guatemala: The case of the Palmas del Ixcan Company," by Arantxa Guerena and Ricardo Zepeda (2013).

"Human Rights and Social Conflict in Oil, Gas, and Mining Industries: Policy recommendations for national human rights institutions," by Ben Collins and Lesley Fleischman (2013).

"The Rice Value Chain in Haiti: Policy proposal," by Carlos Furche (2013).

"Housing Delivery and Housing Finance in Haiti: Operationalizing the national housing policy," by Duong Huynh, et al. (2013).

“Development Assistance on Local Adaptive Capacity to Climate Change: Insights from Senegal," by Henri M. Lo and Emmanuel Tumusiime (2013).

"Agriculture Change, Land, and Violence in Protracted Political Crisis: An examination of Darfur," by Abdal Monium K. Osman, Helen Young, Robert F. Houser, and Jennifer C. Coates (2013).

"Sustainable and inclusive Investments in Agriculture: Lessons on the Feed the Future Initiative in Tanzania," by Emmanuel Tumisiime and Demund Matotay (2014).

"Feed the Future Investment in Haiti: Implications for sustainable food security and poverty reduction," by Danielle Fuller Wimbush and Cardyn Fil-Aime (2014).

"Delivering Aid in contested Spaces: Afghanistan," by Erin Blankenship (2014).

"The Drivers of Economic Inequality: A Primer," by Nick Galasso (2014).

“Ready for gold? Assessing Haiti's governance and regulatory capacity for large-scale mining," by Scott Sellwood and Stuart Levit (2015).

"Global Reach of the US Financial Sector," by Stephanie Fontana (2015).
"Climate change, equity and stranded assets," by Simon Caney (2016).

"Gender and Social Accountability: Ensuring women's inclusion in citizen-led accountability programming relating to extractive industries," by Sarah Bradshaw with Brian Linneker and Lisa Overton (2016).

"Transformative and Feminist Leadership for Women's Rights," by Shawna Wakefield (2017).

"The energy challenge in sub-Saharan Africa: A guide for advocates and policy makers: Part 1: Generating energy for sustainable and equitable development," by Nkiruka Avila, Juan Pablo Carvallo, Brittany Shaw, and Daniel M. Kammen (2017).

"The energy challenge in sub-Saharan Africa: A guide for advocates and policy makers: Part 2: Addressing energy poverty," by James Morrissey (2017).

"Political Rigging: A primer on political capture and influence in the 21st century," by Janine R. Wedel, Nazia Hussain, and Dana Archer Dolan (2017).

"Energy and Women and Girls: Analyzing the needs, uses, and impacts of energy on women and girls in the developing world," by Rebecca Rewald (2017).

"The Rise of Populism and Its Implications for Development NGOs," by Nick Galasso, Gianandrea Nelli Feroci, Kimberly Pfeifer, Martin Walsh (2017).

"Mitigating Poverty and Climate Change: How reducing short-lived climate pollutants can support pro-poor sustainable development", by Ryan Hottle and Thomas Damassa (2018).

"Identifying and analyzing the gendered impact of Hurricane María on WASH practices in rural communities of Puerto Rico," by Christiana Smyrilli, Pamela Silva, Lenulisy Rosado, and Martha Thompson (2018).

"Linking Electrification and Productive Use," by James Morrissey (2019).

"Saving for Change in Mali: From Women's Financial Inclusion to Public Engagement," by Tara F. Deubel and Micah Boyer (2019).

"USAID's AVANSE Project in Haiti: An Assessment of Its Conformity with Aid 
Effectiveness Principles," by Marc Anglade, Marc J. Cohen, and Tonny Joseph (2019).

"Accountable to Whom? Promoting Women's

Rights through Extractive Industries

Revenue Accountability," by Namalie

Jayasinghe, Mirna de la Rosa Jimenez,

Maritza Ruiz, Tamara Billima-Mulenga, and

Mwiinga Cheelo (2019).

"Natural Gas for Development?

Understanding the opportunities and

challenges for gas in a context of climate

change", by Kendra Kintzi (2019).

Achieving Universal Electricity Access at the Lowest Cost: A comparison of least-cost

electrification models, by James Morrissey (2019).

The Demand Side of Impact Investing:

Elevating the Perspectives of Local

Entrepreneurs in the Impact Sector, by Jessica Jones (2019).

Masculinities and the Rise of the Far-Right: Implications for Oxfam's Work on Gender Justice, by Alan Greig (2019).

Can Haiti's Peanut Value Chain Survive US Generosity? Political economy analysis, by Camille Chalmers, Guelsonne Calixte, François Gérard Junior Denart, Tonny Joseph, and Marc J. Cohen (2020).

Zero Hunger, Zero Emissions: Land-based climate change mitigation, food security, and equity, by Krystal Jones (2020).

Policy Landscape for the Scaling-Up of Agroforestry in Mali, by Faye Duan (2020).

Gender-Responsive Budgeting in Ghana An analysis of GRB implementation and its existing and potential impacts on women small-scale farmers, by Ibrahim Akalbila, Emmanuel Ayifah, Lisa Hilt, Hafiz Muntaka, and Rebecca Rewald (2020).

Gender and Technology: A Rights-based and Intersectional Analysis of Key Trends, by Vanessa Ceia, Benji Nothwehr, and Liz Wagner (2021) 
Oxfam is a global movement of people working together to end the injustice of poverty. With 70 years of experience in more than 90 countries, Oxfam takes on the big issues that keep people poor: inequality, discrimination, and unequal access to resources including food, water, and land. We help people save lives in disasters, build stronger futures for themselves, and hold the powerful accountable. Join us. www.oxfamamerica.org.

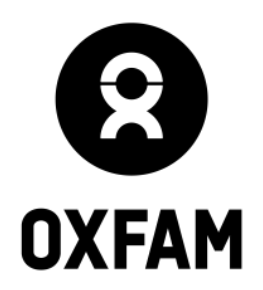

US HEADQUARTERS

226 CAUSEWAY STREET, 5TH FLOOR

BOSTON, MA 02114-2206

(800) 77-OXFAM

US POLICY \& ADVOCACY OFFICE

1101 17TH STREET, NW, SUITE 1300

WASHINGTON, DC 20036

(202) 496-1180

\section{www.oxfamamerica.org}

(C) 2021 Oxfam America Inc. All rights reserved. Oxfam is a trademark of Oxfam America Inc., and the Oxfam logo is a registered trademark of Stichting Oxfam International. None of the trademarks may be used without permission of the owner. 